Check for updates

Cite this: RSC Adv., 2017, 7, 44199

\title{
Multiphase $\mathrm{TiO}_{2}$ nanostructures: a review of efficient synthesis, growth mechanism, probing capabilities, and applications in bio-safety and health
}

\begin{abstract}
Rajni Verma, ${ }^{a b}$ Jitendra Gangwar ${ }^{\mathrm{bc}}$ and Avanish K. Srivastava (D) *ab
This review article provides an exhaustive overview of the efficient synthesis, growth mechanism and research activities that mainly concern an assortment of multiphase $\mathrm{TiO}_{2}$ nanostructures and their structural, morphological, optical and biological properties co-relations. First, a systematic review is provided for the state-of-art and synthetic mechanisms utilized to generate these nanostructured systems. A range of remarkable photoactive characteristics with respect to the effects of the structural phases as well as morphogenesis are then briefly covered and organized into sections presenting the nanostructures' photo-luminescence and photo-catalysis properties. A plausible mechanism for their nano-bio interaction is also reviewed, and clearly shows their potential in bio-safety and health applications. These studies should inspire researchers involved in both fundamental and application based research to pursue further developments in multiphase $\mathrm{TiO}_{2}$ nanostructures.
\end{abstract}

Received 21st June 2017 Accepted 27th August 2017

DOI: $10.1039 / \mathrm{c} 7 \mathrm{ra06925a}$

rsc.li/rsc-advances
'Department of Physics, RPS Degree College, Balana, Mohindergarh, Haryana - 123 029, India
${ }^{a}$ Academy of Scientific and Innovative Research, CSIR - National Physical Laboratory, Dr. K. S. Krishnan Road, New Delhi-110 012, India. E-mail: aks@ nplindia.org; avanish.aks555@gmail.com

${ }^{b}$ Sophisticated and Analytical Equipments Division, CSIR - National Physical Laboratory, Dr. K. S. Krishnan Road, New Delhi - 110 012, India

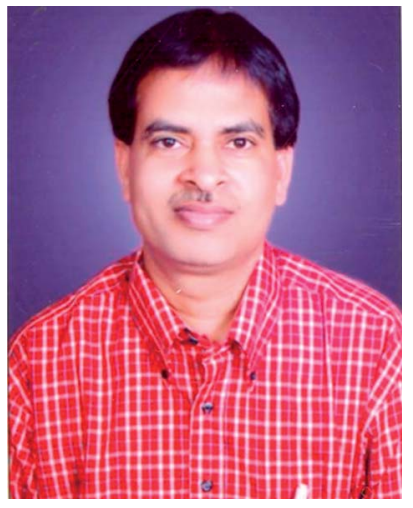

Dr Avanish Kumar Srivastava is a Scientist at CSIR - National Physical Laboratory, New Delhi and an adjunct faculty member of the Academy of Scientific and Innovative Research (AcSIR) at the NPL campus. He received his Master's degree in Physics from the Indian Institute of Technology Roorkee (1986), M.Tech. in Materials Science from the Indian Institute of Technology Kanpur (1988), and Ph.D. in Metallurgy from the Indian Institute of Science, Bangalore (1996). He works in the field of the processing, characterization, properties and possible applications of metals and alloys, composites, semiconductors and various nanostructures. His prolific research to understand the nucleation-growth mechanisms, phase transformations, microstructures and defects of materials is well known. Dr Srivastava has solved complex crystalline structures with the help of reciprocal space analysis employing electron microscopy. He has carried out collaborations with many institutions, including the Indian Institute of Science Bangalore, Banaras Hindu University Varanasi, Indian Institute of Technologies Delhi, Kanpur \& Hyderabad, University of Paris \& University of Reims France, Technical University Darmstadt Germany; Okayama University of Science Japan, University of Arkansas USA, Pohang University of Science and Technology South Korea, Department of Energy, Center for NanoEngineered Materials and Surfaces Milano Italy and Institute for Technical Physics and Materials Science, Hungarian Academy of Sciences Hungary and Argonne National Laboratory USA. He has more than 200 publications in reputed international journals and more than 200 papers and invited talks at different scientific meetings in India and abroad. He has edited a book on Oxide Nanostructures: Growth, Microstructure and Properties, published by PanStanford Singapore and printed by Taylor and Francis, USA. He is the recipient of many awards and positions, including: (i) DSTBOYSCAST fellowship of Government of India, (ii) Kwan Im Thong Travel Fellowship Singapore, (iii) INSA-KOSEF fellowship of the Governments of India \& South Korea, (iv) Materials Research Society of India (MRSI) Medal-2011 and (v) Metallurgist of the Year Award 2011 by the Ministry of Steel, Government of India. He is an elected Fellow of The Indian Institute of Metals and Electron Microscope Society of India. 


\section{Introduction}

Photoactive potential is defined as the capacity of a material to undergo any chemical or physical alteration when a number of photons fall on it. It is well known that when the size of materials or grains approaches the nanometre $(\mathrm{nm})$ scale, many physical, chemical and biological characteristics are strongly influenced and differ significantly from those of bulk materials and from those of an isolated atom/ion/molecule. ${ }^{1-7}$ The possible fundamental causes for this are the following: (i) interatomic interactions, (ii) cations with valence states, (iii) anions with deficiencies, (iv) anisotropy and (v) high surface area-to-volume ratio. ${ }^{8}$ Semiconductor metal oxide nanomaterials (SMONs) are amongst the most widely studied oxide materials in recent years as they have the capability to generate photo-excited electrons and holes when photons of a wavelength equal to or greater than the band gap of the SMON fall on it. ${ }^{9}$ The noteworthy and significant physico-chemical characteristics of SMON can be attributed to their reduction in crystal size as well as their surface structure that would substantially increase the catalysis performance and the ability to tune the band gap by possible modifications of SMON, which is one of the most exciting research areas. In addition, the band gap of SMON can be easily tuned as per the requirement for inhibiting charge-carrier recombination, which is important for photoactive applications. In addition, nanometre-sized SMONs have attracted much interest as a component of electronic devices depending on their structural phases. The intriguing characteristics of several SMONs, together with their electronic and structural phases, that possess photoactive potential are listed in Table 1.

Amongst the various $\mathrm{SMONs},{ }^{10-29} \quad \mathrm{TiO}_{2}$-nanostructured systems (particularly nano-particles, ${ }^{23,30}$-wires, ${ }^{31}$-needles, ${ }^{32}$ -belts ${ }^{33}$ and -tubes ${ }^{34,35}$ ) are the most enthralling classes of SMON with a variety of physico-chemical properties. The dominant physicochemical properties of $\mathrm{TiO}_{2}$ nanostructures are classified in terms of their crystallinity, purity, structure, chemical composition, size- and/or shape-distribution, dimensionality and defect centres, which can be easily modified by changing the parameters during various synthetic methods. $\mathrm{TiO}_{2}$ nanostructures have been widely explored owing to their extensive applications across a myriad of areas, particularly in photocatalysis, including those for the decomposition of organic/ inorganic dyes, ${ }^{16,23,36-40}$ hydrogen production from water, ${ }^{\mathbf{4 1 - 4 4}}$ removal of pollutants and plastics from the environment, ${ }^{45-48}$ dye-sensitized solar cells, ${ }^{49}$ sensors, ${ }^{50}$ sunscreens, ${ }^{51-54}$ paints, ${ }^{55,56}$ rechargeable batteries, ${ }^{57-59}$ supercapacitors, ${ }^{60}$ food colouring, ${ }^{61-64}$ environmental remediation ${ }^{65-94}$ and biomedical fields. ${ }^{95,96}$ Over the past few decades, extensive research effort has been dedicated to the engineering of $\mathrm{TiO}_{2}$ nanostructures synthesized via chemical routes, such as sol-gel, ${ }^{\text {97-107 }}$ hydrothermal, ${ }^{108-126}$ solvothermal, ${ }^{8}$ wet-chemical, ${ }^{6,8,23,127}$ thermolysis ${ }^{128,129}$ and electrodeposition techniques. ${ }^{130} \mathrm{TiO}_{2}$ is effectively used in the aforementioned applications based on its various structural phases, morphologies, exceptional low-cost, nontoxicity, high abundance in nature and slow rate of chargecarrier recombination, ${ }^{\mathbf{1 3 1 - 1 3 9}}$ and therefore is the main concern of this review article. Moreover, the excellent photoactive performances of multiphase $\mathrm{TiO}_{2}$ nanostructures mainly depend on the various synthesis routes. Due to the outburst of publications in this field, the authors do not claim that this dominantly multiphase $\mathrm{TiO}_{2}$ nanostructures review includes all of the published work, but rather an exposure of the efficient syntheses, probing capabilities, photoactive potential and application of these $\mathrm{TiO}_{2}$ nanostructures in biosafety and health. We apologize to the authors of the excellent work that,

Table 1 Summary of different binary and ternary SMONs based on photoactive potential with their band gap, structural phase and melting point ${ }^{a}$

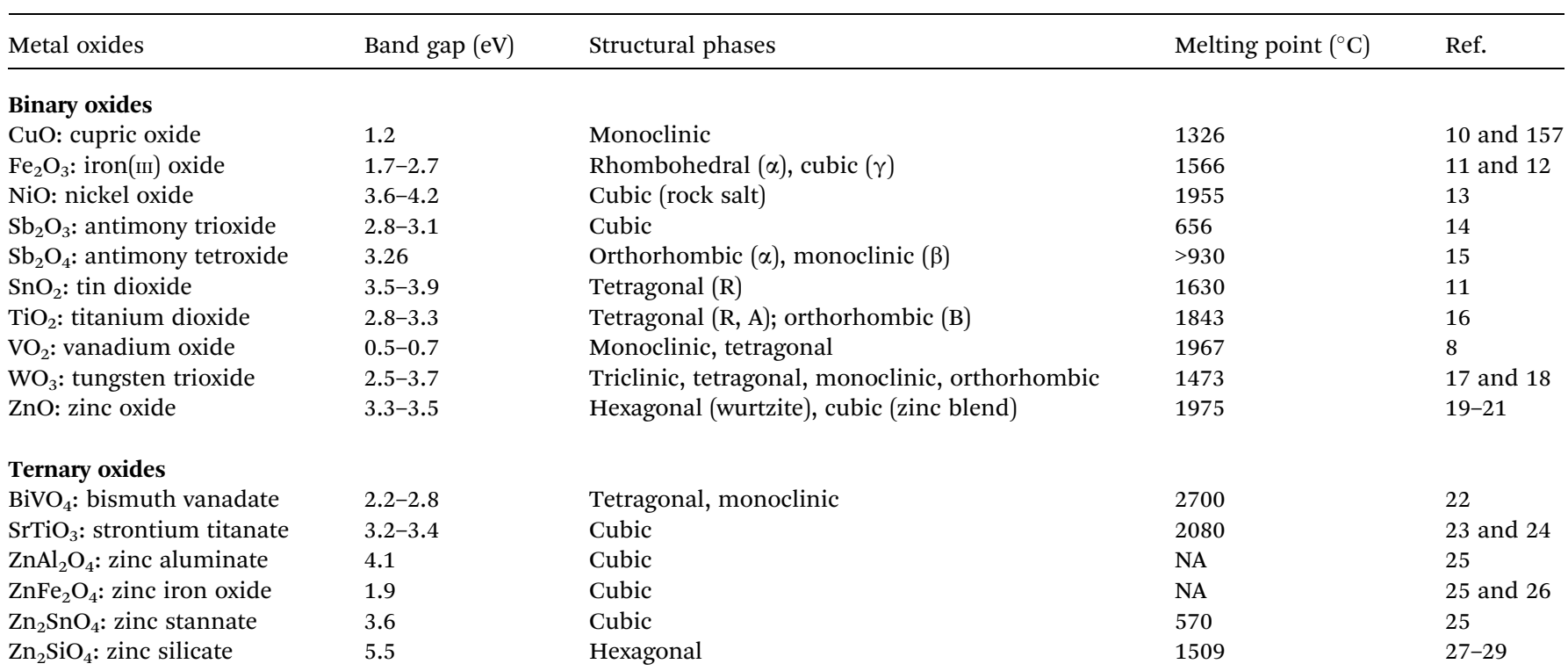

${ }^{a}$ Symbols introduced: $\alpha \rightarrow$ alpha, $\beta \rightarrow$ beta, $\gamma \rightarrow$ gamma, $\mathrm{R} \rightarrow$ rutile, $\mathrm{A} \rightarrow$ anatase and $\mathrm{B} \rightarrow$ brookite. 
due to the large activity in this area, we have inadvertently left out.

Thus, in order to modify the structural, morphological, optical, antimicrobial, physico-chemical and photocatalytic properties of various multiphase- $\mathrm{TiO}_{2}$ nanostructures, by necessity, it is essential to develop and emphasize the design of cost-efficient, high yield and long charge-carrier lifetime materials with desirable controlled morphology as well as specific multifunctional properties based on basic chemistry and physics concepts/models.

\section{Properties of multiphase $\mathrm{TiO}_{2}$ nanostructures}

Titanium dioxide is an alkaline oxide of titanium (Ti) containing the elements $\mathrm{Ti}$ and oxygen $(\mathrm{O})$ with the chemical formula $\mathrm{TiO}_{2}$ and is commonly referred to as titania. Moreover, $\mathrm{TiO}_{2}$ is one of the most abundant and nontoxic compounds on our planet and is a very appealing material for a variety of applications in catalysis, UV sunscreens, cosmetics, medical implants and self-cleaning and antifogging surfaces. ${ }^{97} \mathrm{TiO}_{2}$ nanostructures are conventional wide band gap $\left(E_{\mathrm{g}}=2.8-3.3 \mathrm{eV}\right)$ semiconductor materials with tunable properties, which have attracted growing interest in recent decades from the scientific and engineering community.

\subsection{Structural phases (multiphase $\mathrm{TiO}_{2}$ )}

Structurally, $\mathrm{TiO}_{2}$ nanomaterials are a kind of versatile polymorph material (a material with the same composition but a different crystal structure) and exist in both crystalline and noncrystalline or amorphous $\left(\mathrm{a}-\mathrm{TiO}_{2}\right)$ forms. ${ }^{141-143} \mathrm{Up}$ to now, 14 structural phases of $\mathrm{TiO}_{2}$ have been identified in which 11 phases are crystalline and 3 are noncrystalline. The crystalline phases of $\mathrm{TiO}_{2}$ are rutile, anatase, brookite, $\mathrm{TiO}_{2}-\mathrm{B}$ (bronze), $\mathrm{TiO}_{2}-\mathrm{R}$ (ramsdellite), $\mathrm{TiO}_{2}-\mathrm{H}$ (hollandite), $\mathrm{TiO}_{2}$-II (columbite), $\mathrm{TiO}_{2}$-III (baddeleyite), $\mathrm{TiO}_{2}$-OI (fluorite), $\mathrm{TiO}_{2}$-OII (cotunnite) and $\mathrm{TiO}_{2}$-cubic, ${ }^{144}$ whereas the noncrystalline- $\mathrm{TiO}_{2}$ phases are a low-density a- $\mathrm{TiO}_{2}$ and two high-density a- $\mathrm{TiO}_{2}$ forms. ${ }^{142}$ Mesoporous a- $\mathrm{TiO}_{2}$ with a periodic ordering of the pores was first reported in $1995 \mathrm{via}$ a modified sol-gel process applying an alkyl phosphate surfactant. ${ }^{144}$

To date, the structural characteristics, particularly the nature of phase formation as well as transformations in $\mathrm{TiO}_{2}$, have been inadequately established. The three main naturally existing polymorphs of $\mathrm{TiO}_{2}$ (especially rutile, anatase and brookite) are stable at ambient or low-pressure but differ in how they share the adjacent $\mathrm{TiO}_{6}$ octahedra coordination such that the overall stoichiometry remains $\mathrm{TiO}_{2}$. The relative stability of the $\mathrm{TiO}_{2}$ phases depends mainly on the particle size, with rutile- $\mathrm{TiO}_{2}$ being the thermodynamically most stable form in bulk $\mathrm{TiO}_{2}$. The anatase$\mathrm{TiO}_{2}$ phase is the most stable phase of $\mathrm{TiO}_{2}$ at sizes below $14 \mathrm{~nm}$. Moreover, brookite- $\mathrm{TiO}_{2}$ is the metastable form, which is not commonly observed in minerals and is difficult to synthesize in a pure form. ${ }^{140,145}$ Their densities vary in range from $\sim 4.24\left(\mathrm{TiO}_{2}{ }^{-}\right.$ rutile $)^{146}$ to $3.89\left(\mathrm{TiO}_{2} \text {-anatase }\right)^{146,147}$ and $4.12\left(\mathrm{TiO}_{2} \text {-brookite }\right)^{148} \mathrm{~g}$ $\mathrm{cm}^{-3}$. Anatase- and brookite- $\mathrm{TiO}_{2}$ are regarded amongst the most widely studied phases with the thermodynamically stable rutile$\mathrm{TiO}_{2}$ phase. ${ }^{149,150}$ However, based on the different arrangements of oxide anions $\left(\mathrm{O}^{2-}\right)$ adjoining the titanium cations $\left(\mathrm{Ti}^{4+}\right)$, these transition/multiphase $\mathrm{TiO}_{2}$ polymorphs can be divided into two main categories: (i) a tetragonal structure (in rutile- and anatase$\mathrm{TiO}_{2}$ ), (ii) an orthorhombic structure (in brookite- $\mathrm{TiO}_{2}$ ). ${ }^{151}$ On the basis of the available literature reviews and the experimental Ti-O phase diagram, anatase- $\mathrm{TiO}_{2}$ is more stable than rutile ${ }^{152}$ at room temperature and atmospheric pressure, in contrast to the thermodynamic data, which indicates anatase- $\mathrm{TiO}_{2}$ is metastable with regard to rutile- $\mathrm{TiO}_{2} .{ }^{145}$ The rutile phase of $\mathrm{TiO}_{2}$ consists of $\mathrm{TiO}_{6}$ units with both edge as well as corner sharing, whereas the anatase phase of $\mathrm{TiO}_{2}$ contains $\mathrm{TiO}_{6}$ units only with edge sharing. Additionally, in the brookite phase of $\mathrm{TiO}_{2}$, the $\mathrm{TiO}_{6}$ units are connected through the edges of neighbouring units. ${ }^{153-156}$

In the rutile phase structure, two opposite edges of each octahedra are united forming a linear chain along the (001) direction. These linear chains are then linked to each other by sharing corner oxygen atoms. However, zigzag chains of octahedra are linked through sharing edges, as no corner sharing is observed in the crystal structure of anatase. Four edges are shared per octahedron in anatase. Interstitial spaces between octahedra are larger because of there being more edge sharing and thus this phase structure is less dense than rutile. ${ }^{145}$ The orthorhombic crystal structure of brookite is even more complex, wherein, it comprises an orthorhombic unit constructed by an octahedron of oxygen ions arranged about a single titanium ion. Three edges with adjoining octahedra are shared per octahedron. Moreover, the remarkable properties and excellent performance in various potential applications for the different polymorphs of multiphase $\mathrm{TiO}_{2}$ are outlined in Table 2. Fig. $1\left(a-d_{3}\right)$ illustrate the various applications: (a), balland-stick models $\left(b_{1}-b_{3}\right)$, Wulff structures $\left(c_{1}-c_{3}\right)$ and polyhedron models $\left(\mathrm{d}_{1}-\mathrm{d}_{3}\right)$ of different polymorph $\mathrm{TiO}_{2}$, in particular anatase-, brookite- and rutile- $-\mathrm{TiO}_{2} \cdot{ }^{142}$

\subsection{Morphogenesis characteristics $\left(\mathrm{TiO}_{2}\right.$ nanostructures)}

Accumulating all the available reviews from the early 2000s, a variety of nanostructured materials with fascinating morphologies have piqued the interests of material scientists because of their higher surface-to-volume ratio, which is beneficial to enhancing the efficiency of oxide surface reactions. Based on the orientation of nanocrystals, nanostructured materials or nanomaterials are divided into three main categories within a size range of 1-100 nm: (i) spherical (nano-particles, ${ }^{23}$-spheres, ${ }^{158}$ -granules, ${ }^{159}$-platelets, ${ }^{160}$-pores ${ }^{161}$ ), (ii) elongated (nano-rods, ${ }^{162}$ -tubes, ${ }^{34,35}$-wires, ${ }^{31} \quad$-fibres, ${ }^{98,163}$-needles, ${ }^{164}$-petals, ${ }^{165}$-whiskers, ${ }^{166,167}$-trees, ${ }^{55}$-filaments ${ }^{168,169}$ ) and (iii) planar (nanoplates ${ }^{170,171}$-sheets, ${ }^{172}$-films, ${ }^{173}$-coatings ${ }^{174,175}$ ).

Spherical nanomaterials show a diverse range of applications, such as in electronics, ${ }^{176}$ photodynamic therapy, ${ }^{177,178}$ sensors, ${ }^{50}$ probes, ${ }^{179}$ catalysis $^{23,180}$ and antimicrobial. ${ }^{51,181,182}$ Elongated nanomaterials, on the other hand, also demonstrate various potential applications, such as in display technologies, ${ }^{183,184}$ microelectromechanical systems (MEMS) ${ }^{185}$ optical sensors $^{175}$ and biological areas, such as cancer 
Table 2 Polymorphs- $\mathrm{TiO}_{2}$ structure with their possible properties and applications

\begin{tabular}{lll}
\hline Phase- $\mathrm{TiO}_{2}$ & Properties & Advanced applications \\
\hline Anatase- $\mathrm{TiO}_{2}$ & $\begin{array}{l}\text { Brown to black, metastable polymorph, } \\
\text { lustrous, lower absorption rate, hard, high } \\
\text { density, larger band gap }\end{array}$ & Gems, paints, papers, ceramics, photocatalysis \\
Brookite- $\mathrm{TiO}_{2}$ & $\begin{array}{l}\text { Dark brown to greenish black, brittle, very rare } \\
\text { metastable polymorph, non-fluorescent }\end{array}$ & Photocatalysis, photovoltaic devices, jewellery \\
Rutile- $\mathrm{TiO}_{2}$ & $\begin{array}{l}\text { Dark red, high refractive index, hard, chemical } \\
\text { resistant, UV-ray absorbent, obtained at high } \\
\text { temperature }\end{array}$ & $\begin{array}{l}\text { Paint, paper, plastic, food, sunscreens, } \\
\text { photocatalysis, interference applications }\end{array}$ \\
& &
\end{tabular}

therapeutics, ${ }^{\mathbf{1 8 6 , 1 8 7}}$ sensing, ${ }^{\mathbf{1 8 8 , 1 8 9}}$ imaging ${ }^{\mathbf{1 8 6 , 1 8 7}}$ and drug delivery. Planar nanomaterials are utilized for packaging purposes, as anti-corrosives, ${ }^{190,191}$-bacterial, ${ }^{192,193}$-abrasion, ${ }^{191}$-reflection, ${ }^{194,195}$-graffiti coatings ${ }^{191}$ and in surgical procedures. ${ }^{196}$ such as wound dressing materials and in tissue engineering, ${ }^{197,198}$ such as cellular scaffolds. ${ }^{199}$ Amongst various morphogenesis, nano-particles, ${ }^{23,30}$-fibres, ${ }^{98,163}$-tubes, ${ }^{34,35}$-rods ${ }^{162}$ and layers of multiphase- $\mathrm{TiO}_{2}$ are the most desired nanostructures for many industrial, scientific and technological applications (Fig. 2).

\subsection{Impact of multiphase $\mathrm{TiO}_{2}$ nanostructures on photoactive and biological responses}

The photoactive potential states the capability of a substance to undergo any physical or chemical changes in response to illumination. Herein, the photoactive potential of multiphase $\mathrm{TiO}_{2}$

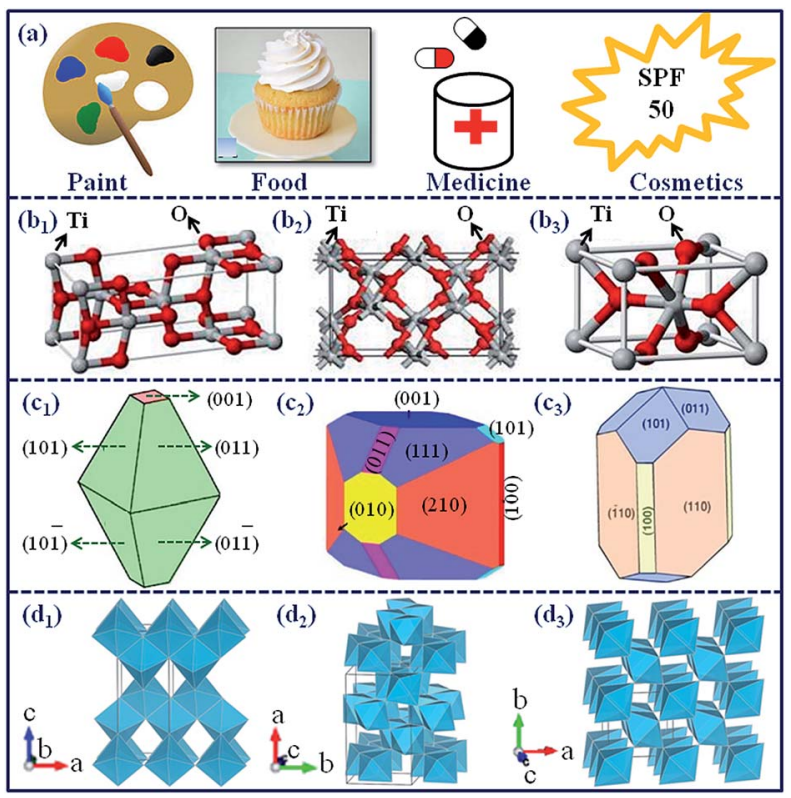

Fig. 1 (a) Various applications, $\left(b_{1}-b_{3}\right)$ ball-and-stick models, $\left(c_{1}-c_{3}\right)$ Wulff structures and $\left(d_{1}-d_{3}\right)$ polyhedron models of different polymorphs $\mathrm{TiO}_{2}$ for $\left(\mathrm{b}_{1}, c_{1}, \mathrm{~d}_{1}\right)$ anatase- $\mathrm{TiO}_{2},\left(\mathrm{~b}_{2}, c_{2}, \mathrm{~d}_{2}\right)$ brookite- $\mathrm{TiO}_{2}$ and $\left(b_{3}, c_{3}, d_{3}\right)$ rutile- $\mathrm{TiO}_{2}$. The unit cells in polyhedron models are outlined using thin lines. ${ }^{142}$ By courtesy of https://www.google.co.in/search? $\mathrm{q}=$ wulff+structure + of + tio2\&tbm $=$ isch\&tbo $=u \&$ source $=$ univ\&sa $=X \&$ ved=0ahUKEwiYgZiDnYXUAhUFT48KHWRAfQQsAQIJg\&biw $=1280$ \&bih $=591 \#$ imgrc $=X 5 z 468 X$ QyZyqOM: Reprinted with permission from ref. 142. Copyright 2014, American Chemical Society. nanostructures stands for: (i) UV-Vis characteristics, (ii) photoluminescence and (iii) photocatalysis properties.

2.3.1. Influence on photoactive potential. Generally, ultraviolet-visible (UV-Vis or UV/Vis) spectroscopy is aimed at absorption or reflectance ranging from $190 \mathrm{~nm}(6.52 \mathrm{eV})$ to $800 \mathrm{~nm}(1.55 \mathrm{eV})$. When an atom or molecule absorbs UV or visible light, electrons are promoted from their ground state (bonding: $\sigma$-, and $\pi$ - or non-bonding: n-electrons) to an excited state (anti-bonding: $\sigma^{*}$ - or $\pi^{*}$-electrons). ${ }^{23,200}$ Atomic vibrations/ rotations also have discrete energy levels, which are considered as being packed on top of each electronic level and appear in the form of a continuous absorption band. ${ }^{\mathbf{1 3 0}}$ In the luminescence process, an energy source stimulates an electron within a material to rise from a ground state to an excited state, and the electron is then released to the ground energy state by liberating the energy in the form of light. In the photoluminescence process, photons are the primary energy source and can be used to analyse the PL spectra of nanomaterials. The separation of photogenerated electron-hole pairs (excitons) when UV rays are illuminated provides a platform for photodegradation by generating reactive oxygen species (ROS). ${ }^{\text {201-205 }} \mathrm{A}$ mechanism related to this photodegradation is depicted in Fig. 3 .

Multiphase $\mathrm{TiO}_{2}$ nanostructures have been widely explored in terms of photocatalysis owing to their high surface area, high absorption capability and slow rate of charge-carrier recombination. ${ }^{23,180}$ The photocatalysis property is useful in many applications that provide a therapeutic action for human health by decontaminating water/air ${ }^{\mathbf{2 0 6}, 207}$ and also by degrading toxic organic/inorganic dyes. ${ }^{23,208}$ Thus, the ability to manipulate the surface property is an extremely vital factor to optimize multiphase $\mathrm{TiO}_{2}$ nanostructures for photo-related phenomena. However, the existing recent reviews scrutinized that the surface modification of multiphase $\mathrm{TiO}_{2}$ nanostructures can be achieved either by organic/inorganic surface coating or by adding dopants. However, surface coating on $\mathrm{TiO}_{2}$ nanostructures with

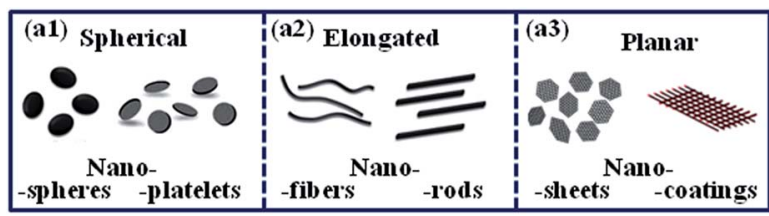

Fig. 2 Illustration showing the orientation of nanomaterials: $\left(a_{1}\right)$ spherical, $\left(a_{2}\right)$ elongated and $\left(a_{3}\right)$ planar. ${ }^{130}$ Reprinted with permission from ref. 130. Copyright 2015, The Royal Society of Chemistry. 


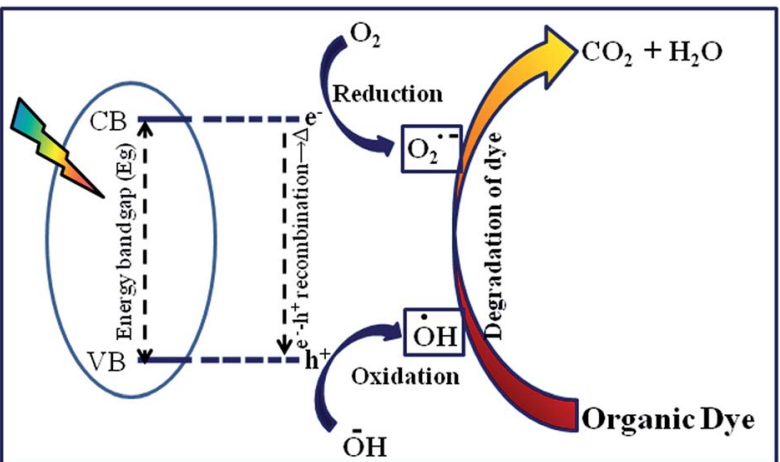

Fig. 3 Photocatalysis mechanism in multiphase $\mathrm{TiO}_{2}$ nanostructures.

numerous inorganic oxide materials, such as $\mathrm{SiO}_{2},{ }^{209} \mathrm{Al}_{2} \mathrm{O}_{3},{ }^{210}$ $\mathrm{ZrO}_{2},{ }^{211} \mathrm{WO}_{3}$ (ref. 212) and $\mathrm{MoO}_{3}$ (ref. 213) can lose their intrinsic property, thus, organic surface coatings are preferred to circumvent this property. In addition, coating with an organic moiety can provide various functional groups, such as hydroxyl-, aldehydic- and carboxyl-groups, as well as the benefit from organic species being cheaper as well as generally more abundant in nature. ${ }^{214,215}$

2.3.2. Influence on bio-safety and human health. When nanostructures enter into the human body, they are distributed into various organs and thus interact with biological moieties, such as proteins and cells. They can either remain in the same structure or become altered. ${ }^{216}$ Nanomaterials may also get absorbed via inhalation, ${ }^{217}$ dermal exposure ${ }^{218,219}$ and could potentially cause some toxic characteristics ${ }^{220-225}$ in the human body. Thus, the pharmacokinetics of nanomaterials depends on various physico-chemical properties of both nanomaterials as well as biological systems, which are elaborated in detail herein.

2.3.2.1. Physico-chemical influences of the nanostructures. The driving forces for nano-bio interactions mainly include the physico-chemical properties of: (i) nanomaterials, such as the structural aspects (size and shape), surface properties (crystallinity, hydrophobicity, coating, stereochemical interactions) and chemical composition (atomic/molecular features, polymorphism); (ii) biological systems, such as the surface charge, conformation, $\mathrm{H}-$ and $\pi$-bonds and (iii) environmental prospects, such as the polarity, $\mathrm{pH}$, viscosity, temperature and ionic strength, as shown in Scheme $1(\mathrm{a}-\mathrm{c}) .^{226-228}$ The available exciting and existing reviews clearly demonstrate the interaction of multiphase $\mathrm{TiO}_{2}$ nanostructures with biological systems through various plausible mechanisms. It is an imperative task, therefore, to present a review to assist composing a novel mechanism emphasizing the effect of multiphase $\mathrm{TiO}_{2}$ nanostructures on human health using fundamental evidence.

2.3.2.2. Pharmacokinetics of nanostructures in the human body. Pharmacokinetics (e.g. absorption, distribution, metabolism and excretion) is defined as the study of the mobility of nanomaterials in a biological system. ${ }^{229-233}$ Nanostructures can be administered in vivo by major routes, such as inhalation, ingestion, transdermal and intravenous injection. Once nanostructures enter into the human body, they are distributed into

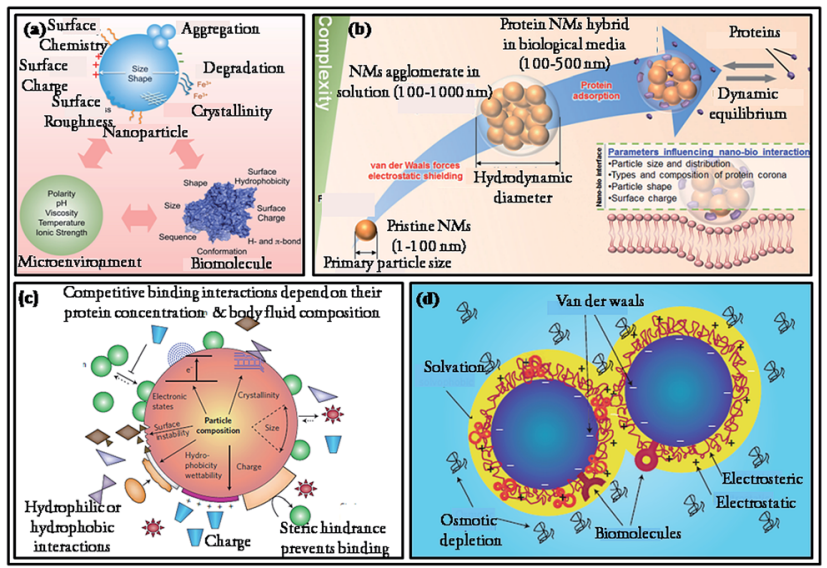

Scheme 1 Schematic representation of nano-bio interactions and: (a) factors influencing the nano-bio interactions, ${ }^{60}$ (b) physico-chemical properties of nanomaterials essential to establish nano-bio relations, ${ }^{239}$ (c) effects of the protein corona surrounding a nanoparticle; the corona constitutes a primary nano-bio interface that determines the fate of the nanoparticle and can cause deleterious effects on the interactive proteins, ${ }^{226}$ (d) interactions between nanoparticles. Traditional forces for colloidal fabrication (for example, electrostatic, VDW, covalent) and other important interactions (for example, solvation, solvophobic, biomolecular, depletion) that occur when particles are suspended in biological media and come into contact with cells. ${ }^{226}$ (a) is reprinted with permission from ref. 60. Copyright 2014, American Chemical Society. (b) is reprinted with permission from ref. 239. Copyright 2014, Wiley Online Library. (c and d) is reprinted with permission from ref. 226. Copyright 2009, Nature Publishing Group.

various organs, where they may remain in the same structure or become amended or metabolised before leaving towards other organs or to be excreted. ${ }^{234,235}$ The study to date on the influence of multiphase $\mathrm{TiO}_{2}$ nanostructures on human health has been focused and debated extensively over the past decade. Several participating factors, including the partial absorption of nanostructures, and parameters associated with the particles (such as the material characteristics, shape, size and concentration) have been considered to account for the anomalous influence on biosafety/human health..$^{236-239}$ The present review briefly outlines the issues around biosafety by taking into account the multiphase $\mathrm{TiO}_{2}$ nanostructures, employing date reported in the various review articles in this area.

\section{Efficient synthesis routes and growth mechanisms}

Synthetic methods of multiphase $\mathrm{TiO}_{2}$ play a crucial role in the development of nanostructures from zero-dimensional (0D) to three-dimensional (3D) structures. The synthesis of multiphase $\mathrm{TiO}_{2}$ nanostructures in a variety of shapes with controlled morphologies, sizes $(\sim 100 \mathrm{~nm})$ and more complex nanostructures are of substantial interest due to their exceptional properties and prevalent application possibilities straddling from physico-chemical to biological fields. ${ }^{240,241}$ With a high degree of synthetic control, the size and shape of multiphase $\mathrm{TiO}_{2}$ nanostructures can be easily tuned from the micro- and 
nanometre to the molecular level and from spherical nanoparticles to nano-rods/-tubes/-wires. Moreover, owing to its excellent stoichiometry (Ti/O: 1/2), multiphase $\mathrm{TiO}_{2}$ nanostructures have always been a subject of enormous research interest and there is emerging attention paid now to the controlled synthesis or fabrication of structurally stoichiometric $\mathrm{TiO}_{2}$ with diverse shapes, with results reported on single and mixed phase $\mathrm{TiO}_{2}$ polymorphs. The synthesis of multiphase $\mathrm{TiO}_{2}$ nanostructures, therefore, is very interesting in terms of: (i) the structural phases (anatase-, brookite- and rutile- $\mathrm{TiO}_{2}$ ), (ii) the well-controlled morphogenesis (nano-particles, ${ }^{23,158}$ -tubes, ${ }^{34,35}$-wires, ${ }^{31}$-rods, ${ }^{162}$-crystals ${ }^{242,243}$ and -flowers ${ }^{144,244}$ ), and (iii) the particle size (regime 1-100 $\mathrm{nm}$ ) for a variety of technological and biosafety applications.

With the emergence of new synthetic techniques that are inexpensive, highly scalable and have a high yield, development of the large-scale cost-effective production of SMON is one of the key challenges for today's nanoscience and nanotechnology. ${ }^{245}$ Each fabrication method of SMON has its own advantages and strategy for the synthesis of SMON in 0D to 3D systems. In this section, we briefly describe the numerous synthesis methods for producing SMON, especially multiphase $\mathrm{TiO}_{2}$ nanostructures. Generally, two fundamental strategies have been developed to broadly prepare multiphase $\mathrm{TiO}_{2}$ nanostructures: the top-down approach and the bottom-up approach.

\subsection{Top-down approach}

Basically, the top-down approach is a miniaturization technique, in which small structures are fabricated from larger ones. The key advantageous of this approach are that the components, e.g. in the production of integrated circuits, are both patterned and assembled in position, so that no separate fabrication step is needed. Lithography, attrition or milling, quenching, etching and successive cutting are all typical examples of the top-down approach for the synthesis of metal oxide nanomaterials. ${ }^{108,246}$

\subsection{Bottom-up approach}

In this context, synthesis through a bottom-up approach, in which molecular precursors react to form the final larger structures, is a unique approach for the preparation of SMONs owing to its exceptional versatility. ${ }^{157,247-249}$ In the bottom-up approach, the molecular precursors self-associate, interact and combine with each other in a coordinated way to give rise to simple and more complex nanostructures. The bottom-up approach has four major branches: (i) physical, (ii) chemical, (iii) hybrid and (iv) biological. Nowadays, these synthetic routes have been established for the engineering of emerging multiphase $\mathrm{TiO}_{2}$ nanostructures (spherical, elongated and planar with sizes smaller than $100 \mathrm{~nm}$ ). ${ }^{103,109,250,251}$ The existing physical, hybrid and/or biological synthesis methods typically involve toxic organic/inorganic reagents and need sophisticated instrumentation with complicated reaction conditions to produce the required materials, which are low in quantity as well as quality, even with a low-yield of the required material. ${ }^{252,253}$ Thus, the technological challenge has moved to the facile synthesis of multiphase $\mathrm{TiO}_{2}$ nanostructures via chemical routes and that could maintain their activity, selectivity and suitability over long-term operation in various potential technological and biosafety applications. In addition, the chemical method is an easy way to produce multiphase- $\mathrm{TiO}_{2}$ nanostructures using hazardless precursors in a short reaction time and at low cost for high scale-up with high purity in high throughput and good yield in industrial production. Due to numerous advantages such as simplicity, inexpensive instrumental set-up, easy operation and good control over the experimental conditions, the chemical routes are encouraged from the view-point of practical application. The chemical synthesis processes to obtain multiphase crystalline $\mathrm{TiO}_{2}$ nanostructures, including amongst others sol-gel or even hydrothermal approaches, wet chemical solution and precipitation methods, have become increasingly popular in recent years to achieve the goals of identically shaped, uniformly sized, perfect crystals, defect-free and high-purity materials. The entire synthetic mechanism, which provides exquisite control over many of the parameters cited above for the synthesis of nanostructures, is demonstrated in Scheme 2.

Using these approaches, various morphologies of multiphase $\mathrm{TiO}_{2}$ have been synthesized and can be easily scaled up for large-scale production. The synthesis methods via a topdown approach normally require harmful organic/inorganic surfactants complex technologies as well as sophisticated instruments. Consequently, the bottom-up approach is preferred and has attracted key interest due to its versatility and potential to produce SMONs for many applications. Moreover, the chemical synthesis of multiphase $\mathrm{TiO}_{2}$ nanostructures via the sol-gel, hydrothermal and co-precipitation methods provides numerous significant advantages, such as:

(i) precise control of the structural phases and stoichiometry,

(ii) control of the size, morphology and homogeneity,

(iii) reproducible process suitable for the large-scale, costeffective and high-purity production of nanomaterials,

(iv) short reaction conditions and inexpensive procedures.

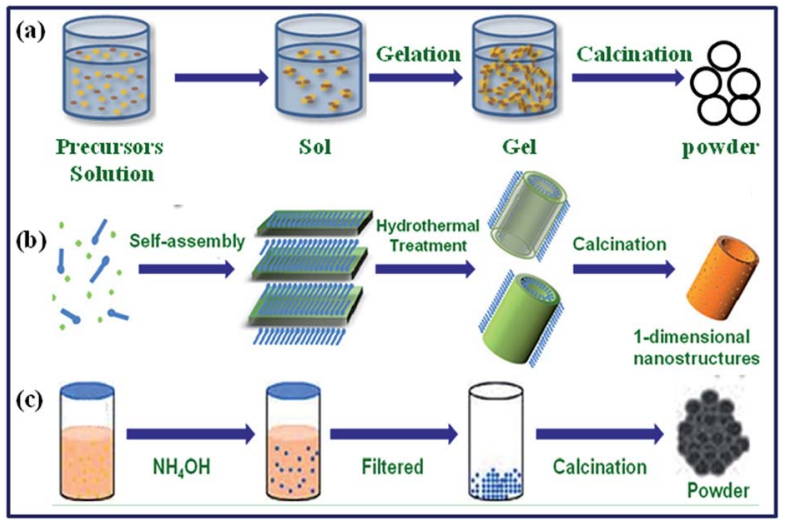

Scheme 2 Schematic representation of the chemical synthesis routes of SMON via (a) sol-gel, (b) hydrothermal, and (c) co-precipitation methods ${ }^{8}$ Reprinted with permission from ref. 8. Copyright 2016, DRDO. 
3.2.1. Sol-gel method. The sol-gel method is broadly used to synthesize oxide materials, especially SMONs. Processing by this method involves the transformation of a sol (a colloidal suspension of nanometre-sized solid particles in a liquid phase) into a gel (a 3D network of metal-oxygen bonds, containing a continuous solid skeleton attached to a continuous liquid phase), which is then usually thermally treated to obtain the desired SMON. ${ }^{98}$ Namely, when the liquid is removed from the sol, the sol turns into a gel. The first gel derived from a metal alkoxide was synthesized by Ebelmen as early as $1846 .{ }^{\mathbf{1 0 1}}$ Amongst all the available processes, the sol-gel approach is mainly based on the controlled hydrolysis, the condensation of appropriate precursors and inorganic polymerization reactions. ${ }^{254}$ The sol-gel process includes four steps: (i) hydrolysis, (ii) polycondensation, (iii) drying and (iv) thermal decomposition. The precursors of metal alkoxides hydrolyze with $\mathrm{H}_{2} \mathrm{O}$ or alcohols according to the hydrolysis process, followed by either $\mathrm{H}_{2} \mathrm{O}$ or alcohol condensation. Additionally, $\mathrm{H}_{2} \mathrm{O}$ or alcohol, an acid or a base can also assist hydrolysis of the precursor. In the case of acids, a reaction takes place between the alkoxide and acid to form a solution. After the sol formation, the solution is condensed to a gel and the solvent $\left(\mathrm{H}_{2} \mathrm{O}\right.$ or alcohol) must be removed. A higher annealing/calcination temperature is needed to decompose the organic/inorganic precursor. ${ }^{240}$ Furthermore, the sol-gel method usually results in SMONs that are amorphous or badly crystalline because they are fabricated at or near room temperature. A thermal treatment (annealing or calcination) is normally needed to transform the gel into the final required SMON. ${ }^{\mathbf{9 7 - 1 0 7}}$

The sol-gel processing of multiphase $\mathrm{TiO}_{2}$ nanostructures is an interesting approach with a high level of control of the shape based on the controlled hydrolysis and condensation of the appropriate precursors. The sol-gel method is valuable for a high-throughput production of multiphase $\mathrm{TiO}_{2}$ nanostructures and much work has been carried out to date on this process, mainly involving the grain nanostructures. Varying the synthesis reaction conditions and parameters (particularly the solution composition, $\mathrm{pH}$ value and temperature) in sol-gel processing markedly affects the fabricated multiphase $\mathrm{TiO}_{2}$ nanostructures with varying sizes and different morphologies. ${ }^{255}$ A schematic diagram of the sol-gel processing for the synthesis of SMONs is shown in Scheme 2(a).

Multiphase $\mathrm{TiO}_{2}$ with different types of nanostructures, such as nano-particles, -whiskers, -fibrous and -spindles, have been successfully synthesized using this method (as shown in Fig. 4). The upper segment of Fig. 4 shows the sol-gel-derived spherical nanostructures of $\mathrm{TiO}_{2}$, whereas the lower segment presents the elongated nanostructures. Fig. $4 \mathrm{a}_{1}$ elucidates anatase- $\mathrm{TiO}_{2}$ with 20-60 $\mathrm{nm}$ crystallites agglomerated into $2 \mu \mathrm{m}$ spherical spheres. Fig. $4 \mathrm{a}_{2}$ demonstrates the brookite- $\mathrm{TiO}_{2}$ nanoparticles are in a uniform spherical shape morphology with a diameter of about $400 \mathrm{~nm} .{ }^{98}$ Fig. $4 \mathrm{a}_{3}$ shows the nano-scaled aggregates of $\mathrm{a}-\mathrm{TiO}_{2}$ crystallites in particulate structure synthesized at ratios of EGMT $: \mathrm{HCl}=1$ : $5.4 .{ }^{144}$ Fig. $4 \mathrm{a}_{4}$ and $\mathrm{b}_{3}$ show the TEM images of highly crystalline anatase- $\mathrm{TiO}_{2}$ nanoparticles with different sizes and shapes prepared by the sol-gel method. ${ }^{256}$ Fig. $4 \mathrm{a}_{5}$

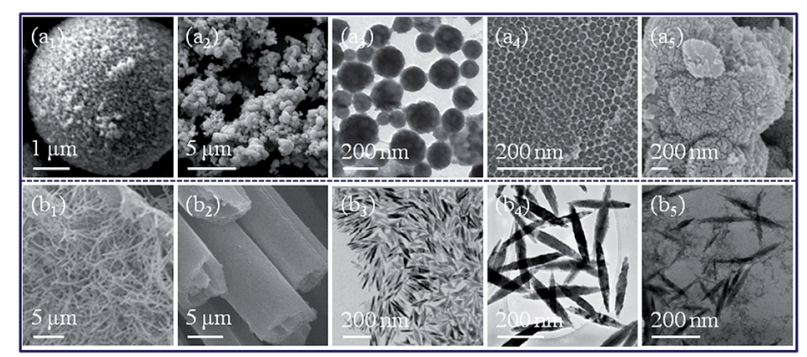

Fig. 4 Sol-gel synthesis of multiphase $\mathrm{TiO}_{2}$ nanostructures; $\left(\mathrm{a}_{1}-\mathrm{a}_{4}\right)$ nanoparticles, $\left(a_{5}\right)$ nanowhiskers, $\left(b_{1}\right)$ nanofibrous, $\left(b_{2}\right)$ nanofibres, $\left(b_{3}\right)$ nanoparticles, $\left(b_{4}\right.$ and $\left.b_{5}\right)$ nanospindle. Ref: $\left[a_{1}, b_{1}\right],{ }^{102}\left[a_{3}, a_{5}\right],{ }^{144}\left[a_{4}\right.$, $\left.b_{3}\right],{ }^{256}\left[b_{2}\right],{ }^{163}\left[b_{4}\right.$ and $\left.b_{5}\right] .^{97}\left(a_{1}, b_{1}\right)$ are reprinted with permission from ref. 102. Copyright 2012, American Chemical Society. $\left(a_{3}, a_{5}\right)$ are reprinted with permission from ref. 144. Copyright 2012, The Royal Society of Chemistry. $\left(a_{4}, b_{3}\right)$ are reprinted with permission from ref. 256. $\left(b_{2}\right)$ is reprinted with permission from ref. 163. Copyright 2011, American Chemical Society. $\left(b_{4}, b_{5}\right)$ are reprinted with permission from ref. 97. Copyright 2014, American Chemical Society.

shows the cauliflower-like nanowhisker arrangements of rutile$\mathrm{TiO}_{2}$ with a diameter of $4-5 \mathrm{~nm}$ and a length of $50 \mathrm{~nm}{ }^{\mathbf{1 4 4}}$ Fig. $4 b_{1}$ represents the higher magnification SEM image of the $\mathrm{TiO}_{2}$ nanofibrous structure. ${ }^{98}$ The fibre-like rutile-TiO ${ }_{2}$ nanostructures are illustrated in Fig. $4 b_{2} \cdot{ }^{163}$ Fig. $4 b_{4}$ and $b_{5}$ indicate the anatase- $\mathrm{TiO}_{2}$ particles with a spindle-like morphology depending on the $\mathrm{pH}$ value of the initial solution. ${ }^{97}$

3.2.2. Hydrothermal method. The hydrothermal method is a simple, versatile and universal synthesis method that employs a solvent (generally water, $\mathrm{H}_{2} \mathrm{O}$ ) at a moderate temperature and high pressure for producing SMONs. A schematic illustration for the formation of a SMON through the hydrothermal method is depicted in Scheme 2(b). The hydrothermal method is very comparable to the solvothermal method, with the main distinction between these two methods being in the precursor solutions. Specifically, aqueous and non-aqueous precursor solutions are used for the hydrothermal and solvothermal methods, respectively. Besides, the solvothermal method offers a better control of the size distribution, shape and crystallinity in SMONs than the hydrothermal method. The major chemical reactions occur at a critical temperature $\left(374{ }^{\circ} \mathrm{C}\right)$ and pressure (218 atm) in a stainless steel Teflon autoclave. In the hydrothermal method, the dielectric constant and viscosity of $\mathrm{H}_{2} \mathrm{O}$ decrease with increasing the temperature and increase with the expanding pressure with the temperature effect predominating. Due to the changes in such characteristics of $\mathrm{H}_{2} \mathrm{O}$, the raised temperature within a hydrothermal system has a considerable effect on the sample solubility and the transport of solids. ${ }^{\mathbf{1 0 8 , 1 0 9}}$ In hydrothermal processing, mostly a lamellar phase is formed before the hydrothermal condition, in which the anions play the key role of surfactant to stabilize the layered organization of metal cation species. The layer, then, rolls up to generate onedimensional (1D) nanostructures (particularly nano-tubes, -wires, -polyhedrons and -rods) in the process of crystallization under hydrothermal treatment. The crystalline/amorphous metal-hydroxide phase is, thus, obtained. After heat treatment annealing or calcination or sintering, the metal-hydroxide 
phase is, therefore, dehydrated and transformed to metal oxide nanostructures, while the 1D morphology is preserved and the organic/inorganic compounds or surfactants are removed. The hydrothermally synthesized 1D SMONs are expected to be identical in crystalline structure, uniform in size distribution, have a regular chemical composition, be perfect in shape and have no morphological defects or dislocations (particle-particle interface), which are exponentially useful for the applications of SMONs in photocatalysis, biosafety and human health. ${ }^{109}$ By using suitable parameters, such as precursors, solvent, surfactants, working temperature and reaction time, the structural phases, shape and size distribution of SMONs can be precisely controlled.

Numerous morphologies of multiphase $\mathrm{TiO}_{2}$ nanostructures (nano-particles, -cuboid shape, -wires, -tubes, -belts and many others) have been effectively fabricated in this way (as represented in Fig. 5). A typical SEM micrograph of $\mathrm{TiO}_{2}$ nanowires made with the hydrothermal method is shown in Fig. $5 \mathrm{a}_{1} \cdot{ }^{256}$ Fig. $5 \mathrm{a}_{2}$ and $\mathrm{a}_{5}$ correspond to the SEM and TEM images of $\mathrm{TiO}_{2}$ nanotubes, indicating a fibrous texture with lengths up to $1-3 \mu \mathrm{m}$, outer diameters between $7 \mathrm{~nm}$ and $10 \mathrm{~nm}$, inner diameters of $5 \mathrm{~nm}$ and an inter-wall spacing of about $0.5 \mathrm{~nm} .{ }^{257}$ Fig. $5 \mathrm{a}_{3}$ and $\mathrm{a}_{4}$ illustrates the representative SEM micrographs of anatase- $\mathrm{TiO}_{2}$ nanopolyhedrons (possessing diameters in the range of 300$600 \mathrm{~nm}$ ) and nano-belts (approximately $130 \mathrm{~nm}$ in width, $50 \mathrm{~nm}$ in thickness and several micrometres in length), respectively. ${ }^{33}$ In addition to elongated $\mathrm{TiO}_{2}$ nanostructures, spherical $\mathrm{TiO}_{2}$ nanostructures (nanoparticles and cuboid shaped or thin sheets, as depicted in Fig. $5 b_{1}-b_{3}$ ) have also been synthesized with this method. ${ }^{172}$ Fig. $5 b_{1}$ clearly shows uniform ultra-fine anatase- $\mathrm{TiO}_{2}$ nanoparticles (about 5-15 nm). Fig. 5 $b_{2}$ elucidates either a cuboid shaped or thin sheets of these anatase- $\mathrm{TiO}_{2}$ nanoparticles. One of these thin sheets with an edge length of $15 \mathrm{~nm}$ is marked in the micrograph (Fig. $5 b_{2}$ ) and a set of Moiré fringes are also marked (encircled in Fig. $5 b_{2}$ ). Fig. $5 b_{4}$ and $b_{5}$ represent the TEM images of $\mathrm{TiO}_{2}$ nano-tubes and -rods, respectively. ${ }^{\mathbf{1 0 8 , 1 1 0 - 1 2 6}}$

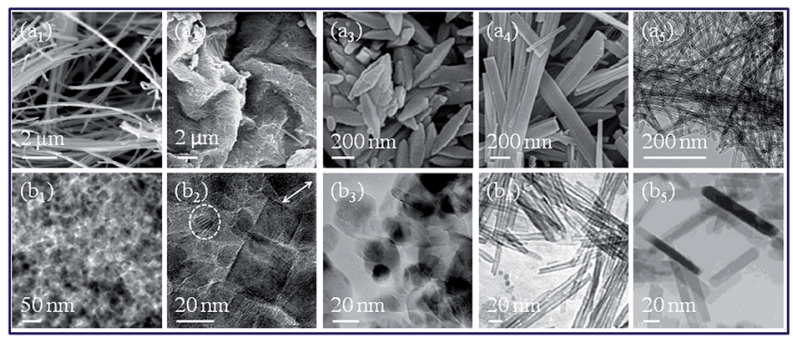

Fig. 5 Hydrothermal synthesis of multiphase $\mathrm{TiO}_{2}$ nanostructures: $\left(\mathrm{a}_{1}\right)$ nanowires, ${ }^{256}\left(a_{2}, a_{5}\right)$ nanotubes, ${ }^{257}\left(a_{3}\right)$ nano-polyhedrons, ${ }^{33}\left(a_{4}\right)$ nanobelts, ${ }^{33}\left(b_{1}\right)$ ultra-fine nanoparticles, ${ }^{172}\left(b_{2}\right)$ nano-cuboid shaped or thin sheets, ${ }^{172}\left(b_{3}\right)$ nanoparticles, ${ }^{256}\left(b_{4}\right)$ nanotubes, ${ }^{256}\left(b_{5}\right)$ nanorods. ${ }^{256}\left(a_{1}, b_{3}-b_{5}\right)$ are reprinted with permission from ref. $256 .\left(a_{2}, a_{5}\right)$ are reprinted with permission from ref. 257. Copyright 2012. Elsevier. $\left(a_{3}-a_{4}\right)$ are reprinted with permission from ref. 33. Copyright 2012. Springer. $\left(b_{1}\right.$ and $\left.b_{2}\right)$ are reprinted with permission from ref. 172. Copyright 2012. Elsevier.
3.2.3. Co-precipitation method. As described above, many physical/chemical methods have been utilized for producing multiphase $\mathrm{TiO}_{2}$ nanostructures. Amongst all the synthetic approaches, the co-precipitation chemical strategy is based on the condition of supersaturation from aqueous solutions followed by thermal decomposition. Co-precipitation is also known as the wet chemical solution method and also a common method to synthesize SMONs with largely scalable production. ${ }^{\mathbf{8} 240}$ In the co-precipitation method, the micro- or nanostructures of multiphase $\mathrm{TiO}_{2}$ are greatly affected by the reaction conditions, but also by the reactivity of the starting/ intermediate materials, $\mathrm{pH}$ value of the reaction medium and the reaction parameters, such as temperature and time. The variations mentioned above present numerous parameters to construct different high-quality nanoparticles and other nanostructures. A schematic illustration for the formation of oxide nanostructures through the co-precipitation method is depicted in Scheme 2(c).

Various shapes of multiphase $\mathrm{TiO}_{2}$ nanostructures have been synthesized, including nanorods and nanoparticles. Fig. $6 \mathrm{a}_{1}-\mathrm{b}_{4}$ elucidate the multiphase $\mathrm{TiO}_{2}$ nanostructures prepared via this method. Fig. $6 \mathrm{a}_{1}$ represents the SEM morphology of anatase- $\mathrm{TiO}_{2}$ nanorods, ${ }^{256}$ while Fig. $6 \mathrm{a}_{2}$ illustrates the rutile- $\mathrm{TiO}_{2}$ nanoparticles with a diameter of about $400 \mathrm{~nm}$ synthesized by the co-precipitation method. ${ }^{258}$ Fig. $6 \mathrm{a}_{3}$ and $\mathrm{a}_{4}$ present the SEM images of anatase- $\mathrm{TiO}_{2}$ and rutile-TiO nanoparticles, ${ }^{23}$ while Fig. $6 b_{3}$ and $b_{4}$ indicate the corresponding TEM images. ${ }^{23,259}$ The morphology of anatase- $\mathrm{TiO}_{2}$ nanoparticles monitored by SEM is depicted in Fig. $6 b_{1} \cdot{ }^{327}$ The TEM micrograph of $\mathrm{TiO}_{2}$ nanoparticles synthesized by this method is shown in Fig. $6 b_{2}$, clearly indicating the uniform nanoparticles (size about 5-10 nm) distributed throughout the sample. Even though the method of preparing $\mathrm{TiO}_{2}$ nanoparticles via coprecipitation is very easy and simple, enormously complicated nanostructures can also be successfully fabricated in this way.

Here, we review all the literature reports, to the best of our knowledge, concerning an easy way to produce multiphase $\mathrm{TiO}_{2}$

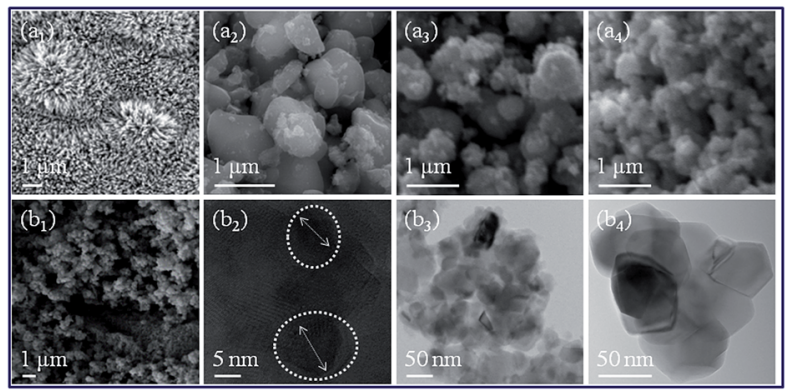

Fig. 6 Co-precipitation synthesis of multiphase $\mathrm{TiO}_{2}$ nanostructures; $\left(a_{1}\right)$ nanorods, ${ }^{256}\left(a_{2}, a_{3}, b_{3}\right)$ rutile nanoparticles, ${ }^{23,258}\left(a_{4}, b_{4}\right)$ anatase nanoparticles, ${ }^{23}\left(b_{1}\right.$ and $\left.b_{2}\right)$ nanoparticles. ${ }^{327}\left(a_{1}\right)$ is reprinted with permission from ref. 256. $\left(a_{2}\right)$ is reprinted with permission from ref. 258. Copyright 2017. Elsevier. $\left(a_{3}, a_{4}\right.$ and $\left.b_{3}\right)$ are reprinted with permission from ref. 23. Copyright 2016. Elsevier. $\left(b_{1}\right)$ is reprinted with permission from ref. 327. Copyright 2016. Thai Journal of Nanoscience and Nanotechnology. 
nanostructures in a short reaction time, using hazardless starting ingredients and that are inexpensive for feasible scaleup and to produce a high yield with high purity in industrial production via the mainly sol-gel, hydrothermal and coprecipitation methods. Table 3 presents an overview of the facile chemical synthesis approaches for multiphase- $\mathrm{TiO}_{2}$ nanostructures that are usually available through these routes.

\subsection{Growth mechanism}

One of the most demanding concerns in the efficient processing of these multiphase $\mathrm{TiO}_{2}$ nanostructures is the control of their size, morphology and microstructure. An apparent interpretation of the growth mechanism for the formation of multiphase $\mathrm{TiO}_{2}$ nanostructures is mandatory in this respect and is shown in Scheme 3. It is well known that the synthesis process for the formation of nanostructures is classically categorized into two events: (i) nucleation and (ii) growth. ${ }^{\mathbf{2 6 0 - 2 6 2}}$ In the nucleation process, small clusters composed of a few atoms (nuclei) are formed in the solution starting from monomers; while in the growth regime, existing nuclei grow to form larger particles. ${ }^{97}$ The mechanistic understanding of various aspects of the synthesis procedure can be established from a combination of crystallography and kinetics. Interestingly, the detailed mechanism still needs further investigation of the phase, structure and shape formation of $\mathrm{TiO}_{2}$. The chemical growth of nanostructured materials certainly entails the process of gelation or precipitation of a solid phase from the solution depending on the synthetic routes. An excellent perceptive of the processes and parameters ensuring the gel or precipitate formation helps to enhance the growth of nanoparticles to obtain the desired size and morphology. ${ }^{127}$ As the recent literature search indicated, there is immense interest in explaining the preliminary mechanisms, such as Finke-Watzky two step mechanisms, coalescence and oriented attachment as well as the LaMer burst nucleation followed by Ostwald ripening, ${ }^{\mathbf{1 3 7}}$ aggregation and

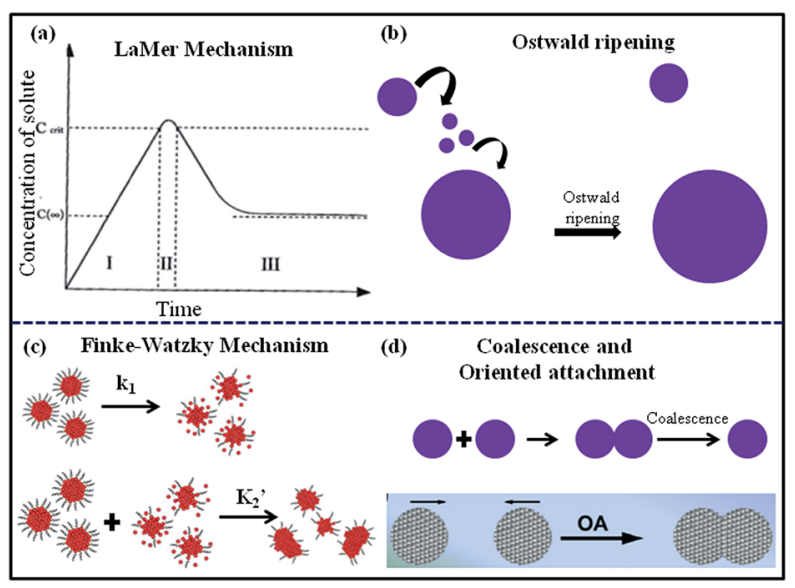

Scheme 3 Different possible growth mechanisms for the synthesis of nanostructured $\mathrm{TiO}_{2}$ materials. (a) is reprinted with permission from ref. 325. Copyright 2014. American Chemical Society. (c) is reprinted with permission from ref. 326. Copyright 2015. The Royal Society of Chemistry many more. ${ }^{\mathbf{2 6 2 - 2 6 5}}$ The study of the nucleation and growth process, the tailored morphology and crystalline structure and annealing/calcination treatments, has thus, become an exciting concern to produce multiphase nanostructures. With that in mind, the present review expresses the description of phase transformation, nucleation, growth, coarsening and agglomeration processes, including the change in temperature and chemical environment of multiphase $\mathrm{TiO}_{2}$ nanostructures synthesized via facile chemical routes.

Herein, the present review elaborates a brief description on the phase formation/transformation and different morphological characteristics of multiphase $\mathrm{TiO}_{2}$ nanostructures. The optimized procedures and growth mechanisms for the sol-gel, hydrothermal and co-precipitation methods of multiphase $\mathrm{TiO}_{2}$ nanostructures are also reviewed. In addition, the impacts of these nanostructures on the photoactive and biological responses are also described. Moreover, the review discusses the phase-, size- and morphology-dependent different transitions relating to the defect sites on multiphase $\mathrm{TiO}_{2}$ nanostructures as assessed by UV-Vis and PL spectroscopy. Furthermore, a comparative study assessed photocatalysis by modifying the surface of multiphase $\mathrm{TiO}_{2}$ nanostructures with inorganic $\left(\mathrm{SiO}_{2}\right)$ to that of an organic coating derived from green tea (Camellia sinensis), independently with a comprehensive mechanism given. Additionally, it covers the fundamental concepts on efficient formation via facile chemical routes and the growth mechanism of multiphase $\mathrm{TiO}_{2}$ nanostructures. Finally, the present review composes a novel mechanism emphasizing the effect of multiphase $\mathrm{TiO}_{2}$ nanostructures on biosafety/human health by using essential evidence available in the literature.

\section{Crystallographic structures}

$\mathrm{X}$-ray diffraction (XRD) analysis is essential to identify the crystallographic characteristics, such as gross structural analysis, phase transition, phase identification and phase purity determination of multiphase $\mathrm{TiO}_{2}$ nanostructures. Illustrations of the XRD patterns of the anatase-, -brookite and -rutile structural phases of $\mathrm{TiO}_{2}$ nanostructures are depicted in Fig. 79, which reveal the crystallinity, phase identification and phase purity of multiphase $\mathrm{TiO}_{2}$ nanostructures. In specific $2 \theta$ ranges $\left(20-80^{\circ}\right)$, the $\mathrm{XRD}$ patterns are sufficiently distinct, creating a clear classification of the multiphase $\mathrm{TiO}_{2}$ nanostructures.

\subsection{Anatase-TiO}

Fig. $7 \mathrm{a}_{1}$ provides the XRD pattern of anatase- $\mathrm{TiO}_{2}$ nanostructures. The Bragg's position of the diffraction peaks and the relative intensity of the diffraction peaks accord perfectly with the standard JCPDF card no. 73-1764, corresponding to the tetragonal crystal system of anatase- $\mathrm{TiO}_{2}$ (space group: $\mathrm{I}_{1} /$ amd (141); $a=b=0.377 \mathrm{~nm}, c=0.948 \mathrm{~nm}) .{ }^{23}$ All of the diffraction peaks were identified as characteristic of the XRD pattern of anatase- $\mathrm{TiO}_{2}$. The presence of diffraction peaks at $\sim 25.06^{\circ}$, $36.9^{\circ}, 37.8^{\circ}, 38.6^{\circ}, 48.1^{\circ}, 54.1^{\circ}, 55.1^{\circ}, 62.7^{\circ}, 68.7^{\circ}, 70.1^{\circ}$ and $75.1^{\circ}$ indicate the (101), (103), (004), (112), (200), (105), (211), (204), (116), (220) and (215) lattice planes, respectively, indexing 


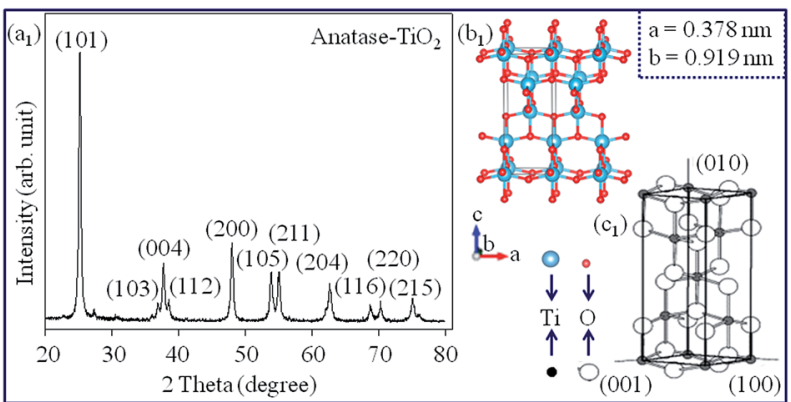

Fig. 7 Structural characteristics of anatase- $\mathrm{TiO}_{2} ;\left(\mathrm{a}_{1}\right)$ XRD pattern, ${ }^{275}$ $\left(b_{1}\right)$ ball-and-stick structure, ${ }^{142}\left(c_{1}\right)$ the tetragonal system with a dipyramidal habit. ${ }^{256}$ Colour code; $\mathrm{O}$ atoms: red (small balls), grey (large balls) and Ti atoms: blue (large balls), black (small balls). Unit cells are outlined using thin lines. $\left(a_{1}\right)$ is reprinted with permission from ref. 275 Copyright 2015. VBRI Press. $\left(b_{1}\right)$ is reprinted with permission from ref. 142. Copyright 2014. American Chemical Society. $\left(c_{1}\right)$ is reprinted with permission from ref. 256.

to a pure and highly crystalline anatase- $\mathrm{TiO}_{2}$ phase. No additional peaks corresponding to impurities and other structural phases were detected, which indicates the phase purity and high crystallinity synthesis of the anatase- $\mathrm{TiO}_{2}$ phase. The representative ball-and-stick structure of anatase- $\mathrm{TiO}_{2}$ is illustrated in Fig. $7 \mathrm{~b}_{1}$. The anatase- $\mathrm{TiO}_{2}$ has a crystalline structure that agrees with the tetragonal system with a dipyramidal habit (as shown in Fig. $\left.7 c_{1}\right)^{142,256}$

\subsection{Brookite-TiO}

The XRD pattern of brookite- $\mathrm{TiO}_{2}$ nanostructures is shown in Fig. $8 \mathrm{a}_{1}$. The Bragg's position of the diffraction peaks and the relative intensity of the diffraction peaks accord perfectly with the standard JCPDF card no. 76-1936, corresponding to an orthorhombic crystal system of brookite- $\mathrm{TiO}_{2}$ (space group: $\mathrm{Pbca}$ (61); $a=0.919 \mathrm{~nm}, b=0.546 \mathrm{~nm}, c=0.515 \mathrm{~nm})$. All of the diffraction peaks were identified as characteristic of the XRD pattern of brookite- $\mathrm{TiO}_{2}$. The presence of diffraction peaks at $\sim 25.26^{\circ}, 37.9^{\circ}$,

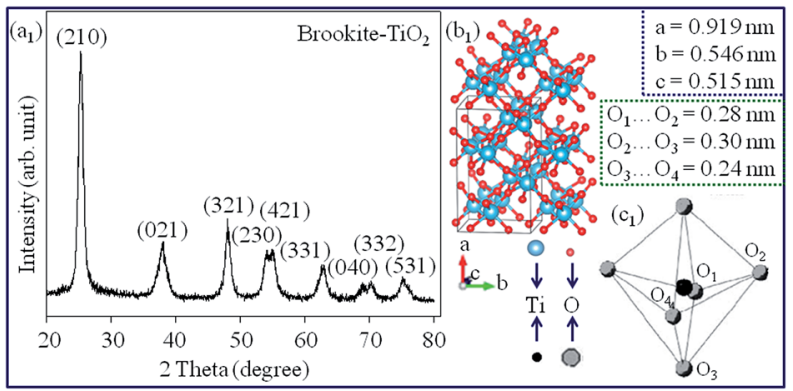

Fig. 8 Structural characteristics of brookite- $\mathrm{TiO}_{2} ;\left(\mathrm{a}_{1}\right)$ XRD pattern, ${ }^{275}$ $\left(b_{1}\right)$ ball-and-stick structure, ${ }^{142}\left(c_{1}\right)$ an orthorhombic crystalline structure. ${ }^{256}$ Colour code; $O$ atoms: red (small balls), grey (large balls) and Ti atoms: blue (large balls), black (small balls). Unit cells are outlined using thin lines. $\left(a_{1}\right)$ is reprinted with permission from ref. 275. Copyright 2015. VBRI Press. $\left(b_{1}\right)$ is reprinted with permission from ref. 142 Copyright 2014. American Chemical Society. $\left(c_{1}\right)$ is reprinted with permission from ref. 256 .

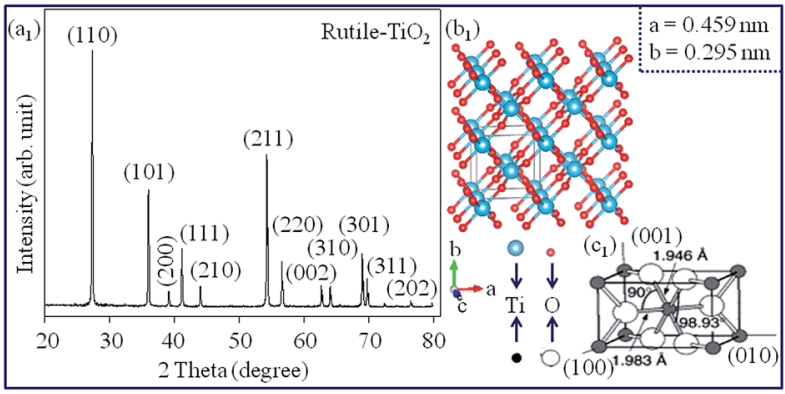

Fig. 9 Structural characteristics of rutile- $\mathrm{TiO}_{2} ;\left(\mathrm{a}_{1}\right)$ XRD pattern, ${ }^{23}\left(\mathrm{~b}_{1}\right)$ ball-and-stick structure, ${ }^{142}\left(c_{1}\right)$ the tetragonal system with a prismatic habit. ${ }^{256}$ Colour code; $O$ atoms: red (small balls), grey (large balls) and Ti atoms: blue (large balls), black (small balls). Unit cells are outlined using thin lines. $\left(a_{1}\right)$ is reprinted with permission from ref. 23. Copyright 2016. Elsevier. $\left(b_{1}\right)$ is reprinted with permission from ref. 142. Copyright 2014. American Chemical Society. $\left(c_{1}\right)$ is reprinted with permission from ref. 256

$47.9^{\circ}, 54.1^{\circ}, 55.1^{\circ}, 62.7^{\circ}, 68.9^{\circ}, 70.3^{\circ}$ and $75.3^{\circ}$ indicate the (210), (021), (321), (230), (421), (331), (040), (332) and (531) lattice planes, respectively, indexing to a pure and highly crystalline brookite$\mathrm{TiO}_{2}$ phase. No additional peaks corresponding to impurities and other structural phases were detected, which indicates the phase purity and high crystallinity synthesis of the anatase- $\mathrm{TiO}_{2}$ phase. The representative ball-and-stick structure of brookite- $\mathrm{TiO}_{2}$ is illustrated in Fig. $8 b_{1}$. The brookite- $\mathrm{TiO}_{2}$ phase has a crystalline structure that agrees with the orthorhombic crystal system (as shown in Fig. $\left.8 \mathrm{c}_{1}\right){ }^{\mathbf{1 4 2 , 2 5 6}}$

\subsection{Rutile-TiO}

Fig. $9 \mathrm{a}_{1}$ provides the XRD pattern of $\mathrm{TiO}_{2}$ nanostructures. The Bragg's position of the diffraction peaks and the relative intensity of the diffraction peaks accord perfectly with the standard JCPDF card no. 73-1765, also corresponding to the tetragonal crystal system of rutile- $\mathrm{TiO}_{2}$ (space group: $P 4_{2} / \mathrm{mnm}$ (136); $a=b=$ $0.458 \mathrm{~nm}, c=0.295 \mathrm{~nm}$ ). All of the diffraction peaks were identified as characteristic of the XRD pattern of rutile-TiO ${ }_{2}$. The presence of diffraction peaks at $\sim 27.5^{\circ}, 36.2^{\circ}, 39.3^{\circ}, 41.4^{\circ}, 44.0^{\circ}$, $54.3^{\circ}, 56.5^{\circ}, 62.7^{\circ}, 63.9^{\circ}, 69.1^{\circ}, 69.8^{\circ}$ and $76.7^{\circ}$ indicate the $(110)$, (101), (200), (111), (210), (211), (220), (002), (310), (301), (311) and (202) lattice planes, respectively, indexing to a pure and highly crystalline rutile- $\mathrm{TiO}_{2}$ phase. No additional peaks corresponding to impurities and other structural phases were detected, which indicates the phase purity and high crystallinity synthesis of the anatase- $\mathrm{TiO}_{2}$ phase. The representative ball-and-stick structure of rutile- $\mathrm{TiO}_{2}$ is illustrated in Fig. $9 \mathrm{~b}_{1}$. The rutile-TiO 2 has a crystalline structure that agrees with the tetragonal system with a prismatic habit (as shown in Fig. $\left.9 c_{1}\right)^{142,256}$

\section{Morphological and microstructural features}

Electron microscopy (EM) studies using scanning EM (SEM), field emission scanning EM (FE-SEM) and high-resolution transmission EM (HR-TEM) were utilized to investigate the different morphologies and for microstructural identification in real as well 


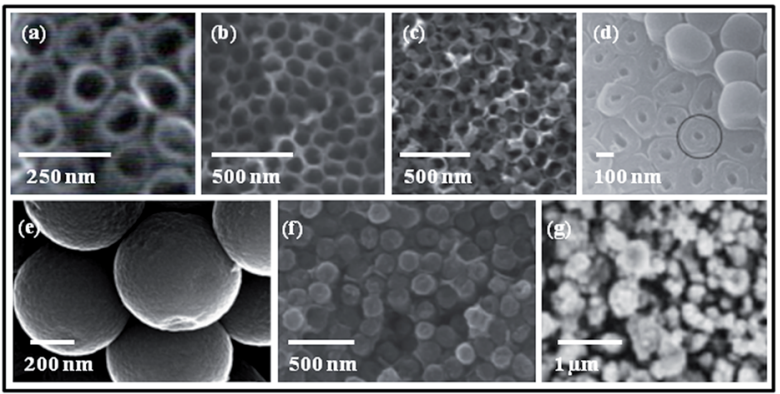

Fig. 10 SEM micrographs of a- $\mathrm{TiO}_{2}$ nanostructures: (a-d) nanotube arrays, (e) nanoparticles, (f) nanotube, (g) thin film. Ref: [a], ${ }^{266}[\mathrm{~b}, \mathrm{c}, \mathrm{f}],{ }^{267}$ $[\mathrm{d}],{ }^{268}[\mathrm{e}],{ }^{328}[\mathrm{~g}]{ }^{173}$ (a) is reprinted with permission from ref. 266. Copyright 2011. American Scientific Publisher. (b, c and f) are reprinted with permission from ref. 267. Copyright 2012. John Wiley and Sons. (d) is reprinted with permission from ref. 268. Copyright 2014. The Chemical Society of Japan. (e) is reprinted with permission from ref. 328. Copyright 2012. John Wiley and Sons. (g) is reprinted with permission from ref. 173. Copyright 2005. Elsevier.

as in reciprocal spaces for assessing the phase-dependent morphology of amorphous- and crystalline- $\mathrm{TiO}_{2}$ nanostructures.

\subsection{SEM aspects}

The representative micrographs of amorphous- and multiphase- $\mathrm{TiO}_{2}$ (anatase-, brookite- and rutile- $\mathrm{TiO}_{2}$ ) nanostructures using SEM and FE-SEM images are shown in Fig. 10-13. These figures reveal the general/surface morphology of the $\mathrm{TiO}_{2}$ nanostructures.

5.1.1. Amorphous-TiO ${ }_{2}$. Fig. 10 depicts the SEM micrographs of amorphous- $\mathrm{TiO}_{2}\left(\mathrm{a}-\mathrm{TiO}_{2}\right)$ nanostructures synthesized via different fabrication routes. Fig. 10(a) shows a SEM image of a-TiO ${ }_{2}$ nanotube arrays synthesized after electrochemical cycling at a current density of $400 \mu \mathrm{A} \mathrm{cm}^{-2} \cdot{ }^{266} \mathrm{Fig} .10$ (b, c and f) represent the $\mathrm{FE}-\mathrm{SEM}$ images of $\mathrm{a}-\mathrm{TiO}_{2}$ nanotube arrays synthesized via the hydrothermal method under different reaction conditions. ${ }^{267}$ Fig. 10(d) illustrates the bottom surface of double-wall a-TiO ${ }_{2}$ nanotube arrays produced via anodization. ${ }^{268}$ Uniform a-TiO 2 nanoparticles with an average diameter of $500 \mathrm{~nm}$ obtained through a sol-gel process is represented in Fig. 10(e). Fig. 10(g) elucidates the electrodeposited thin film of $\mathrm{a}-\mathrm{TiO}_{2} \cdot{ }^{173}$

5.1.2. Multiphase-TiO ${ }_{2}$. When atoms/ions/molecules are arranged in an infinite, periodic, regular and ordered way, the nanomaterials become crystalline and have different structural phases (polymorph materials). The SEM/FE-SEM images of multiphase $\mathrm{TiO}_{2}$, in particular anatase-, brookite- and rutile$\mathrm{TiO}_{2}$, nanostructures, are represented in Fig. 11-13.

5.1.2.1. Anatase- $\mathrm{TiO}_{2}$. Fig. $11\left(\mathrm{a}_{1}-\mathrm{c}_{6}\right)$ show various morphological features of anatase- $\mathrm{TiO}_{2}$ nanostructures (elongated and spherical) synthesized via numerous methods. Fig. 11( $\mathrm{a}_{1}$ and $\left.\mathrm{a}_{2}\right)$ clearly demonstrate the SEM images of nanotubes synthesized

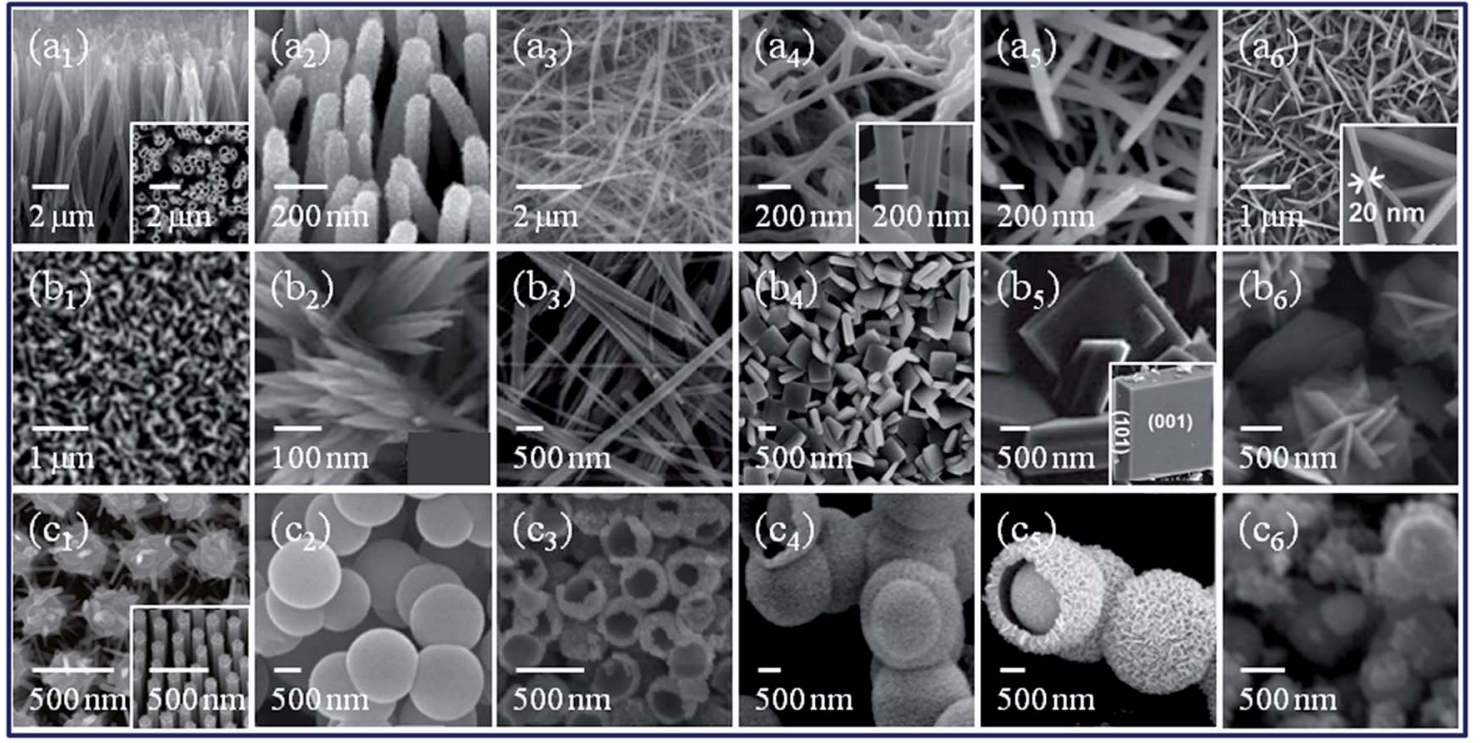

Fig. 11 SEM micrographs of anatase- $\mathrm{TiO}_{2}$ nanostructures: $\left(a_{1}\right.$ and $\left.a_{2}\right)$ nanotubes, $\left(a_{3}\right.$ and $\left.a_{4}\right)$ nanofibres, $\left(a_{5}\right)$ nanorods, $\left(a_{6}\right)$ nanorods with nanoflakes, $\left(b_{1}\right)$ nanorod arrays, $\left(b_{2}\right)$ nanoribbons, $\left(b_{3}\right)$ nanowires, $\left(b_{4}-b_{6}\right)$ nanosheets, $\left(c_{1}\right) 3 D$ network, $\left(c_{2}\right)$ nanospheres, $\left(c_{3}\right)$ nanocups, $\left(c_{4}\right.$ and $c_{5}$ ) nanospheres and $\left(c_{6}\right)$ nanoparticles. Insets $\left(a_{1}, a_{4}, a_{6}, b_{5}\right.$ and $\left.c_{1}\right)$ provide the corresponding higher magnification images. Ref: $\left.\left[a_{1}, a_{2}\right]_{1}, 50 a_{3}\right]_{1}^{329}$ $\left[a_{4}\right],{ }^{50}\left[a_{5}\right],{ }^{269}\left[a_{6}\right],{ }^{270}\left[b_{1}\right],{ }^{330}\left[b_{2}\right],{ }^{271}\left[b_{3}\right],{ }^{50}\left[b_{4}\right],{ }^{292}\left[b_{5}\right],{ }^{41}\left[b_{6}\right],{ }^{331}\left[c_{1}\right],{ }^{50}\left[c_{3}\right],{ }^{274}\left[c_{2}, c_{4}\right.$ and $\left.c_{5}\right],{ }^{273}\left[c_{6}\right] .{ }^{275}\left(a_{1}, a_{2}, a_{4}, b_{3}\right.$ and $\left.c_{1}\right)$ are reprinted with permission from ref. 50. Copyright 2014. American Chemical Society. $\left(a_{3}\right)$ is reprinted with permission from ref. 329. Copyright 2005. Elsevier. $\left(a_{5}\right)$ is reprinted with permission from ref. 269. Copyright 2013. The Royal Society of Chemistry. $\left(a_{6}\right)$ is reprinted with permission from ref. 270. Copyright 2012. The Royal Society of Chemistry. $\left(b_{1}\right)$ is reprinted with permission from ref. 330. Copyright 2004 . The Royal Society of Chemistry. $\left(b_{2}\right)$ is reprinted with permission from ref. 271. Copyright 2011. American Chemical Society. (b $b_{4}$ ) is reprinted with permission from ref. 292. Copyright 2009. American Chemical Society. $\left(b_{5}\right)$ is reprinted with permission from ref. 41. Copyright 2009. American Chemical Society. ( $\left.b_{6}\right)$ is reprinted with permission from ref. 331. Copyright 2011. John Wiley and Sons. $\left(c_{2}, c_{4}\right.$ and $\left.c_{5}\right)$ are reprinted with permission from ref. 273. Copyright 2007. American Chemical Society. $\left(c_{3}\right)$ is reprinted with permission from ref. 274 . Copyright 2013 . The Royal Society of Chemistry. $\left(c_{6}\right)$ is reprinted with permission from ref. 275. VBRI Press. 


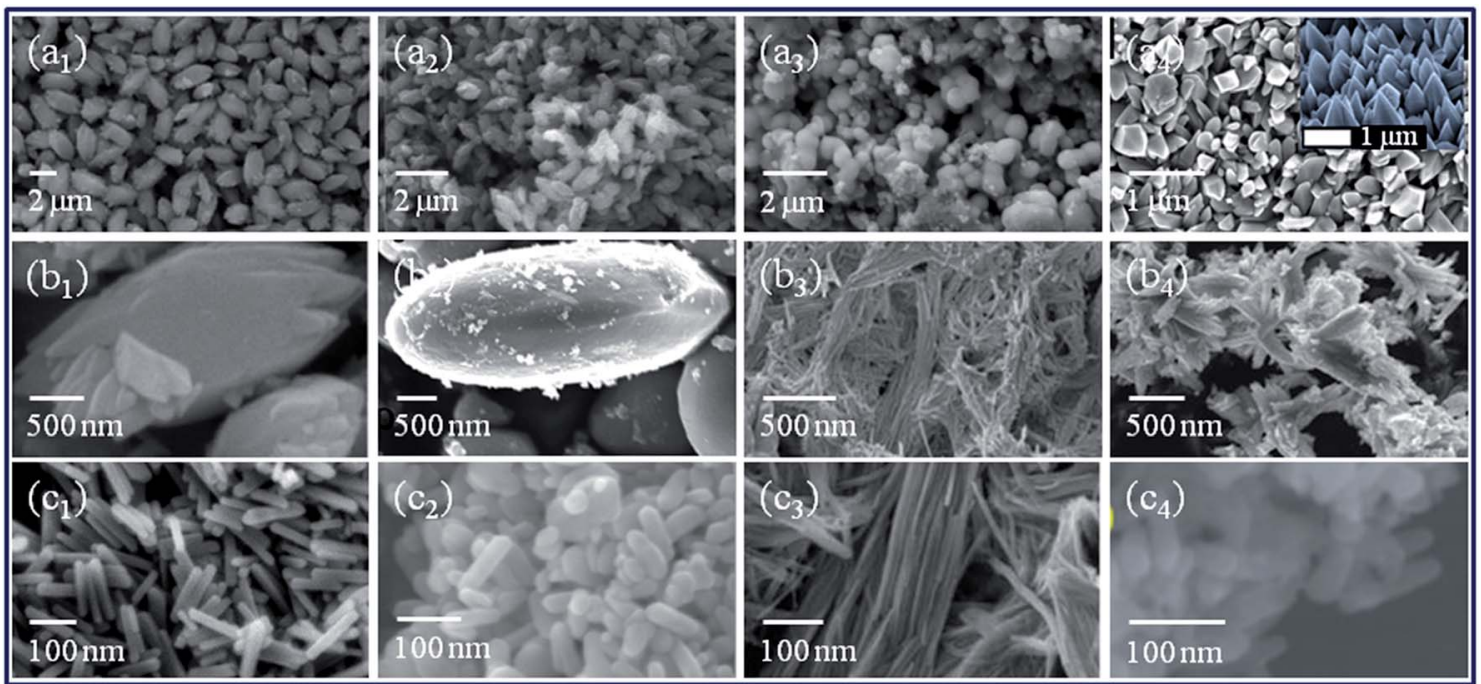

Fig. 12 SEM micrographs of brookite-TiO 2 nanostructures: $\left(a_{1}\right.$ and $\left.a_{2}\right)$ nanorices, ${ }^{276}\left(a_{3}\right)$ nanoparticles, ${ }^{275}\left(a_{4}\right)$ nanobullets, ${ }^{293}\left(b_{1}\right)$ nanorices, ${ }^{276}\left(b_{2}\right)$ eggshell, ${ }^{277}\left(b_{3}\right)$ nanotubes, ${ }^{278}\left(b_{4}\right)$ nanoflowers, $\left(c_{1}\right.$ and $\left.c_{2}\right)$ nanorods, ${ }^{27,280}\left(c_{3}\right)$ nanotubes, ${ }^{278}\left(c_{4}\right)$ nanorods. ${ }^{281}$ Inset $\left(a_{4}\right)$ illustrates the corresponding tilt-view of nanobullets. $\left(a_{1}, a_{2}\right.$ and $\left.b_{1}\right)$ are reprinted with permission from ref. 276. Copyright 2014. The Royal Society of Chemistry. ( $\left.a_{3}\right)$ is reprinted with permission from ref. 275. Copyright 2015. VBRI Press. $\left(a_{4}\right)$ is reprinted with permission from ref. 293. Copyright 2016. Nature Publishing Group. $\left(b_{2}\right)$ is reprinted with permission from ref. 277. $\left(b_{3}, c_{3}\right)$ are reprinted with permission from ref. 278. Copyright 2008. The Royal Society of Chemistry. $\left(c_{1}\right)$ is reprinted with permission from ref. 279. Copyright 2013. The Royal Society of Chemistry. $\left(c_{2}\right)$ is reprinted with permission from ref. 280. Copyright 2012. Elsevier. $\left(c_{4}\right)$ is reprinted with permission from ref. 281. Copyright 2013. The Royal Society of Chemistry.



Fig. 13 SEM micrographs of rutile- $\mathrm{TiO}_{2}$ nanostructures: $\left(a_{1}\right)$ nanorods, ${ }^{282}\left(a_{2}-a_{5}\right)$ nanorod arrays, ${ }^{283}\left(a_{6}\right)$ nanorod spheres, ${ }^{284}\left(b_{1}, b_{3}\right.$ and $\left.b_{4}\right)$ nanorod bundles, ${ }^{283,285}\left(b_{2}\right)$ flower-like super architectures, ${ }^{286}\left(b_{5}\right)$ urchin-like, ${ }^{286}\left(b_{6}\right)$ nanospheres, ${ }^{286}\left(b_{7}\right)$ nanotrees, ${ }^{286}\left(b_{8}\right)$ a single nanoparticle, ${ }^{287}\left(c_{1}\right)$ self-assembled nanowires, ${ }^{288}\left(c_{2}\right)$ microspheres, ${ }^{286}\left(c_{3}\right)$ nanorod arrays, ${ }^{286}\left(c_{4}\right)$ quasi spheres, ${ }^{286}\left(c_{5}\right)$ microspheres ${ }^{286}$ and $\left(c_{6}\right)$ nanoparticles. ${ }^{275}$ Insets: (lower inset in $a_{1}$ ) nanorods at higher magnification, (upper inset in $c_{2}$ ) top view of the nanorods with square-shaped ends. $\left(a_{1}\right)$ is reprinted with permission from ref. 282. Copyright 2011. The Royal Society of Chemistry. $\left(a_{2}-a_{5}\right)$ are reprinted with permission from ref. 283. Copyright 2014. Nature Publishing Group. $\left(a_{6}\right)$ is reprinted with permission from ref. 284. Copyright 2014. American Chemical Society. $\left(b_{1}\right)$ is reprinted with permission from ref. 285 . Copyright 2014. Nature Publishing Group. $\left(b_{2}, b_{5}-b_{7}, c_{2}-c_{5}\right)$ are reprinted with permission from ref. 286. Copyright 2012. The Royal Society of Chemistry. ( $b_{3}$ and $b_{4}$ ) are reprinted with permission from ref. 283. Copyright 2014. Nature Publishing Group. $\left(b_{8}\right)$ is reprinted with permission from ref. 287. Copyright 2002. The Royal Society of Chemistry. $\left(c_{1}\right)$ is reprinted with permission from ref. 288. Copyright 2010. The Royal Society of Chemistry. $\left(c_{6}\right)$ is reprinted with permission from ref. 275. Copyright 2015. VBRI Press. 
via a liquid-phase deposition and ten cycles of $\mathrm{TiCl}_{4}$ followed by the $\mathrm{H}_{2} \mathrm{O}$ deposition method, respectively. ${ }^{50}$ Fig. 11( $\mathrm{a}_{3}$ and $\left.\mathrm{a}_{4}\right)$ illustrate nanofibres of anatase- $\mathrm{TiO}_{2}$ synthesized by calcination at $700{ }^{\circ} \mathrm{C}$ for $4 \mathrm{~h}$ (ref. 268) and an atomic layer deposition process, respectively. ${ }^{50}$ Fig. $11\left(\mathrm{a}_{5}\right.$ and $\left.\mathrm{a}_{6}\right)$ represent the FE-SEM images of nanorods, ${ }^{269}$ and nanorods with a nanoflake film, respectively. ${ }^{270}$ In addition, Fig. $11\left(b_{1}-b_{6}\right)$ show the SEM micrographs of elongated anatase- $\mathrm{TiO}_{2}$ nanostructures: $\left(\mathrm{b}_{1}\right)$ nanorod arrays, ${ }^{271}\left(b_{2}\right)$ nanoribbons, ${ }^{271}\left(b_{3}\right)$ nanobelts, ${ }^{50}\left(b_{4}-b_{6}\right)$ nanosheets. ${ }^{41,272,292,331}$ Moreover, the spherical morphologies of anatase- $\mathrm{TiO}_{2}$ nanostructures are depicted in Fig. $11\left(\mathrm{c}_{1}-\mathrm{c}_{6}\right)$, such as $\left(c_{1}\right)$ a $3 \mathrm{D}$ network grown on the silicon through a surfacereaction-limited pulsed chemical vapour deposition process, ${ }^{50}$ $\left(c_{2}\right)$ uniform, smooth, solid spherical particles, ${ }^{273}\left(c_{3}\right)$ nanocups, ${ }^{274}\left(c_{4}\right.$ and $\left.c_{5}\right)$ nanospheres ${ }^{273}\left(c_{6}\right)$ nanoparticles. ${ }^{275}$

5.1.2.2. Brookite-TiO ${ }_{2}$. Fig. $12\left(\mathrm{a}_{1}-\mathrm{c}_{4}\right)$ represent the spherical and elongated nanostructures of brookite- $\mathrm{TiO}_{2}$ obtained at various reaction conditions. Fig. $12\left(\mathrm{a}_{1}\right.$ and $\left.\mathrm{a}_{2}\right)$ elucidate the SEM images of nanorices obtained hydrothermally with prolonging the reaction time to $24 \mathrm{~h}$ and $48 \mathrm{~h}^{276}$ The SEM images of brookite- $\mathrm{TiO}_{2}$ nanostructures: $\left(\mathrm{a}_{3}\right)$ nanoparticles synthesized by the sol-gel method, ${ }^{275}\left(\mathrm{a}_{4}\right)$ top-view SEM image of nanobullets grown hydrothermally showing sharpened tips, with the upper inset providing the corresponding tilt-view, ${ }^{277}\left(\mathrm{~b}_{1}\right)$ a single ricelike particle, ${ }^{276}\left(b_{2}\right)$ eggshell morphology obtained with the thermolysis method. ${ }^{277}$ Fig. $12\left(b_{3}\right.$ and $\left.c_{3}\right)$ show the SEM images of hydrothermally derived nanotubes, ${ }^{278}\left(b_{4}\right)$ nanoflowers obtained by a one-step hydrothermal synthesis route, ${ }^{181}\left(c_{1}, c_{2}\right.$ and $\mathrm{c}_{4}$ ) nanorods ${ }^{279-281}$ of brookite-TiO $\mathrm{Ti}_{2}$ synthesized via facile chemical routes.

5.1.2.3. Rutile-TiO ${ }_{2}$. Fig. $13\left(\mathrm{a}_{1}-\mathrm{c}_{6}\right)$ depict the microstructural features in the elongated and spherical forms of rutile- $\mathrm{TiO}_{2}$ nanostructures. Fig. 13( $\left.a_{1}\right)$ represents the SEM micrographs of rutile- $\mathrm{TiO}_{2}$ nanorods synthesized under different reaction conditions in the sol-gel process under $365 \mathrm{~nm}$ UV light illumination. The inset in Fig. 13( $\left.a_{1}\right)$ elucidates the nanorods at a higher magnification. ${ }^{282}$ Fig. $13\left(a_{2}-a_{5}\right)$ show bundles of nanorods under different reaction conditions. ${ }^{283}$ Fig. 13( $\left(\mathrm{a}_{6}\right)$ demonstrates a nanorod sphere. ${ }^{284}$ Fig. $13\left(b_{1}, b_{3}\right.$ and $\left.b_{4}\right)$ show nanorod bundles grown hydrothermally. ${ }^{283,285}$ Fig. $13\left(b_{2}\right.$ and $\left.b_{5}\right)$ represent the flower-like super architecture and urchin-like structure composed of loose nanorods. ${ }^{286}$ Fig. $13\left(b_{6}\right.$ and $\left.b_{7}\right)$ represent the SEM micrographs of nano-spheres and -trees, respectively. ${ }^{286}$ Fig. $13\left(b_{8}\right)$ depicts a rutile- $\mathrm{TiO}_{2}$ particle with an average size of $\sim 1 \mathrm{~mm}$ showing a tetragonal prism structure with four planes, which are assigned to the $\{110\}$ faces. Each end of the prism is capped by four planes, which are assigned to the $\{011\}$ faces. ${ }^{287}$ Fig. $13\left(c_{1}\right)$ represents the self-assembled nanowires synthesized via microwave heating. ${ }^{288}$ Fig. 13( $\left.\mathrm{c}_{2}\right)$ displays domain like arrangements of the $\mathrm{TiO}_{2}$ quasi spheres leading apparently to a flat surface. The upper inset in Fig. 13( $\left.c_{2}\right)$ provides the top view of the nanorod with a squareshaped end. ${ }^{286}$ Fig. $12\left(c_{3}\right)$ shows the microspheres connected to each other but not merging together. ${ }^{286}$ Fig. $13\left(c_{4}, c_{5}\right.$ and $\left.c_{6}\right)$ demonstrate the SEM micrographs of microspheres composed of nanorods, spherical architectures ${ }^{286}$ and nanoparticles, ${ }^{275}$ respectively.

\subsection{TEM/HR-TEM aspects}

The detailed microstructural evidence, fine structure arrangement at the atomic level and selected area electron diffraction (SAED) and fast Fourier transform (FFT) patterns of amorphous$\mathrm{TiO}_{2}\left(\mathrm{a}-\mathrm{TiO}_{2}\right)$ and crystalline-TiO ${ }_{2}$ (anatase-, brookite- and rutile- $\mathrm{TiO}_{2}$ ) nanostructures can be realized in real and reciprocal spaces through taking and analyzing the TEM and HRTEM images, which are discussed in Fig. 14-17.

5.2.1. Amorphous-TiO ${ }_{2}$. Amorphous solids do exhibit short-range order in their structures. Fig. $14\left(a_{1}-a_{6}\right)$ provide the TEM and HR-TEM images and SAED and FFT patterns of a-TiO nanostructures. Fig. 14( $\left.a_{1}\right)$ represents the TEM micrograph of a$\mathrm{TiO}_{2}$ nanoparticles having a narrowly distributed size of about 10-15 nm. ${ }^{259}$ Fig. 14 $\left(\mathrm{a}_{2}\right.$ and $\left.\mathrm{a}_{3}\right)$ show the morphological changes of the nanotube arrays with the introduction (as shown in Fig. 14( $\left.\mathrm{a}_{2}\right)$ ) and without the introduction (as depicted in Fig. 14 $\left.\left(\mathrm{a}_{3}\right)\right)$ of oxygen $\left(\mathrm{O}_{2}\right)$ gas. ${ }^{268}$ Fig. $14\left(\mathrm{a}_{4}\right.$ and $\left.\mathrm{a}_{5}\right)$ elucidate the typical HR-TEM micrograph at low and high magnifications, respectively. The FFT pattern of $\mathrm{a}^{-\mathrm{TiO}_{2}}$ (as illustrated in the upper inset of Fig. 14( $\left(\mathrm{a}_{5}\right)$ ) represents the semicircle-like diffuse spots centred at $3.1 \pm 0.1 \AA$. The FFT pattern reveals that the contrast patterns in the micrograph can be assigned to the chains of octahedral species linked through Ti-O-Ti bridges at a distance that is: (i) lower than that related to the corner sharing (generally $\sim 3.5 \AA$ ), but (ii) higher than the characteristic distance for Ti-O-Ti octahedrons in an edge-sharing configuration (normally $\sim 3.0 \AA$ ) ${ }^{289}$ Fig. $14\left(\mathrm{a}_{6}\right)$ shows the TEM image of a-TiO ${ }_{2}$ nanotube arrays with a gradually thickened wall with depth. The upper inset of Fig. 14( $\left.\mathrm{a}_{6}\right)$ reveals the diffuse ring SAED pattern of the single nanotube and indicates the amorphous nature of nanotube arrays. ${ }^{267}$

5.2.2. Multiphase $\mathbf{T i O}_{2}$. Most solids are crystalline, with the atoms, ions, or molecules of which they are composed falling into regular, repeated $3 \mathrm{D}$ patterns. The presence of long-range order is thus the defining property of a crystal. The

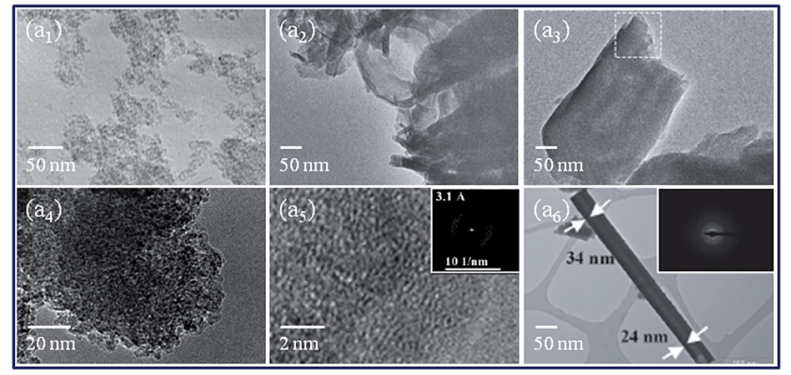

Fig. 14 TEM/HR-TEM micrographs of a- $\mathrm{TiO}_{2}$ nanostructures: $\left(\mathrm{a}_{1}\right)$ TEM image of nanoparticles, ${ }^{259}\left(a_{2}\right)$ nanotubes with the introduction of $\mathrm{O}_{2}$ gas, ${ }^{268}\left(a_{3}\right)$ nanotubes without the introduction of $\mathrm{O}_{2}$ gas, ${ }^{268} \mathrm{HR}-\mathrm{TEM}$ image of nanoparticles at low $\left(a_{4}\right)$ and high $\left(a_{5}\right)$ magnification, ${ }^{289}\left(a_{6}\right)$ TEM images of a single nanotube. ${ }^{267}$ Insets provide: $\left(a_{5}\right)$ corresponding FFT pattern and $\left(a_{6}\right)$ corresponding SAED pattern. $\left(a_{1}\right)$ is reprinted with permission from ref. 259. Copyright 2013. Indian Journal of Engineering \& Materials Sciences. $\left(a_{2}\right.$ and $\left.a_{3}\right)$ are reprinted with permission from ref. 268. Copyright 2014. The Chemical Society of Japan. $\left(a_{4}\right.$ and $\left.a_{5}\right)$ are reprinted with permission from ref. 289. $\left(a_{6}\right)$ is reprinted with permission from ref. 267. Copyright 2012. John Wiley and Sons. 


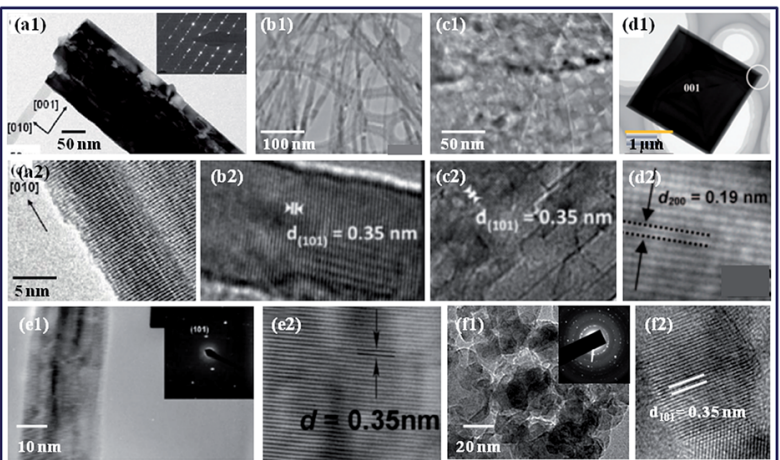

Fig. 15 TEM/HR-TEM micrographs of anatase- $\mathrm{TiO}_{2}$ nanostructures: $\left(a_{1}\right)$ bright-field TEM image of a nanobelt and the corresponding HRTEM image, ${ }^{290}\left(a_{2}\right)$ taken along the [100] direction, ${ }^{290}\left(b_{1}\right)$ low- and $\left(b_{2}\right)$ high-magnification TEM images of nanorods, ${ }^{291}\left(c_{1}\right)$ low- and $\left(c_{2}\right)$ highmagnification TEM images of nanoflakes, ${ }^{291}\left(d_{1}\right)$ HR-TEM image of a nanocrystal and its corresponding lattice fringe image $\left(d_{2}\right){ }^{292}\left(e_{1}\right)$ TEM and $\left(e_{2}\right)$ HR-TEM images of the nanofibres ${ }^{329}$ and $\left(f_{1}\right)$ TEM and corresponding HR-TEM image $\left(f_{2}\right)$ of nanoparticles. ${ }^{23}$ Insets in $\left(a_{1}, e_{1}, f_{1}\right)$ provide their corresponding SAED pattern. $\left(a_{1}\right.$ and $\left.a_{2}\right)$ are reprinted with permission from ref. 290. Copyright 2015. John Wiley and Sons. $\left(b_{1}, b_{2}, c_{1}\right.$ and $\left.c_{2}\right)$ are reprinted with permission from ref. 291. Copyright 2012. The Royal Society of Chemistry. $\left(d_{1}\right.$ and $\left.d_{2}\right)$ are reprinted with permission from ref. 292. Copyright 2009. American Chemical Society. $\left(e_{1}\right.$ and $\left.e_{2}\right)$ are reprinted with permission from ref. 329. Copyright 2005. Elsevier. $\left(f_{1}\right.$ and $\left.f_{2}\right)$ are reprinted with permission from ref. 23. Copyright 2016. Elsevier.

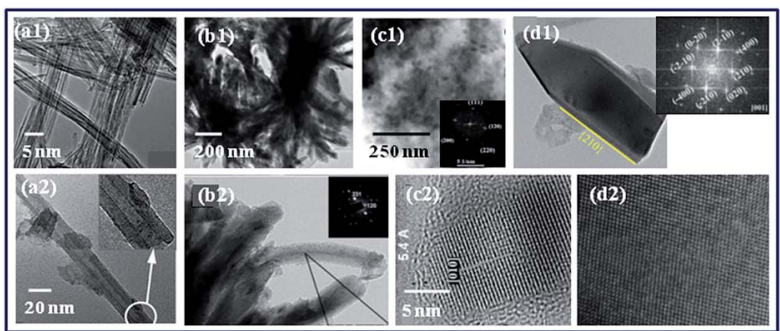

Fig. 16 TEM/HR-TEM micrographs of brookite- $\mathrm{TiO}_{2}$ nanostructures: $\left(a_{1}, b_{1}, c_{1}, d_{1}\right)$ TEM images of nanotubes, ${ }^{244,278,289,293}\left(a_{2}, b_{2}, c_{2}, d_{2}\right)$ HRTEM images of nano-tubes, -flowers, -particles, -bullets, respectively. ${ }^{244,278,289,293}$ Insets (in $\left.b_{2}, c_{1}, d_{1}\right)$ correspond to the FFT patterns. $\left(a_{1}\right.$ and $a_{2}$ ) are reprinted with permission from ref. 278. Copyright 2008. The Royal Society of Chemistry. $\left(b_{1}\right.$ and $\left.b_{2}\right)$ are reprinted with permission from ref. 244. Copyright 2009. The Royal Society of Chemistry. $\left(c_{1}\right.$ and $\left.c_{2}\right)$ are reprinted with permission from ref. $289 .\left(d_{1}\right.$ and $d_{2}$ ) are reprinted with permission from ref. 293. Copyright 2016. Nature Publishing Group.

observation of multiphase $\mathrm{TiO}_{2}$ (especially anatase-, brookite-, and rutile- $\mathrm{TiO}_{2}$ ) nanostructures by means of TEM/HR-TEM are commonly overlooked, but here the results are displayed as well as discussed in Fig. 15-17.

5.2.2.1. Anatase-TiO . Fig. $15\left(\mathrm{a}_{1}-\mathrm{f}_{2}\right)$ provide the TEM/HRTEM micrographs at low and high magnifications as well as the SAED and FFT patterns of anatase- $\mathrm{TiO}_{2}$ nanostructures. Fig. 15 $\left(\mathrm{a}_{1}\right.$ and $\left.\mathrm{a}_{2}\right)$ represent the bright-field TEM and HR-TEM micrographs of nanobelts obtained from an alkalihydrothermal process with the growth direction along the

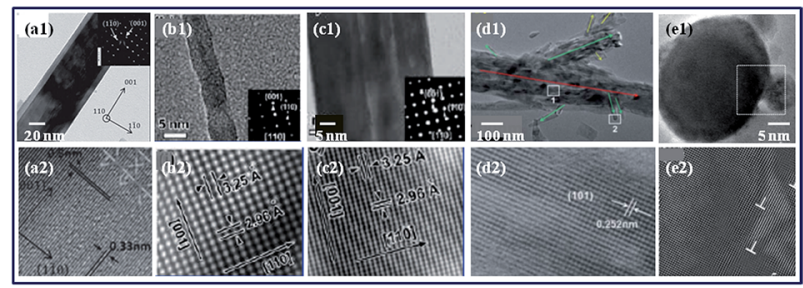

Fig. 17 TEM/HR-TEM micrographs of rutile- $\mathrm{TiO}_{2}$ nanostructures: $\left(\mathrm{a}_{1}\right.$ and $a_{2}$ ) TEM image and corresponding HR-TEM image of a nanobelt, ${ }^{290}$ $\left(b_{1}\right.$ and $\left.c_{1}\right)$ TEM images of one individual nanowire and nanorod, ${ }^{271}\left(b_{2}\right.$ and $\mathrm{C}_{2}$ ) corresponding HR-TEM images of the nanowire and nano$\operatorname{rod}_{1}^{271}\left(d_{1}\right.$ and $\left.d_{2}\right)$ low magnification TEM and HR-TEM images of multilevel branched architectures, ${ }^{286}\left(e_{1}\right)$ the lattice image and $\left(e_{2}\right)$ reconstructed image from the square region in $\left(e_{1}\right){ }^{294}$ Insets (in $a_{1}, b_{1}$ and $\left.c_{1}\right)$ illustrate the corresponding SAED patterns. $\left(a_{1}\right.$ and $\left.a_{2}\right)$ are reprinted with permission from ref. 290. Copyright 2015. John Wiley and Sons. $\left(b_{1}, b_{2}, c_{1}\right.$ and $\left.c_{2}\right)$ are reprinted with permission from ref. 271. Copyright 2011. American Chemical Society. $\left(d_{1}\right.$ and $\left.d_{2}\right)$ are reprinted with permission from ref. 286. Copyright 2012. The Royal Society of Chemistry. $\left(e_{1}\right.$ and $\left.e_{2}\right)$ are reprinted with permission from ref. 294. Copyright 2004. Nature Publishing Group.

[010] plane. ${ }^{290}$ Fig. $15\left(b_{1}\right.$ and $\left.b_{2}\right)$ show the low- and highmagnification TEM images of nanorods, respectively. From the figures, it can clearly be observed that the crystalline behaviour is along their entire lengths. The calculated interplanar spacing $d_{(101)}=0.35 \mathrm{~nm}$, which affirms the presence of anatase- $\mathrm{TiO}_{2} \cdot{ }^{291}$ Fig. $15\left(\mathrm{c}_{1}\right.$ and $\left.\mathrm{c}_{2}\right)$ elucidate the low- and highmagnification TEM images of nanoflakes. The lattice fringes with interplanar spacings of $d_{(101)}=0.35 \mathrm{~nm}$ are consistent with the anatase- $\mathrm{TiO}_{2}{ }^{291}$ Fig. $15\left(\mathrm{~d}_{1}\right.$ and $\left.\mathrm{d}_{2}\right)$ show the continuous (200) atomic planes with a lattice spacing of $0.19 \mathrm{~nm}^{292}$ Fig. 15 $\left(\mathrm{e}_{1}\right.$ and $\left.\mathrm{e}_{2}\right)$ indicate the TEM and HR-TEM images of the nanofibres, respectively. ${ }^{268}$ Moreover, the TEM and HR-TEM images of nanoparticles synthesized by a wet chemical method are displayed in Fig. $15\left(\mathrm{f}_{1}\right.$ and $\left.\mathrm{f}_{2}\right)$, respectively. ${ }^{23}$

5.2.2.2. Brookite-TiO ${ }_{2}$. Fig. $16\left(\mathrm{a}_{1}-\mathrm{d}_{2}\right)$ display the TEM/HRTEM micrographs and SAED and FFT patterns of brookite$\mathrm{TiO}_{2}$ nanostructures. Fig. $16\left(\mathrm{a}_{1}\right.$ and $\left.\mathrm{a}_{2}\right)$ elucidate the TEM images of a nanotube adapting the tube-like morphology with a crystalline multiwall structure. ${ }^{278}$ Fig. $16\left(b_{1}\right)$ represents the TEM images of nanorods, revealing that the length of a single nanorod is about $1000 \mathrm{~nm}$, and a single cluster of flowers can also be observed due to agglomerated nanorods. Fig. 16( $\left.b_{2}\right)$ shows the HR-TEM image of a nanorod with a diameter of about $40 \mathrm{~nm}$. The SAED pattern represented in the upper inset of Fig. 16 $\left(b_{2}\right)$ also confirms that the nanorods are a single crystal of brookite-TiO ${ }_{2} \cdot{ }^{244}$ Fig. $16\left(c_{1}\right.$ and $\left.c_{2}\right)$ depict the TEM and HR-TEM images of agglomerated nanoparticles. ${ }^{289}$ Fig. $16\left(\mathrm{~d}_{1}\right.$ and $\left.\mathrm{d}_{2}\right)$ also elucidate the TEM and HR-TEM images of nanobullets, respectively. ${ }^{293}$

5.2.2.3. Rutile- $\mathrm{TiO}_{2}$. Fig. $17\left(\mathrm{a}_{1}-\mathrm{e}_{2}\right)$ illustrate the TEM/HRTEM micrographs and SAED pattern of rutile-TiO ${ }_{2}$ nanostructures. Fig. $17\left(\mathrm{a}_{1}\right.$ and $\left.\mathrm{a}_{2}\right)$ show the TEM and HR-TEM images of a nanobelt prepared by the hydrothermal method. ${ }^{290}$ Fig. $17\left(b_{1}\right)$ represents the TEM image of nanowires, indicating the nanowires are narrow with diameters of around 
$5 \mathrm{~nm}$. The observed lattice fringes in Fig. $17\left(b_{2}\right)$ demonstrate that the growth of the nanowires is parallel to the (110) planes but perpendicular to the (001) planes. ${ }^{271}$ Fig. $17\left(c_{1}\right)$ elucidates the TEM image of one individual nanorod. Fig. $17\left(c_{2}\right)$ demonstrates the distance between adjacent lattice fringes was around $0.325 \mathrm{~nm}$, corresponding to the interplanar distance of (110) planes in the rutile- $\mathrm{TiO}_{2}$. The distance between the fringes perpendicular to the wall, $d=0.296 \mathrm{~nm}$, corresponds to the interplanar distance of $(001)$ planes. ${ }^{271} \mathrm{Fig} .17\left(\mathrm{~d}_{1}\right.$ and $\left.\mathrm{d}_{2}\right)$ display the TEM images of the multi-trunk and branch structure, where the red arrowhead indicates the primary growth, whereas the first and second secondary growths are indicated by green and yellow arrowheads, respectively. Fig. $17\left(d_{1}\right)$ also reveals that the tips of the nanorods contain many small nanorods with a diameter of $20-30 \mathrm{~nm}$. The lattice fringes, taken from the region labelled by white squares (as marked with 1 and 2 in Fig. $17\left(d_{1}\right)$ ) are shown in Fig. $17\left(d_{2}\right)$, which reveal that the nanorods are highly crystalline in nature. The clean lattice fringes with a spacing of $0.252 \mathrm{~nm}$ correspond to the (101) plane. ${ }^{286}$ Fig. $17\left(\mathrm{e}_{1}\right)$ depicts the lattice image of two rutile- $\mathrm{TiO}_{2}$ nanoparticles coalesced over the (110) face into a single crystal in the [110] zone axis. Fig. $17\left(\mathrm{e}_{2}\right)$ is the reconstructed image from the square region in Fig. $17\left(\mathrm{e}_{1}\right)$ showing the edge dislocations (denoted by $\mathrm{T}$ symbols) at the interface and within the smaller particle. ${ }^{294}$

\section{Spectroscopic and band characteristics}

The optical properties of SMONs have been studied via numerous spectroscopic techniques, such as Raman, Fourier transform infrared (FT-IR), UV-Visible (UV-Vis) and photoluminescence (PL) spectroscopy. ${ }^{322}$ Raman spectroscopy is a spectroscopic technique that is mainly based on an inelastic scattering of monochromatic light, normally from a laser source in the visible, near IR or ultraviolet range. Raman peaks initiate mainly from the vibrational modes $\left(E_{g}\right.$ and $\left.A_{1 g}\right)$, which are related to different crystal planes. This provides, thus, a high accuracy and sensitivity for measuring the percentage of the exposed facets from the micro perspective of molecular bonding together with the benefit of fewer measured errors. FT-IR spectroscopy is an absorption spectroscopic technique that establishes the vibrational transitions in molecules generated by various stretching or bending motions in the chemical bonds. It is well known that an optical transition occurs when a photon is absorbed or emitted by a defect; and because this transition takes place essentially instantaneously on the scale of lattice relaxations, it arises at fixed atomic coordinates. The absorption band characteristics of photons have been widely observed using UV-Vis spectroscopy. ${ }^{13,275,299,300,313,314,321-324}$

\subsection{Raman spectroscopy}

Fig. 18 shows the Raman spectra of multiphase $\mathrm{TiO}_{2}$ (anatase-, brookite- and rutile- $\mathrm{TiO}_{2}$ ) nanoparticles synthesized by the solgel method. Raman spectroscopy is analyzed in the Raman shift ranging from $200 \mathrm{~cm}^{-1}$ to $800 \mathrm{~cm}^{-1}$ at the excitation line of

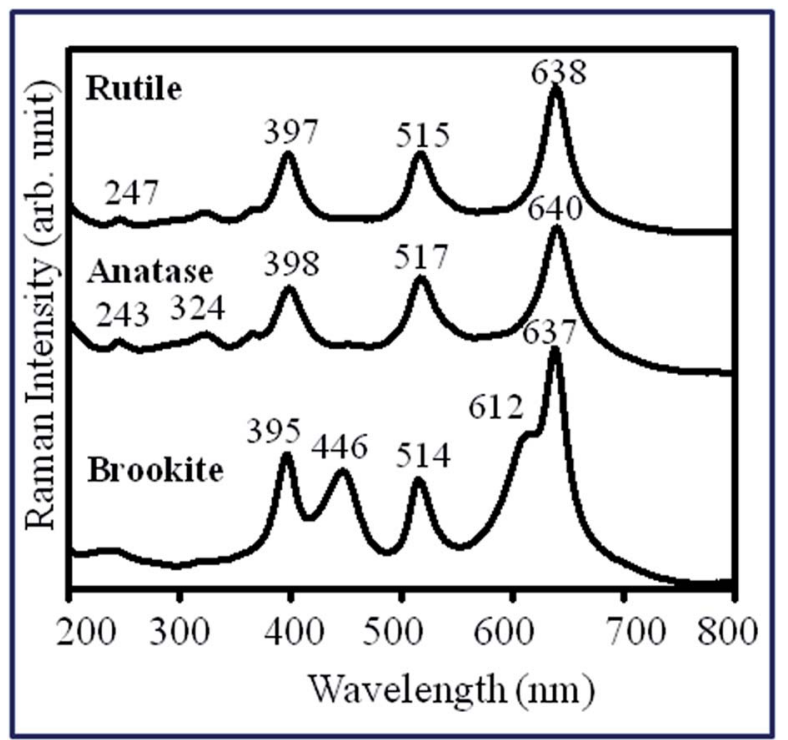

Fig. 18 Raman spectra of brookite-, anatase- and rutile- $\mathrm{TiO}_{2}$ nanoparticles. ${ }^{275}$ Reprinted with permission from ref. 275. Copyright 2015. VBRI Press.

$514 \mathrm{~nm}$ at room temperature. When Raman spectroscopy was applied to characterize the nanoparticles, it was observed that: (i) the $\mathrm{E}_{\mathrm{g}}$ peak is mainly caused by symmetric stretching, (ii) the $B_{1 g}$ peak is caused by symmetric bending and (iii) the $A_{1 g}$ peak is caused by antisymmetric bending vibrations of O-Ti-O in the $\mathrm{TiO}_{2}$ nanoparticles. The major Raman bands were observed at 398, 517 and $640 \mathrm{~cm}^{-1}$ and verify the anatase phase of $\mathrm{TiO}_{2}$. These bands can be attributed to Raman active modes of the anatase structural phase with the symmetries of $B_{1 g}, A_{1 g}$ and $E_{g}$, respectively. The strong Raman peaks of brookite- $\mathrm{TiO}_{2}$ were seen at 395, 446 and $637 \mathrm{~cm}^{-1}$, where the peaks at $395 \mathrm{~cm}^{-1}$ and $637 \mathrm{~cm}^{-1}$ correspond to $\mathrm{B}_{2 \mathrm{~g}}$ and $\mathrm{A}_{1 \mathrm{~g}}$, respectively. ${ }^{295}$ The thermodynamically stable rutile- $\mathrm{TiO}_{2}$ exhibited major peaks at 397 , 515 and $638 \mathrm{~cm}^{-1}$ with a minor peak at $247 \mathrm{~cm}^{-1} .^{296-298}$

\subsection{FT-IR spectroscopy}

FT-IR spectroscopy has been used to investigate the nature of chemical bonding present in multiphase $\mathrm{TiO}_{2}$ nanostructures. Fig. 19 represents the FT-IR spectra in the region 4000$400 \mathrm{~cm}^{-1}$ versus the transmittance for anatase-, brookite-, and rutile- $\mathrm{TiO}_{2}$ nanoparticles synthesized by facile chemical routes. The observed transmittance bands in the region $800-400 \mathrm{~cm}^{-1}$ are attributed to $\mathrm{Ti}-\mathrm{O}$ and/or $\mathrm{Ti}-\mathrm{O}-\mathrm{Ti}$ bonds, as represented in Fig. 19. The peaks, therefore, at 545, 745 and $770 \mathrm{~cm}^{-1}$ can be associated with $\nu(\mathrm{Ti}-\mathrm{O})$ vibrations in multiphase- $\mathrm{TiO}_{2}$ nanoparticles. ${ }^{23}$ Also, transmittance bands are found at 1431, 1451, 1637, 1648 and $1655 \mathrm{~cm}^{-1}$ and were assigned to an $\mathrm{O}-\mathrm{H}$ bending mode. Two transmittance bands were noticed at 2514 and $2922 \mathrm{~cm}^{-1}$, representing the combination bands in $\mathrm{TiO}_{2}$ nanoparticles. ${ }^{\mathbf{2 3 , 2 9 9 , 3 0 0}}$ Additionally, broad transmittance bands were ascertained in the wavenumber region of $3650-3000 \mathrm{~cm}^{-1}$ and could be ascribed to physically adsorbed water on the surface of $\mathrm{TiO}_{2}$ nanoparticles. ${ }^{301,302}$ 


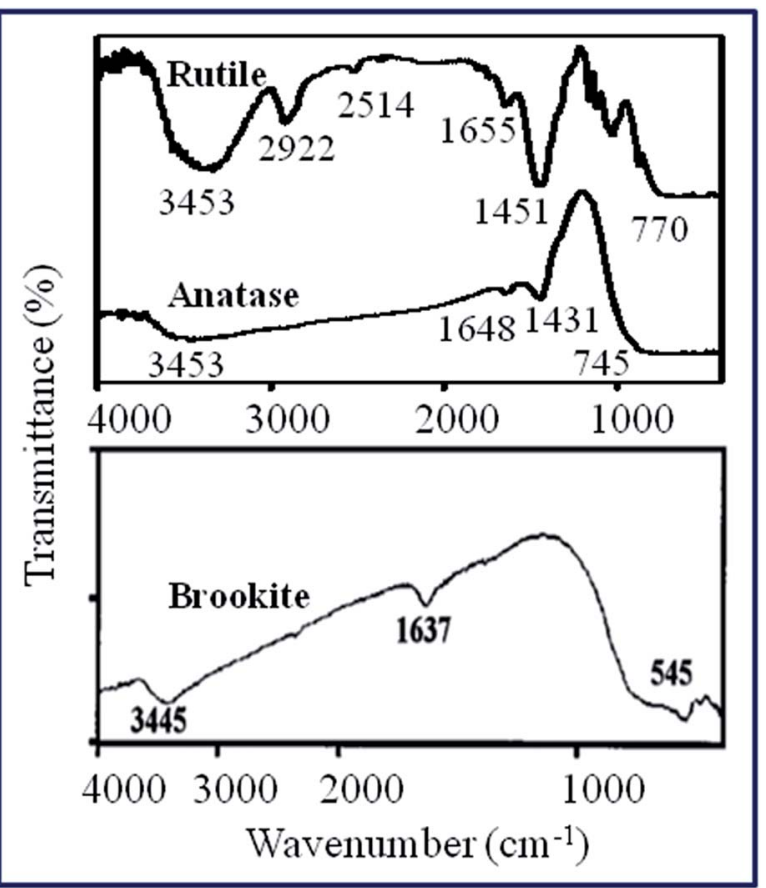

Fig. 19 FT-IR spectra of brookite-, anatase- and rutile- $\mathrm{TiO}_{2}$ nanoparticles. ${ }^{23,301}$ Reprinted with permission from ref. 23. Copyright 2016. Elsevier and ref. 301. Copyright 2000. Springer.

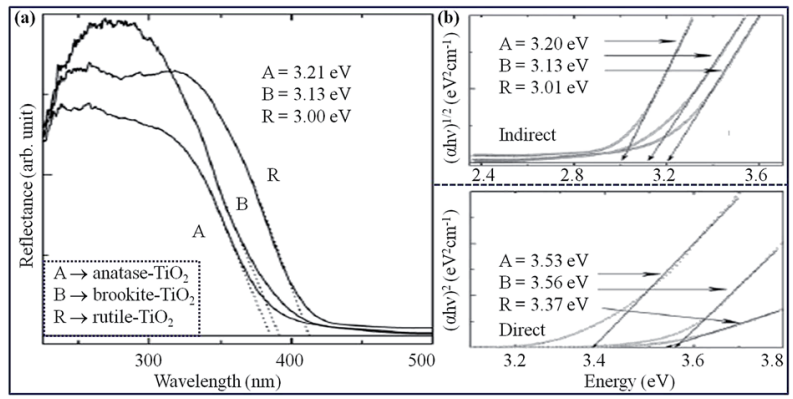

Fig. 20 Optical characteristics: (a) UV-Vis reflectance spectra, (b) optical band gap evaluation of multiphase $\mathrm{TiO}_{2}$ nanoparticles, where the symbols A, B and R correspond to anatase-, brookite and rutile$\mathrm{TiO}_{2}{ }^{289}$ Reprinted with permission from ref. 289.

\subsection{UV-Vis spectroscopy}

The optical properties and related band gap characteristics have been studied using UV-Vis spectroscopy and the results are displayed in Fig. 20(a and b). Fig. 20(a) shows the results from reflectance measurements of anatase-, brookite-, and rutile-
Table 4 Summary of the obtained parameters from UV-Vis spectra and the indirect and direct optical band gaps of multiphase- $\mathrm{TiO}_{2}$ nanostructures

\begin{tabular}{|c|c|c|c|}
\hline \multirow[b]{2}{*}{ Multiphase- $\mathrm{TiO}_{2}$} & \multicolumn{3}{|c|}{ Optical band gap values $\left(E_{\mathrm{g}}\right.$ in eV) } \\
\hline & Extrapolation & Indirect & Direct \\
\hline Anatase- $\mathrm{TiO}_{2}$ & 3.21 & 3.20 & 3.53 \\
\hline Brookite-TiO $_{2}$ & 3.13 & 3.13 & 3.56 \\
\hline Rutile- $\mathrm{TiO}_{2}$ & 3.00 & 3.01 & 3.37 \\
\hline
\end{tabular}

$\mathrm{TiO}_{2}$ nanostructures. The corresponding optical band gaps of the multiphase $\mathrm{TiO}_{2}$ nanostructures are calculated from the UVVis reflectance spectra using the Tauc equation:

$$
(\alpha h \nu)^{n}=B\left(h \nu-E_{\mathrm{g}}\right)
$$

where $\alpha$ is the absorption coefficient, $h \nu$ is the energy of the incident photon, $B$ is a constant (characteristic of the SMON), $n$ has two different values, either 2 for direct or $1 / 2$ for indirect band gap transitions, and $E_{\mathrm{g}}$ is the optical band gap of SMON. The intercept on the abscissa (X-axis) of the Tauc plot $(\alpha h \nu)^{n}$ versus $h \nu$ gives the optical band gap energy of the SMON (Fig. 20(b)). The extrapolation of the reflectance versus the wavelength curves determines the optical band gap energy of multiphase $\mathrm{TiO}_{2}$ nanoparticles: (i) $3.21 \mathrm{eV}$ for anatase- $\mathrm{TiO}_{2}$, (ii) $3.13 \mathrm{eV}$ for brookite- $\mathrm{TiO}_{2}$ and (iii) $3.00 \mathrm{eV}$ for rutile- $\mathrm{TiO}_{2}$ nanoparticles. The obtained reflectance spectra were converted to equivalent absorption coefficients ${ }^{289}$ providing the same results as those obtained from extrapolation for indirect transitions (as provided in the upper segment in Fig. 20(b)). Furthermore, analysis for the direct transitions (as shown in the lower segment in Fig. 20(b)) resulted in transitions at higher energies. ${ }^{204}$ A summary of the obtained parameters from the UV-Vis spectra and the indirect and direct optical band gaps are displayed in Table 4.

\section{Applications}

\subsection{Photocatalysis}

Photocatalysis is the surface phenomenon that is defined as the catalytic property of a SMON when photons are irradiated on it. The surface property of multiphase- $\mathrm{TiO}_{2}$ nanoparticles (in particular anatase- and rutile- $\mathrm{TiO}_{2}$ ) can be manipulated by coating their surfaces with either an inorganic (silica) or organic (green tea) layer via a chemical approach. In general, the main constituent of green tea extract is polyphenols, predominantly the catechins. ${ }^{303-305}$ Out of the four major catechins [(i) epicatechin (EC)

Table 3 Summary of various synthesis routes for multiphase- $\mathrm{TiO}_{2}$ nanostructures

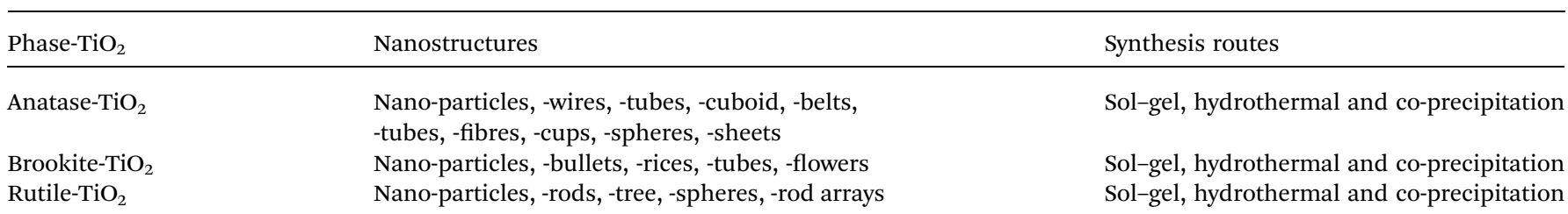




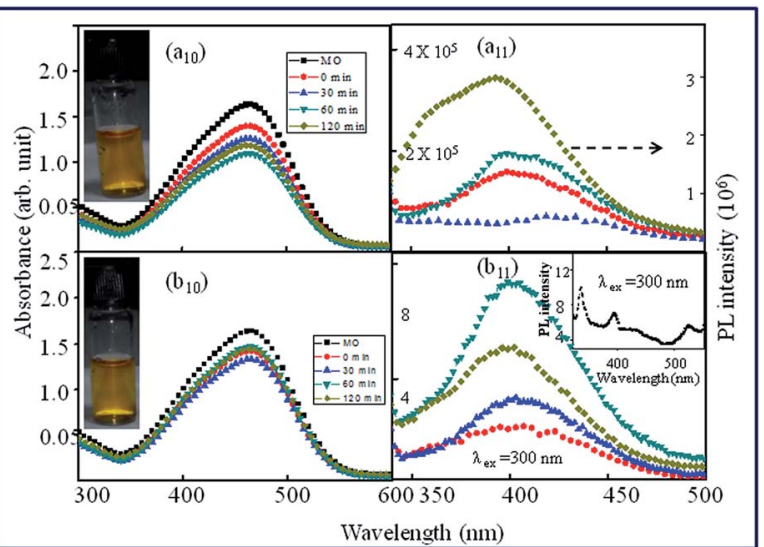

Fig. 21 Photocatalytic and photoluminescence spectra of anataseand rutile- $\mathrm{TiO}_{2}$ nanoparticles. UV-Vis spectra of the photodegradation of methyl orange dye by anatase $\left(a_{20}\right)$ and rutile $\left(b_{20}\right)$, respectively, at various time intervals. $\left(a_{21}\right)$, and $\left(b_{21}\right)$ show the $P L$ characteristics of anatase and rutile, respectively at $\lambda_{\mathrm{ex}}=300 \mathrm{~nm} \cdot{ }^{23}$ Reprinted with permission from ref. 23. Copyright 2016. Elsevier.

(ii) epicatechin gallate (ECG) (iii) epigallocatechin (EGC) and (iv) epigallocatechin gallate (EGCG)], EGCG is the main component found in green tea. ${ }^{306}$ The antioxidant action of polyphenols found in green tea is known to increase the antioxidant capacity of blood. ${ }^{307}$ Thus, green tea extract was expected to be an attractive material for modifying the surface of photocatalysts. ${ }^{227,235}$ Herein, anatase- and rutile- $\mathrm{TiO}_{2}$ were selected in the present context in regard to their photocatalytic applications. In addition, these two structural phases were coated with: (i) silica $\left(\mathrm{TiO}_{2 \_}\right.$silica; anatase/ rutile_silica) and (ii) green tea $\left(\mathrm{TiO}_{2} \_\right.$polyphenol; anatase/ rutile_polyphenol). ${ }^{23}$

7.1.1. Bare anatase- and rutile- $\mathrm{TiO}_{2}$ nanoparticles. The photocatalytic activity of bare anatase- and rutile- $\mathrm{TiO}_{2}$ nanoparticles was analyzed by studying the photodegradation of methyl orange (MO) solution and then confirmed by the PL spectra, as depicted in Fig. $21\left(a_{10}\right.$ and $\left.b_{11}\right)$. PL is an important tool for exploring the recombination phenomenon occurring in the excitons analysis of SMON. The UV-Vis absorption spectrum of MO solution with an initial concentration $0.153 \mathrm{mg} \mathrm{l}^{-1}$ established as a broad band at $464 \mathrm{~nm}$, which corresponds to $\pi$ $\rightarrow \pi^{*}$ transition, ${ }^{308}$ as depicted in Fig. $21\left(\mathrm{a}_{10}\right.$ and $\left.\mathrm{b}_{10}\right)$. In the PL spectrum (inset in Fig. 21( $\left.b_{11}\right)$ ), three peaks can be observed at 334, 394 and $524 \mathrm{~nm}$ in the case of the bare MO solution. A summary of the photodegradation and photoluminescence characteristics of methyl orange dye by the catalysts, bare anatase- and rutile- $\mathrm{TiO}_{2}$ nanoparticles at various UV irradiation time is represented in Table 5. However, the trend in photocatalytic activity as evidenced by UV-Vis absorption was found to be peculiar after $60 \mathrm{~min}$ and $30 \mathrm{~min}$ when anatase- $\mathrm{TiO}_{2}$ and rutile- $\mathrm{TiO}_{2}$, respectively, were used as the catalyst. The reason behind this is that deactivation of the catalyst occurs to some extent due to the formation of a number of degradation fragments of MO at the catalyst surface that block the active sites of the catalyst and also as the solution becomes concentrated, which scatters the UV light instead of transmitting it through the solution. These cause hindrance for further photodegradation. . $^{23,309,310}$

\subsubsection{Coated anatase- and rutile- $\mathrm{TiO}_{2}$ nanoparticles}

7.1.2.1. Anatase- and rutile-TiO ${ }_{2}$ silica. The photocatalytic activity of anatase- and rutile- $\mathrm{TiO}_{2} \_$silica nanoparticles was also assessed by studying the photodegradation of methyl orange

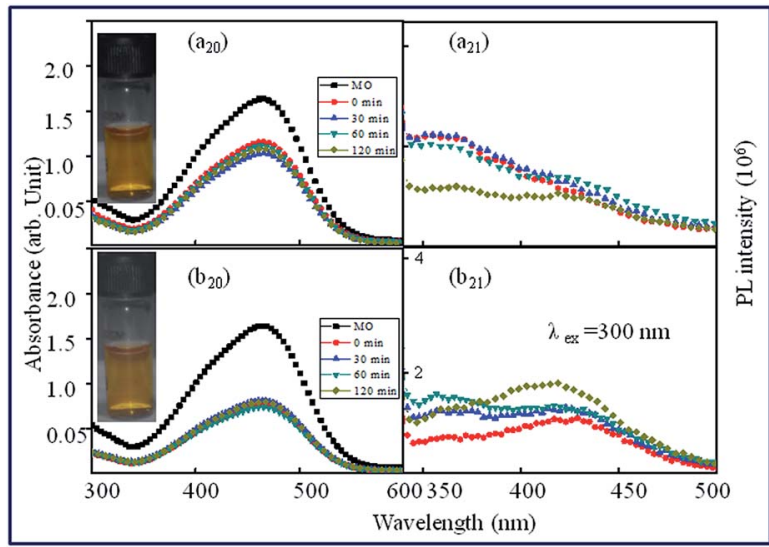

Fig. 22 Photocatalytic and photoluminescence spectra of silicacoated anatase- and rutile- $\mathrm{TiO}_{2}$ nanoparticles. UV-Vis spectra of the photodegradation of methyl orange dye by anatase_silica $\left(a_{20}\right)$ and rutile_silica $\left(b_{20}\right)$, respectively, at various time intervals. $\left(a_{21}\right)$ and $\left(b_{21}\right)$ show the PL characteristics of anatase_silica and rutile_silica, respectively. ${ }^{23}$ Reprinted with permission from ref. 23. Copyright 2016. Elsevier.

Table 5 Summary of the photodegradation and photoluminescence $(\mathrm{PL})$ characteristics of methyl orange dye by bare anatase- and rutile-TiO ${ }_{2}$ nanoparticles $^{a}$

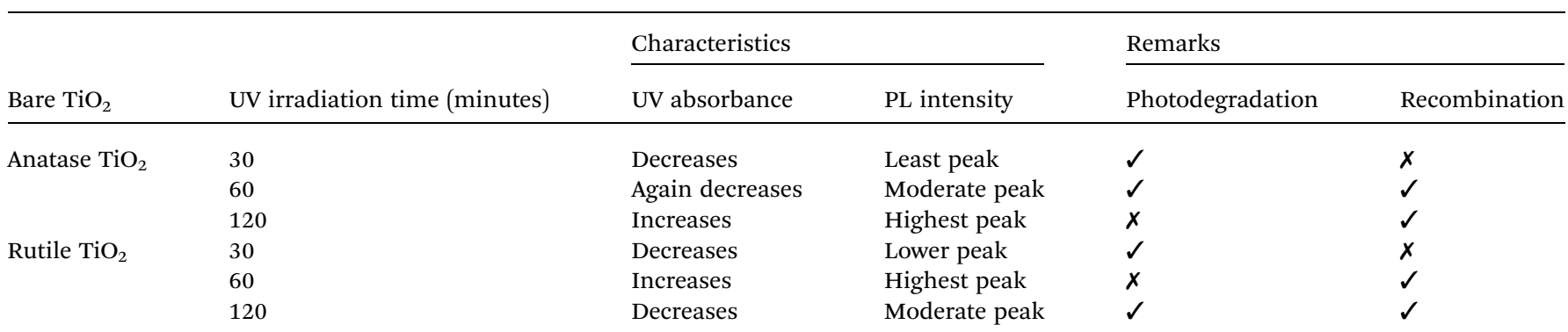

${ }^{a}$ Symbols introduced: $\checkmark \rightarrow$ yes, $\boldsymbol{x} \rightarrow$ no. 


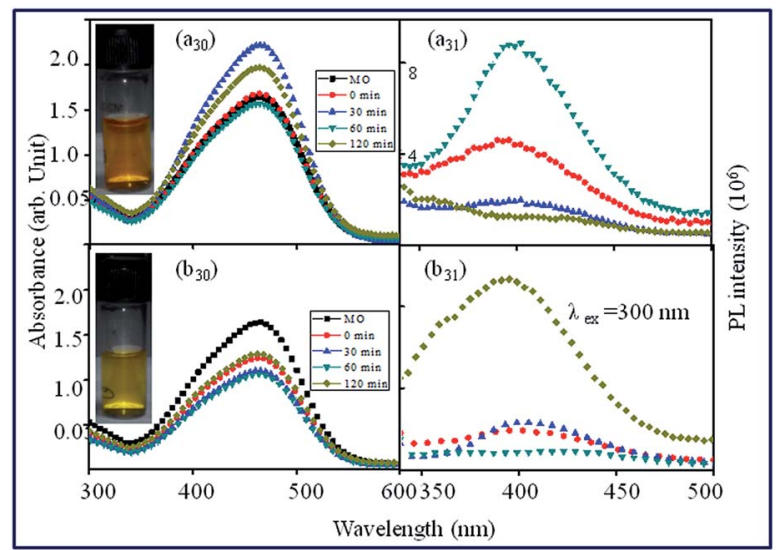

Fig. 23 Photocatalytic and photoluminescence spectra of polyphenol-coated-anatase and -rutile- $\mathrm{TiO}_{2}$ nanoparticles. UV-Vis spectra of the photodegradation of methyl orange dye by anatase_polyphenol $\left(a_{30}\right)$ and rutile_polyphenol $\left(b_{30}\right)$, respectively, at various time intervals. $\left(a_{31}\right)$ and $\left(b_{31}\right)$ show the PL characteristics of anatase_polyphenol and rutile_polyphenol, respectively. ${ }^{23}$ Reprinted with permission from ref. 23. Copyright 2016. Elsevier.

(MO) solution, and then its corresponding PL spectra was also investigated, as depicted in Fig. 22( $a_{20}$ and $\left.b_{21}\right)$. The photocatalytic degradation of MO dye by anatase_silica and rutile_silica show a frequent decrease in absorbance at $0 \mathrm{~min}$ as compared to pristine MO solution, which may be due to inter/intra-chain interactions $^{\mathbf{3 1 1}}$ of the catalyst with the MO dye as shown in Fig. 22( $a_{20}$ and $\left.b_{20}\right)$. As UV irradiation is exposed at various time intervals, overlapping and diminished intensity absorbance curves are observed revealing the uniform nature of the silica coating helps to inhibit the photocatalytic activity of the catalyst. Silica, being a good radical scavenger, engulfs all the radicals produced by $\mathrm{TiO}_{2}$. To understand the fate of the photogenerated charge carriers, PL spectrum analysis was also employed at $\lambda_{\text {ex }}=$ $300 \mathrm{~nm}$, which showed a decreasing trend with increasing irradiation time, indicating that the electrons and holes generated are involved in degradation and not in exciton generation, thus leading to a drop in PL emission, as shown in Fig. 22( $a_{21}$ and $\left.b_{21}\right)$. The reduction in the photodegradation of MO dye by coating the surface of rutile with silica correlates with the already reported results in the literature. ${ }^{3 \mathbf{3 2}}$
7.1.2.2. Anatase- and rutile-TiO ${ }_{2}$ polyphenol. The photocatalytic activity of anatase- and rutile- $\mathrm{TiO}_{2}$-polyphenol nanoparticles was also evaluated by studying the photodegradation of methyl orange (MO) solution, and then its corresponding PL spectra was also analyzed, as depicted in Fig. 23( $a_{30}$ and $\left.b_{31}\right)$. On 30 min exposure of UV irradiation, the absorbance increases, leading to the reduced photocatalytic degradation of MO dye by anatase_polyphenol, as shown in Fig. 23( $\left.b_{30}\right)$. However, at 60 min UV exposure, the photocatalysis is observed to be enhanced, which is accounted for as due to its microstructural characteristics, showing that a prolonged UV irradiation time (around $60 \mathrm{~min}$ ) is required to increase photodegradation. A summary of the photodegradation and photoluminescence characteristics of methyl orange dye by anatase- and rutile$\mathrm{TiO}_{2}$ ppolyphenol nanoparticles is represented in Table 6 . However, in the case of rutile_polyphenol as a photocatalyst, dye degradation was found to be higher up to the initial $60 \mathrm{~min}$ of UV irradiation, as shown in Fig. $23\left(b_{30}\right)$. The generation of excitons supporting $\mathrm{e}^{-}-\mathrm{h}^{+}$separation (photocatalysis) as well as mild recombination are evidenced in the PL emission spectra. At $120 \mathrm{~min}$ of prolonged UV irradiation, PL emission is favoured. Thus, it can be inferred that the improved textural properties and efficient excitonic separation are responsible for the enhanced light photocatalytic activities. ${ }^{23,306,313,314}$

\subsection{Concomitant summary}

On comparing the coated forms of anatase- and rutile- $\mathrm{TiO}_{2}$ nanoparticles, the polyphenol-coated form shows a higher photocatalytic activity than silica-coated forms, which is accounted for by some microstructural alterations and by the nature and thickness of the coating moiety. In summary, (as illustrated in Scheme 4), the results show that anatase- and rutile- $\mathrm{TiO}_{2}$ silica were found to be least photocatalytically active, ensuring their cosmetic application in sunscreens, whereas rutile- $\mathrm{TiO}_{2}$-polyphenol and bare anatase- $\mathrm{TiO}_{2}$ had the highest photocatalytic activity amongst their corresponding forms when reviewed in a broad research area including the photodegradation of toxic organic dyes.

\subsection{Bio-safety and human health}

$\mathrm{TiO}_{2}$ nanoparticles are utilized to inhibit bacterial growth owing to their broad antibacterial characteristics. The influence of

Table 6 Summary of the photodegradation and photoluminescence characteristics of methyl orange dye by anatase- and rutile- $\mathrm{TiO}_{2-}-$ polyphenol nanoparticles ${ }^{a}$

\begin{tabular}{|c|c|c|c|c|c|}
\hline $\mathrm{Phase}^{-\mathrm{TiO}_{2} \text { ppolyphenol }}$ & UV irradiation time (minutes) & UV absorbance & PL intensity & Photodegradation & Recombination \\
\hline & 60 & Decreases & Highest intensity & $\checkmark$ & $\checkmark$ \\
\hline & 120 & Increases & Least intensity & $x$ & $x$ \\
\hline Rutile-TiO ${ }_{2 \_ \text {polyphenol }}$ & 30 & Decreases & Lower intensity & $\checkmark$ & $x$ \\
\hline
\end{tabular}

${ }^{a}$ Symbols introduced: $\checkmark \rightarrow$ yes, $\boldsymbol{X} \rightarrow$ no. 


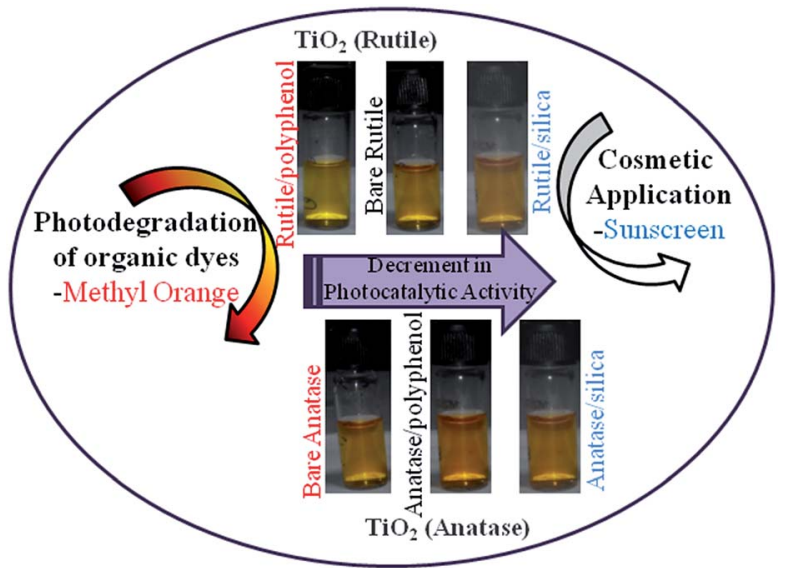

Scheme 4 Pictorial representation of the photodegradation of methyl orange by $\mathrm{TiO}_{2}$ nanoparticles. ${ }^{23}$ Reprinted with permission from ref. 23. Copyright 2016. Elsevier.

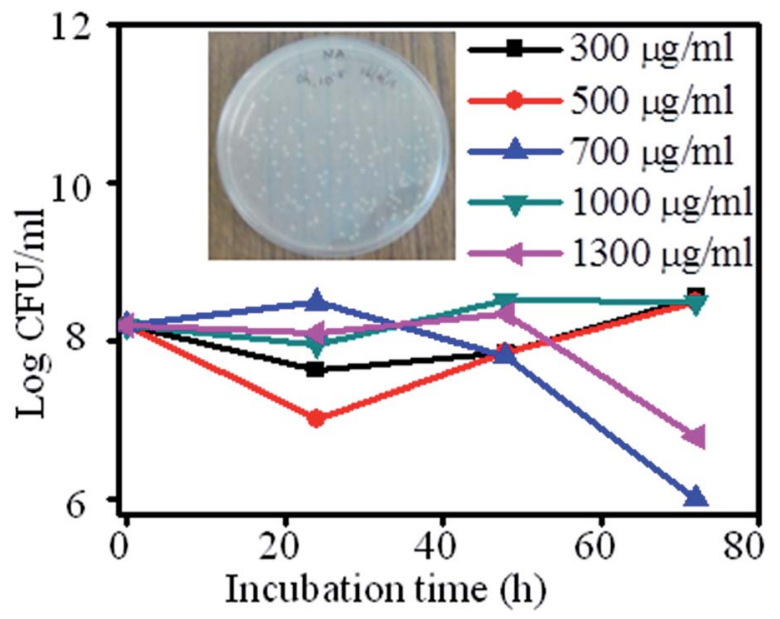

Fig. 24 Growth of bacterial species versus incubation time (h) for Enterobacter sp. $^{51}$ Reprinted with permission from ref. 51. Copyright 2017. Taylor and Francis.

nano-sized anatase- $\mathrm{TiO}_{2}$ particles on biofilms formed by Enterobacter sp. $(1.25 \mu \mathrm{m})^{315}$ was evaluated to treat wound infection. Different concentrations of anatase- $\mathrm{TiO}_{2}$ nanoparticles were utilized to assist gaining an in-depth understanding. In our case, in the presence of nanoparticles, it was noticed that bacteria using their appendages expressed surface adhesion proteins, became adhered to the solid surface and formed a biofilm via a defence mechanism.

These nanoparticles showed antibacterial characteristics as evidenced by the serial dilution plate method, as displayed in Fig. 24, which clearly demonstrate that cell viability could be observed to be completely arrested at $700 \mu \mathrm{g} \mathrm{ml} \mathrm{m}^{-1}$ of nanoparticle concentration and at $72 \mathrm{~h}$ incubation time.

The obtained results from the serial dilution plate method were supported by electron microscopy analysis, SEM and TEM, as represented in Fig. 25(a-i). EM results revealed the interaction of the bacterial biofilm with nanoparticles. SEM

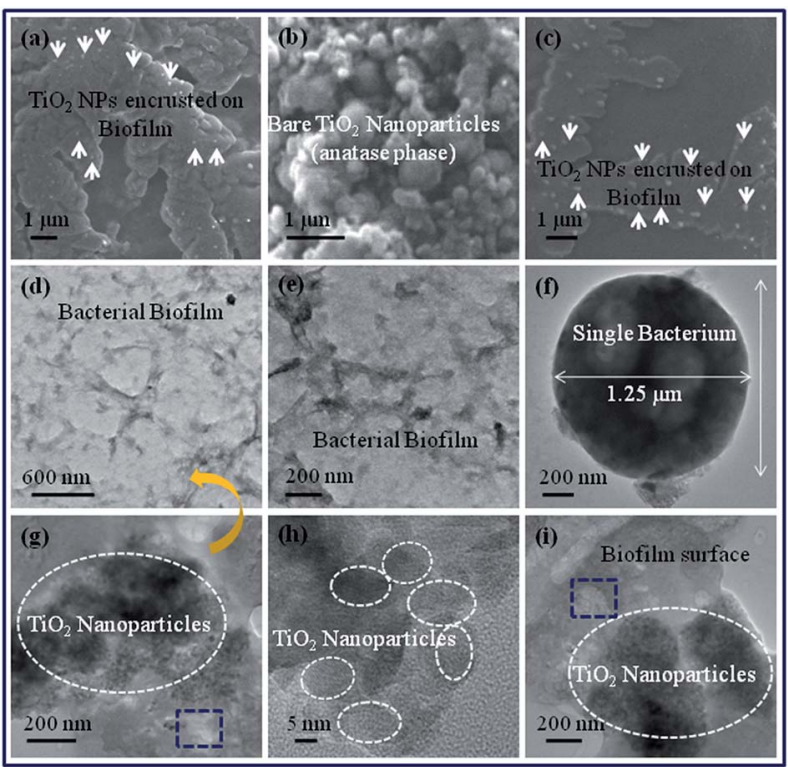

Fig. 25 (a)-(c) SEM micrographs of $\mathrm{TiO}_{2}$ nanoparticles $\left(700 \mu \mathrm{g} \mathrm{ml}^{-1}\right)$ interaction with Enterobacter sp. for $72 \mathrm{~h}$ incubation, TEM images of (d)-(f) bare Enterobacter sp. and (g)-(i) interaction of $\mathrm{TiO}_{2}$ nanoparticles with bacterial biofilm. Blue squares (in (g) and (i)) represent a ruptured biofilm. ${ }^{51}$ Reprinted with permission from ref. 51. Copyright 2017. Taylor and Francis

micrographs, as shown in Fig. 25(a-c), revealed the fact that nanoparticles were spread all over the bacterial lump and thus the biofilms were encrusted with nanoparticles. To orchestrate the bio-distribution of nanoparticles into the biofilm and to detect the size of bacterium, HR-TEM was performed, as elucidated in Fig. 25(d-i). The formation of a bacterial biofilm was again confirmed by TEM, as depicted in Fig. 25(d-e). The size of single Enterobacter sp. bacterium was observed to be $\sim 1.25 \mu \mathrm{m}$, which was found to be in agreement with Bergey's Manual of Determinative Bacteriology. ${ }^{315}$ Moreover, complete entrapment of agglomerated $\mathrm{TiO}_{2}$ nanoparticles into the biological mass was affirmed by HR-TEM, as portrayed in Fig. 25(g-i). The nanoparticles also affected the morphology of bacterial cells as represented by blue squares, shown in Fig. 25(g and i). Thus, the antibacterial activity of anatase- $\mathrm{TiO}_{2}$ nanoparticles against a biofilm can be used to treat human wound infection..$^{51,316-320}$

\section{Conclusions}

Thanks to the efficient efforts of experienced scientists and engineers throughout the world working on multiphase $\mathrm{TiO}_{2}$ nanomaterials over the past decades, the advances made in research in this field are enormously significant and noteworthy. The present review article has presented a widespread analysis of the state-of-art research into the growth mechanism behind the efficient synthesis of multiphase $\mathrm{TiO}_{2}$ nanostructures through chemical routes. More exploration on a wide variety of unique nanostructures has been analyzed according to their various structural, morphological and microstructural features. 
In brief, the present review mainly provides key information to unveil more about the multiphase $\mathrm{TiO}_{2}$ nanostructures, ranging from their efficient synthesis to control the morphology, growth mechanism and properties to their photoactive potential characteristics. Additionally, the optobiological properties are strongly influenced by the tunable morphologies, particle sizes and phase transformations of multiphase $\mathrm{TiO}_{2}$ nanostructures.

Ultimately, we hope that this review article not only summarizes the recent progress but will also help to inspire research activity in this field on understanding the intriguing characteristics of multiphase $\mathrm{TiO}_{2}$ nanostructures. The present review has mainly focused on anatase, brookite and rutile; however, the research focus on the structural, morphological and microstructural features of the remaining crystalline and noncrystalline phases of $\mathrm{TiO}_{2}$ should also be interesting in the near future. Moreover, their nano-bio assessment also deserves more attention in the future.

\section{Conflicts of interest}

There are no conflicts to declare.

\section{Acknowledgements}

The authors sincerely thank the Director, NPL New Delhi, India for providing the necessary experimental facilities. We would like to acknowledge CSIR network project, BSC-0112 (NanoSHE). We also acknowledge to all the authors whose published articles help us as a resource for completion of this review article. There is no financial concern to publish this review article.

\section{Notes and references}

1 C. C. Yang and Y. W. Mai, Mater. Sci. Eng., R, 2014, 79, 1-40.

2 M. K. Song, S. Park, F. M. Alamgir, J. Cho and M. Liu, Mater. Sci. Eng. R, 2011, 72, 203-252.

3 D. C. Sayle, J. A. Doig, S. A. Maicaneanu and G. W. Watson, Phys. Rev. B: Condens. Matter Mater. Phys., 2002, 65, 245414.

4 A. Chandran, J. Prakash, J. Gangwar, T. Joshi, A. K. Srivastava, D. Haranath and A. M. Biradar, RSC Adv., 2016, 6, 53873-53881.

5 J. M. Petroski, T. C. Green and M. A. El-Sayed, J. Phys. Chem. A, 2001, 105, 5542-5547.

6 R. Datt, J. Gangwar, S. K. Tripathi, R. K. Singh and A. K. Srivastava, Quantum Matter, 2016, 5, 1.

7 M. I. Khan, J. Solid State Chem., 2000, 152, 105-112.

8 J. Gangwar, B. K. Gupta and A. K. Srivastava, Def. Sci. J., 2016, 66, 323.

9 K. K. Dey, D. Bhatnagar, A. K. Srivastava, M. Wan, S. Singh, R. R. Yadav, B. C. Yadav and M. Deepa, Nanoscale, 2015, 7, 6159-6172.

10 K. K. Dey, A. Kumar, R. Shanker, A. Dhawan, M. Wan, R. R. Yadav and A. K. Srivastava, RSC Adv., 2012, 2, 1387.

11 M. Niu, F. Huang, L. Cui, P. Huang, Y. Yu and Y. Wang, ACS Nano, 2010, 4, 681-688.
12 J. Yu, X. Yu, B. Huang, X. Zhang and Y. Dai, Cryst. Growth Des., 2009, 9, 1474-1480.

13 J. Gangwar, K. K. Dey, S. K. Tripathi, M. Wan, R. R. Yadav, R. K. Singh, Samta and A. K. Srivastava, Nanotechnology, 2013, 24, 415705.

14 C. Ye, G. Wang, M. Kong and L. Zhang, J. Nanomater., 2006, 2006, 1-5.

15 Z. Zhang, J. Mater. Res., 2002, 17, 1698-1701.

16 Y. R. Smith, A. Kar and V. Subramanian, Ind. Eng. Chem. Res., 2009, 48, 10268-10276.

17 P. P. González-Borrero, F. Sato, A. N. Medina, M. L. Baesso, A. C. Bento, et al., Appl. Phys. Lett., 2010, 96, 061909.

18 Q. Wang, A. Puntambekar and V. Chakrapani, Nano Lett., 2016, 16, 7067-7077.

19 X. Hu, J. Gong, L. Zhang and J. C. Yu, Adv. Mater., 2008, 20, 4845-4850.

20 G. Z. Shen, Y. Bando, B. Liu, D. Golberg and C. Lee, $A d v$. Funct. Mater., 2006, 16, 410-416.

21 Z. Y. Wang, B. B. Huang, X. Y. Qin, X. Y. Zhang, P. Wang, J. Y. Wei, J. Zhan, X. Y. Jing, H. X. Liu, Z. H. Xu, H. F. Cheng, X. N. Wang and Z. K. Zheng, Mater. Lett., 2009, 63, 130-132.

22 V. Sivakumar, R. Suresh, K. Giribabu and V. Narayanan, Cogent Chem., 2015, 1, 1074647.

23 R. Verma, A. Awasthi, P. Singh, R. Srivastava, H. Sheng, J. Wen, D. J. Miller and A. K. Srivastava, J. Colloid Interface Sci., 2016, 475, 82-95.

24 K. Karthick, S. R. Ede, U. Nithiyanantham and S. Kundu, New J. Chem., 2017, 41, 3473-3486.

25 C. G. Anchieta, D. Sallet, E. L. Folettoa, S. S. da Silva, O. C. Filhob and C. A. O. do Nascimentoc, Ceram. Int., 2014, 40, 4173-4178.

26 P. Guo, L. Cui, Y. Wang, M. Lv, B. Wang and X. S. Zhao, Langmuir, 2013, 29, 8997-9003.

27 S. Zhang, L. Ren and S. Peng, CrystEngComm, 2014, 16, 6195.

28 Dhiraj, B. K. Gupta, S. P. Singh, S. Singh, Govind and A. K. Srivastava, A Process for the Synthesis of highly Luminescent Green Emitting Undoped $\mathrm{Zn}_{2} \mathrm{SiO}_{4}$ afterglow Nano Phosphor, Indian Patent Filing No. 0044NF2017, 17Mar-2017.

29 Y. Li, M. Gecevicius and J. Qiu, Chem. Soc. Rev., 2016, 45, 2090.

30 S. E. John, S. K. Mohapatra and M. Misra, Langmuir, 2009, 25, 8240 .

31 J. Yu, L. Qi and M. Jaroniec, J. Phys. Chem. C, 2010, 114, 13118-13125.

32 R. A. Patil, R. S. Devan, Y. Liou and Y. R. Ma, Sol. Energy Mater. Sol. Cells, 2016, 147, 240-245.

33 L. Huang, T. Liu, H. Zhang, W. W. Guo and W. Zeng, J. Mater. Sci.: Mater. Electron., 2012, 23, 2024.

34 Z. Miao, D. Xu, J. Ouyang, G. Guo, X. Zhao and Y. Tang, Nano Lett., 2002, 2, 717.

35 D. K. Yi, S. J. Yoo and D. Y. Kim, Nano Lett., 2002, 2, 1101. 36 T. Aarthi and G. Madras, Ind. Eng. Chem. Res., 2007, 46, 7.

37 R. Asahi, T. Morikawa, T. Ohwaki, K. Aoki and Y. Taga, Science, 2001, 293, 269-271. 
38 A. Fujishima, X. T. Zhang and D. A. Tryk, Surf. Sci. Rep., 2008, 63, 515-582.

39 I. K. Konstantinou and T. A. Albanis, Appl. Catal., B, 2004, 49, 1-14.

40 J. C. Yu, J. G. Yu, W. K. Ho, Z. T. Jiang and L. Z. Zhang, Chem. Mater., 2002, 14, 3808-3816.

41 G. Liu, H. G. Yang, X. Wang, L. Cheng, H. Lu, L. Wang, G. Q. Lu and H. M. Cheng, J. Phys. Chem. C, 2009, 113, 21784.

42 G. Liu, H. G. Yang, X. Wang, L. Cheng, J. Pan, G. Q. Lu and H. M. Cheng, J. Am. Chem. Soc., 2009, 131, 12868.

43 F. Turci, E. Peira, I. Corazzari, I. Fenoglio, M. Trotta and B. Fubini, Chem. Res. Toxicol., 2013, 26, 1579.

44 A. Jaroenworaluck, W. Sunsaneeyametha, N. Kosachan and R. Stevens, Surf. Interface Anal., 2006, 38, 473.

45 S. Li, S. Xu, L. He, F. Xu, Y. Wang and L. Zhang, Polym.-Plast. Technol. Eng., 2010, 49, 400-406.

46 S. Kumar and P. Maiti, RSC Adv., 2016, 6, 67449-67480.

47 E. Yousif and R. Haddad, SpringerPlus, 2013, 2, 398.

48 X. Zhao, Z. Li, Y. Chen, L. Shi and Y. Zhu, J. Mol. Catal. A: Chem., 2007, 268, 101-106.

49 Y. Liu and Y. Yang, J. Nanomater., 2016, 2016, 8123652.

50 J. Bai and B. Zhou, Chem. Rev., 2014, 114, 10131-10176.

51 R. Verma, V. B. Chaudhary, L. Nain and A. K. Srivastava, Mater. Tech., 2017, 32, 385-390.

52 C. Y. Flores, C. Diaz, A. Rubert, G. A. Benitez, M. S. Moreno, M. A. F. L. De Mele, R. C. Salvarezza, P. L. Schilardi and C. Vericat, J. Colloid Interface Sci., 2010, 350, 402.

53 J. F. Jacobs, L. V. de Poel and P. Osseweijer, Nanoethics, 2010, 4, 103-113.

54 J. M. Davis, T. C. Long, J. A. Shatkin and A. Wang, Nanomaterials Case Studies: Nanoscale Titanium Dioxide in Water Treatment and in Topical Sunscreen, Draft Agency, E. P., Research Triangle Park, NC, 2009.

55 P. Prasannalakshmia, N. Shanmugama, A. Senthil Kumarb and N. Kannadasan, J. Electroanal. Chem., 2016, 775, 356363.

56 R. Kaegi, A. Ulrich, B. Sinnet, R. Vonbank, A. Wichser, S. Zuleeg, H. Simmler, S. Brunner, H. Vonmont, M. Burkhardt and M. Boller, Environ. Pollut., 2008, 156, 233-239.

57 A. Weir, P. Westerhoff, L. Fabricius and N. V. Goetz, Environ. Sci. Technol., 2012, 46, 2242-2250.

58 X. Li, Y. Zhang, T. Li, Q. Zhong, H. Li and J. Huang, J. Power Sources, 2014, 268, 372-378.

59 J. Jin, S. Z. Huang, J. Liu, et al., J. Mater. Chem. A, 2014, 2, 9699-9708.

60 K. Liu, M. Cao, A. Fujishima and L. Jiang, Chem. Rev., 2014, 114, 7740.

61 ICIS Titanium Dioxide Uses and Market, http:// www.icis.com/Articles/2007/11/07/9076546/titanium-dioxidetio2-uses-and-market-data.html, 1st June 2011.

62 N. Pradhan, S. Singh, N. Ojha, A. Shrivastava, A. Barla, V. Rai and S. Bose, BioMed Res. Int., 2015, 2015, 365672 .

63 K. A. Abbas, A. M. Saleh, A. Mohamed and N. MohdAzhan, J. Food, Agric. Environ., 2009, 7, 14-17.
64 M. C. E. Lomer, R. P. H. Thompson, J. Commisso, C. L. Keen and J. J. Powell, Analyst, 2000, 125, 2339-2343.

65 K. Liu, M. Cao, A. Fujishima and L. Jiang, Chem. Rev., 2014, 114, 10044-10094.

66 F. Gao, Q. Y. Lu and S. Komarneni, Chem. Mater., 2005, 17, 856.

67 G. Q. Tan, Y. Q. Zheng, H. Y. Miao, A. Xia, H. J. Ren and H. Hintzen, J. Am. Ceram. Soc., 2012, 95, 280.

68 Z. H. Ai, K. J. Deng, Q. F. Wan, L. Z. Zhang and S. C. Lee, J. Phys. Chem. C, 2010, 114, 6237.

69 M. Larhed, C. Moberg and A. Hallberg, Acc. Chem. Res., 2002, 35, 717.

70 J. Du, L. R. Espelt, I. A. Guzei and T. P. Yoon, Chem. Sci., 2011, 2, 2115.

71 Q. J. Xiang, J. G. Yu and M. Jaroniec, Chem. Soc. Rev., 2012, 41, 782.

72 K. F. Zhou, Y. H. Zhu, X. L. Yang, X. Jiang and C. Z. Li, New J. Chem., 2011, 35, 353.

73 J. T. Zhang, Z. G. Xiong and X. S. Zhao, J. Mater. Chem., 2011, 21, 3634.

74 Q. Shen, W. Zhang, Z. P. Hao and L. D. Zou, Chem. Eng. J., 2010, 165, 301.

75 F. Y. Shen, W. X. Que, Y. L. Liao and X. T. Yin, Ind. Eng. Chem. Res., 2011, 50, 9131.

76 M. Y. Xing, Y. M. Wu, J. L. Zhang and F. Chen, Nanoscale, 2010, 2, 1233.

77 V. Iliev, D. Tomova and S. Rakovsky, Desalination, 2010, 260, 101.

78 X. H. Peng, A. C. Santulli, E. Sutter and S. S. Wong, Chem. Sci., 2012, 3, 1262.

79 Z. Ren, E. Kim, S. W. Pattinson, K. S. Subrahmanyam, C. N. R. Rao, A. K. Cheetham and D. Eder, Chem. Sci., 2012, 3, 209.

80 N. Wang, T. Tachikawa and T. Majima, Chem. Sci., 2011, 2, 891.

81 L. W. Zhang, H. Y. Cheng, R. L. Zong and Y. F. Zhu, J. Phys. Chem. C, 2009, 113, 2368.

82 J. T. Tian, L. J. Chen, Y. S. Yin, X. Wang, J. H. Dai, Z. B. Zhu, X. Y. Liu and P. W. Wu, Surf. Coat. Technol., 2009, 204, 205.

83 H. B. Fu, T. G. Xu, S. B. Zhu and Y. F. Zhu, Environ. Sci. Technol., 2008, 42, 8064.

84 L. A. Ghule, A. A. Patil, K. B. Sapnar, S. D. Dhole and K. M. Garadkar, Toxicol. Environ. Chem., 2011, 93, 623.

85 S. F. Chen, W. Zhao, S. J. Zhang and W. Liu, Chem. Eng. J., 2009, 148, 263.

86 D. Lin, H. Wu, R. Zhang and W. Pan, Chem. Mater., 2009, 21, 3479.

87 M. Gratzel, Nature, 2001, 414, 338.

88 M. J. Zhou, Y. Hu, Y. Liu, W. L. Yang and H. S. Qian, CrystEngComm, 2012, 14, 7686.

89 A. Kajbafvala, H. Ghorbani, A. Paravar, J. P. Samberg, E. Kajbafvala and S. K. Sadrnezhaad, Superlattices Microstruct., 2012, 51, 512.

90 L. Poul, S. Ammar, N. Jouini, F. Fieovet and F. Villain, Solid State Sci., 2001, 3, 31.

91 H. M. Kou, J. Wang, Y. B. Pan and J. K. Guo, Mater. Chem. Phys., 2006, 99, 325. 
92 S. M. Wang, Z. S. Yang, M. K. Lu, Y. Y. Zhou, G. J. Zhou, Z. F. Qiu, S. F. Wang, H. P. Zhang and A. Y. Zhang, Mater. Lett., 2007, 61, 3005.

93 Y. Zhou and M. Antonietti, J. Am. Chem. Soc., 2003, 125, 14960.

94 J. J. Wu and C. C. Yu, J. Phys. Chem. B, 2004, 108, 3377.

95 S. Pavasupreea, S. Ngamsinlapasathiana, M. Nakajimaa, Y. Suzukia and S. Yoshikawa, J. Photochem. Photobiol., A, 2006, 184, 163-169.

96 A. Al-Kattan, A. Wichser, S. Zuin, Y. Arroyo, L. Golanski, A. Ulrich and B. Nowack, Environ. Sci. Technol., 2014, 48, 6710-6718.

97 M. Cargnello, T. R. Gordon and C. B. Murray, Chem. Rev., 2014, 114, 9319.

98 D. D. Camillo, F. Ruggieri, S. Santucci and L. Lozzi, J. Phys. Chem. C, 2012, 116, 18427-18431.

99 J. Gangwar, K. K. Dey, P. Komal, S. K. Tripathi and A. K. Srivastava, Adv. Mater. Lett., 2011, 2, 402.

100 J. Gangwar, A. K. Srivastava, S. K. Tripathi, M. Wan and R. R. Yadav, Appl. Phys. Lett., 2014, 105, 063108.

101 Ebelmen, Ann. Chim. Phys. Ser., 1846, 57, 319.

102 R. Sui and P. Charpentier, Chem. Rev., 2012, 112, 3057.

103 R. Verma, K. K. Naik, J. Gangwar and A. K. Srivastava, Mater. Chem. Phys., 2014, 148, 1064-1070.

104 N. Pinna and M. Niederberger, Angew. Chem., Int. Ed., 2008, 47, 5292.

105 D. Kundu, T. Manna and G. De, J. Sol-Gel Sci. Technol., 2002, 23, 145.

106 G. L. Teoh, K. Y. Liew and W. A. K. Mahmood, J. Sol-Gel Sci. Technol., 2007, 44, 177.

107 S. W. Bian, J. Baltrusaitis, P. Galhotra and V. H. Grassian, J. Mater. Chem., 2010, 20, 8705.

108 K. K. Dey and A. K. Srivastava, in Oxide Nanostructures: Growth, Microstructures, and Properties, ed. A. K. Srivastava, Pan Stanford Publishing, 2014, vol. 1, pp. 198, ISBN-13: 978-9814411356.

109 R. S. Devan, R. A. Patil, J. H. Lin and Y. R. Ma, Adv. Funct. Mater., 2012, 22, 3326.

110 Y. Qi, H. Qi, C. Lu, Y. Yang and Y. Zhao, J. Mater. Sci.: Mater. Electron., 2009, 20, 479.

111 G. Zhu, C. Xi, H. Xu, D. Zheng, Y. Liu, X. Xu and X. Shen, RSC Adv., 2012, 2, 4236.

112 M. A. Shah, Nanoscale Res. Lett., 2008, 3, 255.

113 L. Liu, Y. Li, S. Yuan, M. Ge, M. Ren, C. Sun and Z. Zhou, J. Phys. Chem. C, 2010, 114, 251.

114 W. L. Suchanek, J. M. Garcés, P. F. Fulvio and M. Jaroniec, Chem. Mater., 2010, 22, 6564.

115 W. L. Suchanek and J. M. Garcés, CrystEngComm, 2010, 12, 2996.

116 L. Yan, J. Zhuang, X. Sun, Z. Deng and Y. Li, Mater. Chem. Phys., 2002, 76, 119.

117 W. Zhu, L. Zhang, G. L. Tian, R. Wang, H. Zhang, X. Piao and Q. Zhang, CrystEngComm, 2014, 16, 308.

118 L. X. Yang, Y. J. Zhu, H. Tong, Z. H. Liang and W. W. Wang, Cryst. Growth Des., 2007, 7, 2716.

119 L. Dong, Y. Chu and W. Sun, Chem.-Eur. J., 2008, 14, 5064.
120 Y. Y. Xi, D. Li, A. B. Djurišić, M. H. Xie, K. Y. K. Man and W. K. Chan, Electrochem. Solid-State Lett., 2008, 11, D56.

121 L. Lepleux, B. Chavillon, Y. Pellegrin, E. Blart, L. Cario, S. Jobic and F. Odobel, Inorg. Chem., 2009, 48, 8245.

122 B. Zhao, X. K. Ke, J. H. Bao, C. L. Wang, L. Dong, Y. W. Chen and H. L. Chen, J. Phys. Chem. C, 2009, 113, 14440.

123 X. Zhang, W. Shi, J. Zhu, W. Zhao, J. Ma, S. Mhaisalkar, T. L. Maria, Y. Yang, H. Zhang, H. H. Hng and Q. Yan, Nano Res., 2010, 3, 643.

124 S. Shang, K. Xue, D. Chen and X. Jiao, CrystEngComm, 2011, 13, 5094.

125 H. Gao, F. Xiao, C. B. Ching and H. Duan, ACS Appl. Mater. Interfaces, 2012, 4, 2801.

126 J. Yang, S. Mei and J. M. F. Ferreira, Mater. Sci. Eng., C, 2001, 15, 183.

127 C. Burda, X. Chen, R. Narayanan and M. A. El-Sayed, Chem. Rev., 2005, 105, 1025.

128 A. Pottier, C. Chanéac, E. Tronc, L. Mazerolles and J. P. Jolivet, J. Mater. Chem., 2001, 11, 1116-1121.

129 M. Wu, G. Lin, D. Chen, G. Wang, D. He, et al., Mater. Chem., 2002, 14, 1974.

130 J. Gangwar, B. K. Gupta, S. K. Tripathi and A. K. Srivastava, Nanoscale, 2015, 7, 13313.

131 J. L. Gole, J. D. Stout, C. Burda, Y. B. Lou and X. B. Chen, J. Phys. Chem. B, 2004, 108, 1230-1240.

132 M. Iwase, K. Yamada, T. Kurisaki, O. O. Prieto-Mahaney, B. Ohtani and H. Wakita, Appl. Catal., B, 2013, 132, 3944.

133 Y. K. Lai, L. Sun, Y. C. Chen, H. F. Zhuang, C. J. Lin and J. W. Chin, J. Electrochem. Soc., 2006, 153, D123-D127.

134 D. Li, H. Haneda, S. Hishita and N. Ohashi, Chem. Mater., 2005, 17, 2596-2602.

135 S. Sato, R. Nakamura and S. Abe, Appl. Catal., A, 2005, 284, 131-137.

136 L. Sun, J. Li, C. L. Wang, S. F. Li, Y. K. Lai, H. B. Chen and C. J. Lin, J. Hazard. Mater., 2009, 171, 1045-1050.

137 C. C. Yec and H. C. Zeng, J. Mater. Chem. A, 2014, 2, 4843.

138 M. Wang, L. Sun, Z. Lin, J. Cai, K. Xie and C. Lin, Energy Environ. Sci., 2013, 6, 1211-1220.

139 Q. Wu, J. J. Ouyang, K. P. Xiea, L. Sun, M. Y. Wang and C. J. Lin, J. Hazard. Mater., 2012, 199, 410-417.

140 Y. Ohno, K. Tomita, Y. Komatsubara, T. Taniguchi, K. Katsumata, N. Matsushita, T. Kogure and K. Okada, Cryst. Growth Des., 2011, 11, 4831-4836.

141 S. Hu, M. R. Shaner, J. A. Beardslee, M. Lichterman, B. S. Brunschwig and N. S. Lewis, Science, 2014, 344, 1005.

142 H. Zhang and J. F. Banfield, Chem. Rev., 2014, 114, 96139644.

143 K. Lee, A. Mazare and P. Schmuki, Chem. Rev., 2014, 114, 9385-9454.

144 T. Froschl, U. Hormann, P. Kubiak, G. Kucherova, M. Pfanzelt, C. K. Weiss, R. J. Behm, N. Husing, U. Kaiser, K. Landfester and M. Wohlfahrt-Mehrenes, Chem. Soc. Rev., 2012, 41, 5313.

145 M. Gopal, W. J. Moberlychan and L. C. De Jonghe, J. Mater. Sci., 1997, 32, 6001-6008. 
146 K. Fujita, J. Konishi, K. Nakanishi and K. Hirao, Appl. Phys. Lett., 2004, 85, 5595.

147 A. Wypych, I. Bobowska, M. Tracz, A. Opasinska, S. Kadlubowski, A. K. Kaliszewska, J. Grobelny and P. Wojciechowski, J. Nanomater., 2014, 124814.

148 D. Komaraiah, P. Madhukar, Y. Vijayakumar, M. V. R. Reddy and R. Sayanna, Mater. Today, 2016, 3, 3770-3778.

149 J. L. Mi, C. Clausen, M. Bremholm, N. Lock, K. M. Ø. Jensen, M. Christensen and B. B. Iversen, Cryst. Growth Des., 2012, 12, 6092-6097.

150 Y. Qu, C. Sun, G. Sun, X. Kong and W. Zhang, Results Phys., 2016, 6, 100-106.

151 S. S. Watson, D. Beydoun, J. A. Scott and R. Amal, Chem. Eng. J., 2003, 95, 213-220.

152 S. Patra, C. Davoisne, H. Bouyanfif, D. Foix and F. Sauvage, Sci. Rep., 2015, 5, 10928.

153 W. Hu, L. Li, G. Li, Y. Liu and R. L. Withers, Sci. Rep., 2014, 4, 6582 .

154 D. A. H. Hanaor and C. C. Sorrell, J. Mater. Sci., 2011, 46, 855.

155 J.-G. Li, T. Ishigaki and X. Sun, J. Phys. Chem. C, 2007, 111, 4969.

156 K. Bourikas, C. Kordulis and A. Lycourghiotis, Chem. Rev., 2014, 114, 9754-9823.

157 K. K. Dey, P. Kumar, R. R. Yadav, A. Dhar and A. K. Srivastava, RSC Adv., 2014, 4, 10123.

158 S. Wang, Y. Ding, S. Xu, Y. Zhang, G. Li, L. Hu and S. Dai, Chem.-Eur. J., 2014, 20, 4916-4920.

159 H. Yaghoubi, N. Taghavinia, E. K. Alamdari and A. A. Volinsky, ACS Appl. Mater. Interfaces, 2010, 9, 26292636.

160 R. Menzel, A. Duerrbeck, E. Liberti, H. C. Yau, D. McComb and M. S. P. Shaffer, Chem. Mater., 2013, 25, 2137-2145.

161 H. Ming, Z. Ma, H. Huang, S. Lian, H. Li, X. He, H. Yu, K. Pan, Y. Liu and Z. Kang, Chem. Commun., 2011, 47, 8025-8027.

162 Z. R. Tian, J. A. Voigt, J. Liu, B. McKenzie and H. Xu, J. Am. Chem. Soc., 2003, 125, 12384.

163 J. Zeng, R. Li, S. Liu and L. Zhang, ACS Appl. Mater. Interfaces, 2011, 3, 2074-2079.

164 R.-C. Wang, C.-C. Hsu and S.-J. Chen, Ind. Eng. Chem. Res., 2012, 51, 3677-3681.

165 P. C. Shih, J. D. Peng, C. P. Lee, R. Y. Y. Lin, T. C. Chu, R. Vittal and K. C. Ho, ChemElectroChem, 2014, 1, 532-535.

166 F. U. Rehman, C. Zhao, H. Jiang, M. Selke and X. Wang, Photodiagn. Photodyn. Ther., 2016, 13, 267-275.

167 C. Zhao, F. U. Rehman, Y. Yang, X. Li, D. Zhang, H. Jiang, M. Selke, X. Wang and C. Liu, Sci. Rep., 2015, 5, 11518.

168 M. H. Yang, P. C. Chen, M. C. Tsai, T. T. Chen, I. C. Chang, H. T. Chiu and C. Y. Lee, CrystEngComm, 2014, 16, 441.

169 Y. Yamaguchi, T. Shimodo, S. Usuki, K. Torigoe, C. Terashima, K. Katsumata, M. Ikekita, A. Fujishima, H. Sakaia and K. Nakata, Photochem. Photobiol. Sci., 2016, 15, 988 .

170 W. Sun, H. Liu, J. Hu and J. Li, RSC Adv., 2015, 5, 513-520.
171 C. Song, L. Wang, F. Gao and Q. Lu, Chem, 2016, 22, 63686373.

172 P. Singh, O. P. Sinha, R. Srivastava, A. K. Srivastava, J. K. Bindra, R. P. Singh and M. N. Kamalasanan, Mater. Chem. Phys., 2012, 133, 317.

173 S. Karuppuchamy and J. M. Jeong, Mater. Chem. Phys., 2005, 93, 251-254.

174 V. K. Yemmireddy, G. D. Farrell and Y. C. Hung, J. Food Sci., 2015, 80, N1903-N1911.

175 L. Wensheng, J. C. Chang and S. T. Lee, Nano Lett., 2008, 8, 104-109.

176 S. Karmakar, S. Kumar, R. Rinaldi and G. Maruccio, J. Phys.: Conf. Ser., 2011, 292, 012002.

177 S. S. Lucky, K. C. Soo and Y. Zhang, Chem. Rev., 2015, 115, 1990-2042.

178 D. K. Chatterjee, L. S. Fong and Y. Zhang, Adv. Drug Delivery Rev., 2008, 60, 1627-1637.

179 A. B. Chinen, C. M. Guan, J. R. Ferrer, S. N. Barnaby, T. J. Merkel and C. A. Mirkin, Chem. Rev., 2015, 115, 10530-10574.

180 J. Schneider, M. Matsuoka, M. Takeuchi, J. Zhang, Y. Horiuchi, M. Anpo and D. W. Bahnemann, Chem. Rev., 2014, 114, 9919-9986.

181 A. Kubacka, M. S. Diez, D. Rojo, R. Bargiela, S. Ciordia, I. Zapico, J. P. Albar, C. Barbas, V. A. P. M. dos Santos, M. F. García and M. Ferrer, Sci. Rep., 2014, 4, 4134.

182 M. A. Vargas and J. E. R. Páez, J. Non-Cryst. Solids, 2017, 459, 192-205.

183 N. Marwaha, B. K. Gupta, R. Verma and A. K. Srivastava, J. Mater. Sci., 2017, 52, 10480-10484.

184 F. Todescato, I. Fortunati, A. Minotto, R. Signorini, J. J. Jasieniak and R. Bozio, Materials, 2016, 9, 672.

185 A. C. Fischer, F. Forsberg, M. Lapisa, S. J. Bleiker, G. Stemme, N. Roxhed and F. Niklaus, Microsyst. Nanoeng., 2015, 1, 15005.

186 G. Chen, I. Roy, C. Yang and P. N. Prasad, Chem. Rev., 2016, 116, 2826-2885.

187 J. Yao, M. Yang and Y. Duan, Chem. Rev., 2014, 114, 61306178.

188 N. Puri, S. K. Mishra, A. Niazi, A. K. Srivastava and Rajesh, J. Chem. Technol. Biotechnol., 2015, 90, 1699-1706.

189 S. K. Mishra, A. K. Srivastava, D. Kumar, A. M. Biradar and Rajesh, Nanoscale, 2013, 5, 10494-10503.

190 D. Prasai, J. C. Tuberquia, R. R. Harl, G. K. Jennings and K. I. Bolotin, ACS Nano, 2012, 6, 1102-1108.

191 M. J. Nine, M. A. Cole, D. N. H. Trana and D. Losic, J. Mater. Chem. A, 2015, 3, 12580-12602.

192 S. S. Nanda, D. K. Yi and K. Kim, Sci. Rep., 2016, 6, 28443. 193 H. Ji, H. Sun and X. Qu, Adv. Drug Delivery Rev., 2016, 105, 176-189.

194 S. Yavuz, C. Kuru, D. Choi, A. Kargar, S. Jina and P. R. Bandaru, Nanoscale, 2016, 8, 6473-6478.

195 X. Jiang, Y. Cao, K. Wang, J. Wei, D. Wu and H. Zhu, Surf. Coat. Technol., 2015, 261, 327-330.

196 K. O. Park, J. H. Lee, J. H. Park, Y. C. Shin, J. B. Huh, J. H. Bae, S. H. Kang, S. W. Hong, B. Kim, D. J. Ayng, 
D. W. Han and J. H. Yeum, Appl. Spectrosc. Rev., 2016, 51, 540.

197 S. R. Shin, H. L. Jang, P. Khoshakhlagh, M. Akbari, A. Nasajpour, Y. S. Zhang, A. Tamayol and A. Khademhosseini, Adv. Drug Delivery Rev., 2016, 105, 255-274.

198 S. Kumar and K. Chatterjee, ACS Appl. Mater. Interfaces, 2016, 8, 26431-26457.

199 L. Wang and T. Sasaki, Chem. Rev., 2014, 114, 9455-9486.

200 E. Ertekin, L. K. Wagner and J. C. Grossman, Phys. Rev. B: Condens. Matter, 2013, 87, 155210.

201 D. Jassby, J. F. Budarz and M. Wiesner, Environ. Sci. Technol., 2012, 46, 6934-6941.

202 L. Pan, X. Liu, Z. Suna and C. Q. Sun, J. Mater. Chem. A, 2013, 1, 8299.

203 W. He, H. Jia, J. Cai, X. Han, Z. Zheng, W. G. Wamer and J. J. Yin, J. Phys. Chem. C, 2016, 120, 3187-3195.

204 A. A. Alfadda and R. M. Sallam, J. Biomed. Biotechnol., 2012, 2012, 936486.

205 S. H. Lee, M. K. Gupta, J. B. Bang, H. Bae and H. J. Sung, Adv. Healthcare Mater., 2013, 2, 908-915.

206 E. L. Cates, Environ. Sci. Technol., 2017, 51, 757-758.

207 J. Zhao and X. Yang, Build. Environ., 2003, 38, 645-654.

208 Y. Yu, T. He, L. Guo, Y. Yang, L. Guo, Y. Tang and Y. Cao, Sci. Rep., 2015, 5, 9561.

209 L. Yuan, C. Han, M. Pagliaro and Y. J. Xu, J. Phys. Chem. C, 2016, 120, 265-273.

210 W. Kim, T. Tachikawa, T. Majima and W. Cho, J. Phys. Chem. C, 2009, 113, 10603-10609.

211 G. P. Fotou, T. T. Kodas and B. Anderson, Aerosol Sci. Technol., 2000, 33, 557-571.

212 M. M. Momeni and Y. Ghayeb, Ceram. Int., 2016, 42, 70147022.

213 Y. Takahashi, P. Ngaotrakanwiwat and T. Tatsuma, Electrochim. Acta, 2004, 49, 2025-2029.

214 T. K. Kim, M. N. Lee, S. H. Lee, Y. C. Park, C. K. Jung and J. H. Boo, Thin Solid Films, 2005, 475, 171.

215 X. Fu, L. A. Clark, Q. Yang and M. A. Anderson, Environ. Sci. Technol., 1996, 30, 647.

216 A. Pietroiusti, Nanoscale, 2012, 4, 1231.

217 L. Shang, K. Nienhaus and G. U. Nienhaus, J. Nanobiotechnol., 2014, 12, 5.

218 A. M. Holmes, Z. Song, H. R. Moghimi and M. S. Roberts, ACS Nano, 2016, 10, 1810-1814.

219 M. Schneider, F. Stracke, S. Hansen and U. F. Schaefer, Derm.-Endocrinol., 2009, 1, 197-206.

220 D. Wang, Z. Lin, T. Wang, Z. Yao, M. Qin, S. Zheng and W. Lu, J. Hazard. Mater., 2016, 308, 328-334.

221 H. Zhang, Z. Ji, T. Xia, H. Meng, C. Low-Kam, R. Liu, S. Pokhrel, S. Lin, X. Wang and Y.-P. Liao, ACS Nano, 2012, 6, 4349-4368.

222 M. Pandurangan and D. H. Kim, J. Nanopart. Res., 2015, 17, 1-8.

223 L. C. Wehmas, C. Anders, J. Chess, A. Punnoose, C. B. Pereira, J. A. Greenwood and R. L. Tanguay, Toxicol. Rep., 2015, 2, 702-715.
224 G. Applerot, A. Lipovsky, R. Dror, N. Perkas, Y. Nitzan, R. Lubart and A. Gedanken, Adv. Funct. Mater., 2009, 19, 842-852.

225 Y. Xiao, M. G. Vijver, G. Chen and W. J. Peijnenburg, Environ. Sci. Technol., 2015, 49, 4657-4664.

226 A. E. Nel, L. Mädler, D. Velegol, T. Xia, E. M. V. Hoek, P. Somasundaran, F. Klaessig, V. Castranova and M. Thompson, Nat. Mater., 2009, 8, 543.

227 M. C. Moulton, L. K. B. Stolle, M. N. Nadagouda, S. Kunzelman, S. M. Hussain and R. S. Varma, Nanoscale, 2010, 2, 763.

228 S. K. Misra, A. Dybowska, D. Berhanu, S. N. Luoma and E. Valsami-Jones, Sci. Total Environ., 2012, 438, 225-232.

229 S. D. Li and L. Huang, Mol. Pharmaceutics, 2008, 5, 496-504. 230 H. Arami, A. Khandhar, D. Liggitt and K. M. Krishnan, Chem. Soc. Rev., 2015, 44, 8576.

231 H. Kang, S. Mintri, A. V. Menon, H. Y. Lee, H. S. Choi and J. Kim, Nanoscale, 2015, 7, 18848-18862.

232 S. M. Moghimi, A. C. Hunter and T. L. Andresen, Annu. Rev. Pharmacol. Toxicol., 2012, 52, 481-503.

233 S. E. Dunn, A. G. A. Coombes, M. C. Garnett, S. S. Davis, M. C. Davies and L. Illum, J. Controlled Release, 1997, 44, 65-76.

234 S. Sharifi, S. Behzadi, S. Laurent, M. L. Forrest, P. Stroeve and M. Mahmoudi, Chem. Soc. Rev., 2012, 41, 2323-2343.

235 Z. Wang, C. Fang and M. Megharaj, ACS Sustainable Chem. Eng., 2014, 1022, 2.

236 D. E. Owens III and N. A. Peppas, Int. J. Pharm., 2006, 307, 93.

237 A. E. Nel, L. Mädler, D. Velegol, T. Xia, E. M. V. Hoek, P. Somasundaran, F. Klaessig, V. Castranova and M. Thompson, Nat. Mater., 2009, 8, 543-557.

238 Q. Mu, G. Jiang, L. Chen, H. Zhou, D. Fourches, A. Tropsha and B. Yan, Chem. Rev., 2014, 114, 7740-7781.

239 C. Y. Tay, M. I. Setyawati, J. Xie, W. J. Parak and D. T. Leong, Adv. Funct. Mater., 2014, 24, 5936.

240 A. Fujishima and K. Honda, Nature, 1972, 238, 37-38.

241 X. Chen and A. Selloni, Chem. Rev., 2014, 114, 9281-9282.

242 G. Longoni, R. L. P. Cabrera, S. Polizzi, M. D'Arienzo, C. M. Mari, Y. Cui and R. Ruffo, Nano Lett., 2017, 17, 9921000 .

243 D. V. Potapenko, Z. Li and R. M. Osgood Jr, J. Phys. Chem. C, 2015, 119, 28946-28953.

244 B. Zhao, F. Chen, Q. Huang and J. Zhang, Chem. Commun., 2009, 5115.

245 C. T. Sousa, D. C. Leitao, M. P. Proenca, J. Ventura, A. M. Pereira and J. P. Araujo, Appl. Phys. Rev., 2014, 1, 031102.

246 Y. Wang and Y. Xia, Nano Lett., 2004, 4, 2047-2050.

247 E. Gazit, Chem. Soc. Rev., 2007, 36, 1263-1269.

248 Y. Wan, Y. Shia and D. Zhao, Chem. Commun., 2007, 897-926.

249 S. H. Cai, S. N. Rashkeev, S. T. Pantelides and K. Sohlberg, Phys. Rev. B: Condens. Matter, 2003, 67, 224104.

250 V. L. Colvin, Nat. Biotechnol., 2003, 21, 1166.

251 R. Yuan, X. Fu, X. Wang, P. Liu, L. Wu, Y. Xu, X. Wang and Z. Wang, Chem. Mater., 2006, 18, 4700. 
252 C. N. R. Rao, S. R. C. Vivekchand, K. Biswas and A. Govindaraj, Dalton Trans., 2007, 2007, 3728.

253 A. I. Y. Tok, F. Y. C. Boey and X. L. Zhao, J. Mater. Process. Technol., 2006, 178, 270.

254 T. Fröschl, U. Hörmann, P. Kubiak, G. Kučerová, M. Pfanzelt, C. K. Weiss, R. J. Behm, N. Hüsing, U. Kaiser, K. Landfesterd and M. W. Mehrens, Chem. Soc. Rev., 2012, 41, 5313-5360.

255 D. P. Macwan, P. N. Dave and S. Chaturvedi, J. Mater. Sci., 2011, 46, 3669-3686.

256 M. M. Byranvanda, A. N. Kharata, L. Fatholahib and Z. M. Beiranvand, J. Nanostruct., 2013, 3, 1-9.

257 I. Tacchini, A. Ansón-Casaos, Y. Yu, M. T. Martínez and M. L. Cantu, Mater. Sci. Eng., B, 2012, 177, 19-26.

258 H. A. Budiarti, R. N. Puspitasari, A. M. Hatta, Sekartedjo and D. D. Risanti, Procedia Eng., 2017, 170, 65.

259 H. Pan, X. D. Wang, S. S. Xiao, L. G. Yu and Z. J. Zhang, Indian J. Eng. Mater. Sci., 2013, 20, 561-567.

260 J. Gangwar, B. K. Gupta, P. Kumar, S. K. Tripathi and A. K. Srivastava, Dalton Trans., 2014, 43, 17034.

261 C. B. Murray, C. R. Kagan and M. G. Bawendi, Annu. Rev. Mater. Sci., 2000, 30, 545-610.

262 N. T. K. Thanh, N. Maclean and S. Mahiddine, Chem. Rev., 2014, 114, 7610.

263 K. Sabyrov, N. D. Burrows and R. L. Penn, Chem. Mater., 2013, 25, 1408-1415.

264 S. C. Zhu, S. H. Xie and Z. P. Liu, J. Am. Chem. Soc., 2015, 137, 11532.

265 J. Lee, J. Yang, S. G. Kwon and T. Hyeon, Nat. Rev. Mater., 2016, 16034.

266 D. Guan, C. Cai and Y. Wang, J. Nanosci. Nanotechnol., 2011, 11, 3641-3650.

267 K. Huo, H. Wang, X. Zhang, Y. Cao and P. K. Chu, ChemPlusChem, 2012, 77, 323-329.

268 C. Xue, T. Narushima, Y. Ishida, T. Tokunaga and T. Yonezawa, Chem. Lett., 2014, 43, 1514-1516.

269 D. H. Kim, W. M. Seong, I. J. Park, E. S. Yoo, S. S. Shin, J. S. Kim, H. S. Jung, S. Lee and K. S. Hong, Nanoscale, 2013, 5, 11725.

270 B. Liu, A. Khare and E. S. Aydil, Chem. Commun., 2012, 48, 8565.

271 Z. Sun, J. H. Kim, Y. Zhao, F. Bijarbooneh, V. Malgras, Y. Lee, Y. M. Kang and S. X. Dou, J. Am. Chem. Soc., 2011, 133, 19314.

272 M. V. Dozzi and E. Selli, Catalysts, 2013, 3, 455.

273 H. Li, Z. Bian, J. Zhu, D. Zhang, G. Li, Y. Huo, H. Li and Y. Lu, J. Am. Chem. Soc., 2007, 129, 8406.

274 J. Lu, P. Zhang, A. Li, F. Su, T. Wang, Y. Liu and J. Gong, Chem. Commun., 2013, 49, 5817-5819.

275 R. Verma, B. Mantri, Ramphal and A. K. Srivastava, Adv. Mater. Lett., 2015, 6, 324.

276 K. Li, J. Xu, W. Shi, Y. Wang and T. Peng, J. Mater. Chem. A, 2014, 2, 1886.

277 A. D. Paola, M. Bellardita and L. Palmisano, Catalysts, 2013, 3, 36.

278 Q. Deng, M. Wei, X. Ding, L. Jiang, B. Ye and K. Wei, Chem. Commun., 2008, 3657.
279 T. A. Kandiel, L. Robben, A. Alkaim and D. Bahnemann, Photochem. Photobiol. Sci., 2013, 12, 602.

280 L. Zhanga, V. M. M. Floresa, N. Murakami and T. Ohno, Appl. Surf. Sci., 2012, 258, 5803.

281 H. Zhao, L. Liu, J. M. Andinobc and Y. Li, J. Mater. Chem. A, 2013, 1, 8209.

282 T. Y. Ke, P. C. Chen, M. H. Yang, H. T. Chiuc and C. Y. Lee, CrystEngComm, 2011, 13, 5292.

283 J. Lin, Y. U. Heo, A. Nattestad, Z. Sun, L. Wang, J. H. Kim and S. X. Dou, Sci. Rep., 2014, 4, 5769.

284 D. F. Rohlfing, A. Zaleska and T. Bein, Chem. Rev., 2014, 114, 9487-9558.

285 M. Yu, X. Ren, L. Ma and Y. Wu, Nat. Commun., 2014, 5, 5111.

286 D. Sarkar, C. K. Ghosh and K. K. Chattopadhyay, CrystEngComm, 2012, 14, 2683.

287 T. Ohno, K. Sarukawa and M. Matsumura, New J. Chem., 2002, 26, 1167.

288 D. Zhang, G. Li, F. Wanga and J. C. Yu, CrystEngComm, 2010, 12, 1759.

289 D. R. Coronado, G. R. Gattorno, M. E. E. Pesqueira, C. Cab, R. deCoss and G. Oskam, Nanotechnology, 2008, 19, 145605.

290 Z. Zhao, J. Tian, Y. Sang, A. Cabot and H. Liu, Adv. Mater., 2015, 27, 2557-2582.

291 B. Liu, A. Khare and E. S. Aydil, Chem. Commun., 2012, 48, 8565.

292 H. G. Yang, G. Liu, S. Z. Qiao, C. H. Sun, Y. G. Jin, S. C. Smith, J. Zou, H. M. Cheng and G. Q. (Max) Lu, J. Am. Chem. Soc., 2009, 131, 4078-4083.

293 M. Choi, J. H. Lee, Y. J. Jang, D. Kim, J. S. Lee, H. M. Jang and K. Yong, Sci. Rep., 2016, 6, 36099.

294 M. H. Tsai, S. Y. Chen and P. Shen, Nano Lett., 2004, 4, 1197-1201.

295 M. Rezaee, S. M. M. Khoie and K. H. Liu, CrystEngComm, 2011, 13, 5055.

296 B. Choudhary and A. Choudhary, Int. Nano Lett., 2013, 3, 55.

297 J. Zhang, M. Li, Z. Feng, J. Chen and C. Li, J. Phys. Chem. B, 2006, 110, 927.

298 H. C. Choi, Y. M. Jung and S. B. Kim, Vib. Spectrosc., 2005, $37,33$.

299 S. Hu, F. Li and Z. Fan, Bull. Korean Chem. Soc., 1895, 2012, 33.

300 J. Das, F. S. Freitas, I. R. Evans, A. F. Nogueira and D. Khushalani, J. Mater. Chem., 2010, 20, 4425.

301 Z. Yanqing, S. Erwei, C. Suxian, L. Wenjun and H. Xingfang, J. Mater. Sci. Lett., 2000, 19, 1445-1448.

302 L. Pinho and M. J. Mosquera, J. Phys. Chem. C, 2011, 115, 22851-22862.

303 H. N. Graham, Prev. Med., 1992, 21, 334.

304 S. P. J. N. Senanayake, J. Funct. Foods, 2013, 5, 1529.

305 D. A. Balentine, S. A. Wiseman and L. C. Bouwens, Crit. Rev. Food Sci. Nutr., 1997, 37, 693.

306 L. Xiao, M. Mertens, L. Wortmann, S. Kremer, M. Valldor, T. Lammers, F. Kiessling and S. Mathur, ACS Appl. Mater. Interfaces, 2015, 7, 6530-6540.

307 Canadian Food Inspection Agency, Guide to Food Labelling and Advertising, 2010. 
308 J. B. Birks, Photophysics of Aromatic Molecules, WileyInterscience, London, 1970.

309 C. Chen, J. Liu, P. Liu and B. Yu, Adv. Chem. Eng. Sci., 2011, 1, 9-14.

310 Y. Yang, G. Wang, Q. Deng, D. H. L. Ng and H. Zhao, ACS Appl. Mater. Interfaces, 2014, 6, 3008-3015.

311 P. Singh, O. P. Sinha, R. Srivastava, A. K. Srivastava, J. K. Bindra, R. P. Singh and M. N. Kamalasanan, Mater. Chem. Phys., 2012, 133, 317-323.

312 M. H. Lee, U. M. Patil, S. T. Kochuveedu, C. S. Lee and D. H. Kim, Bull. Korean Chem. Soc., 2012, 33, 3767-3771.

313 U. Soni, P. Tripathy and S. Sapra, J. Phys. Chem. Lett., 2014, 5, 1909-1916.

314 V. Etacheri, R. Roshan and V. Kumar, ACS Appl. Mater. Interfaces, 2012, 4, 2717-2725.

315 J. G. Cappuccino and N. Sherman, Microbiology: a laboratory manual, Benjamin Cummings, California, CA, 1999, 10th edn, p. 471.

316 J. G. Holt, N. R. Krieg and P. H. A. Sneath, et al., Bergey's manual of determinative bacteriology, Lippincott Williams \& Wilkins, Baltimore, MD, 9th edn, 1994, p. 787.

317 C. M. Kunin and C. Steele, J. Clin. Microbiol., 1985, 21, 902908.

318 J. Beranova, G. Seydlova, H. Kozak, et al., FEMS Microbiol. Lett., 2014, 351, 179-186.

319 S. J. Parikh and J. Chorover, Langmuir, 2006, 22, 8492-8500.
320 B. Girase, D. Depan, J. S. Shah, et al., Mater. Sci. Eng., C, 2011, 31, 1759-1766.

321 J. Gangwar, J. Kim, A. Kumar, D. Bhatnagar, K. Senthil, S. K. Tripathi, K. Yong and A. K. Srivastava, Nanosci. Nanotechnol. Lett., 2013, 5, 67.

322 J. Gangwar, A. Chandran, T. Joshi, R. Verma, A. M. Biradar, S. K. Tripathi, B. K. Gupta and A. K. Srivastava, Mater. Res. Express, 2015, 2, 075013.

323 J. S. Tawale, K. K. Dey, R. Pasricha, K. N. Sood and A. K. Srivastava, Thin Solid Films, 2010, 519, 1244-1247.

324 N. Jain, N. Marwaha, R. Verma, B. K. Gupta and A. K. Srivastava, $R S C A d v$., 2016, 6, 4960.

325 N. T. K. Thanh, N. Maclean and S. Mahiddine, Chem. Rev., 2014, 114, 7610-7630.

326 B. Stein, D. Zopes, M. Schmudde, R. Schneider, A. Mohsen, C. Goroncy, S. Mathur and C. Graf, Faraday Discuss., 2015, 181, 85-102.

327 P. Junlabhut and P. Nuthongkum, Thai J. Nanosci. Nanotechnol., 2016, 1, 1-7.

328 J. S. Lee, K. H. You and C. B. Park, Adv. Mater., 2012, 24, 1084-1088.

329 S. Pavasupreea, Y. Suzukia, S. Yoshikawaa and R. Kawahata, J. Solid State Chem., 2005, 178, 3110-3116.

330 X. Peng and A. Chen, J. Mater. Chem., 2004, 14, 2542-2548. 331 W. Q. Fang, J. Z. Zhou, J. Liu, Z. G. Chen, C. Yang, C. H. Sun, G. R. Qian, J. Zou, S. Z. Qiao and H. G. Yang, Chem.-Eur. J., 2011, 17, 1423-1427. 